Annales Geophysicae (2003) 21: 1601-1628 (C) European Geosciences Union 2003

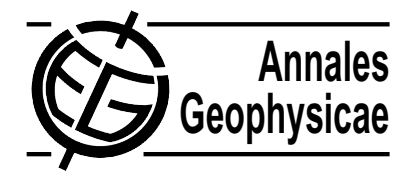

\title{
New method in computer simulations of electron and ion densities and temperatures in the plasmasphere and low-latitude ionosphere
}

\author{
A. V. Pavlov \\ Institute of Terrestrial Magnetism, Ionosphere and Radio-Wave Propagation, Russia Academy of Science (IZMIRAN), \\ Troitsk, Moscow Region, 142190, Russia
}

Received: 23 August 2002 - Revised: 16 January 2003 - Accepted: 15 February 2003

\begin{abstract}
A new theoretical model of the Earth's low- and mid-latitude ionosphere and plasmasphere has been developed. The new model uses a new method in ionospheric and plasmaspheric simulations which is a combination of the Eulerian and Lagrangian approaches in model simulations. The electron and ion continuity and energy equations are solved in a Lagrangian frame of reference which moves with an individual parcel of plasma with the local plasma drift velocity perpendicular to the magnetic and electric fields. As a result, only the time-dependent, one-dimension electron and ion continuity and energy equations are solved in this Lagrangian frame of reference. The new method makes use of an Eulerian computational grid which is fixed in space coordinates and chooses the set of the plasma parcels at every time step, so that all the plasma parcels arrive at points which are located between grid lines of the regularly spaced Eulerian computational grid at the next time step. The solution values of electron and ion densities $N_{e}$ and $N_{i}$ and temperatures $T_{e}$ and $T_{i}$ at the Eulerian computational grid are obtained by interpolation. Equations which determine the trajectory of the ionospheric plasma perpendicular to magnetic field lines and take into account that magnetic field lines are "frozen" in the ionospheric plasma are derived and included in the new model.

We have presented a comparison between the modeled $N m \mathrm{~F} 2$ and $h m \mathrm{~F} 2$ and $N m \mathrm{~F} 2$ and $h m \mathrm{~F} 2$ which were observed at the anomaly crest and close to the geomagnetic equator simultaneously by the Huancayo, Chiclayo, Talara, Bogota, Panama, and Puerto Rico ionospheric sounders during the 7 October 1957 geomagnetically quiet time period at solar maximum. The model calculations show that there is a need to revise the model local time dependence of the equatorial upward $\boldsymbol{E} \times \boldsymbol{B}$ drift velocity given by Scherliess and Fejer (1999) at solar maximum during quiet daytime equinox conditions. Uncertainties in the calculated $N_{i}, N_{e}, T_{e}$, and $T_{i}$ resulting from the difference between the NRLMSISE00 and MSIS-86 neutral temperatures and densities and from
\end{abstract}

Correspondence to: A. V. Pavlov (pavlov@izmiran.rssi.ru) the difference between the EUV97 and EUVAC solar fluxes are evaluated. The decrease in the NRLMSISE-00 model $[\mathrm{O}] /\left[\mathrm{N}_{2}\right]$ ratio by a factor of $1.7-2.1$ from $16: 12$ UT to 23:12 UT on 7 October brings the modeled and measured $N m \mathrm{~F} 2$ and $h m \mathrm{~F} 2$ into satisfactory agreement. It is shown that the daytime peak values in $T_{e}$, and $T_{i}$ above the ionosonde stations result from the daytime peak in the neutral temperature. Our calculations show that the value of $T_{e}$ at F2region altitudes becomes almost independent of the electron heat flow along the magnetic field line above the Huancayo, Chiclayo, and Talara ionosonde stations, because the nearhorizontal magnetic field inhibits the heat flow of electrons. The increase in geomagnetic latitude leads to the increase in the effects of the electron heat flow along the magnetic field line on $T_{e}$. It is found that at sunrise, there is a rapid heating of the ambient electrons by photoelectrons and the difference between the electron and neutral temperatures could be increased because nighttime electron densities are less than those by day, and the electron cooling during morning conditions is less than that by day. This expands the altitude region at which the ion temperature is less than the electron temperature near the equator and leads to the sunrise electron temperature peaks at $h m \mathrm{~F} 2$ altitudes above the ionosonde stations. After the abrupt increase at sunrise, the value of $T_{e}$ decreases, owing to the increasing electron density due to the increase in the cooling rate of thermal electrons and due to the decrease in the relative role of the electron heat flow along the magnetic field line in comparison with cooling of thermal electrons. These physical processes lead to the creation of sunrise electron temperature peaks which are calculated above the ionosonde stations at $h m \mathrm{~F} 2$ altitudes. We found that the main cooling rates of thermal electrons are electronion Coulomb collisions, vibrational excitation of $\mathrm{N}_{2}$ and $\mathrm{O}_{2}$, and rotational excitation of $\mathrm{N}_{2}$. It is shown that the increase in the loss rate of $\mathrm{O}^{+}\left({ }^{4} \mathrm{~S}\right)$ ions due to the vibrational excited $\mathrm{N}_{2}$ and $\mathrm{O}_{2}$ leads to the decrease in the calculated $N m \mathrm{~F} 2$ by a factor of 1.06-1.44 and to the increase in the calculated $h m \mathrm{~F} 2$, up to the maximum value of $32 \mathrm{~km}$ in the low-latitude ionosphere between -30 and $+30^{\circ}$ of the geomagnetic lati- 
tude. Inclusion of vibrationally excited $\mathrm{N}_{2}$ and $\mathrm{O}_{2}$ brings the model and data into better agreement.

Key words. Ionosphere (equatorial ionosphere; electric fields and currents, plasma temperature and density; ion chemistry and composition; ionosphere-atmosphere interactions; modeling and forecasting)

\section{Introduction}

At low- and mid-latitudes, the Earth's magnetic field can be represented, to a good approximation, by a dipole. The horizontal orientation of the geomagnetic field at the geomagnetic equator is known to be the basic reason for the active nature of the low-latitude ionosphere, which is characterised by the equatorial electrojet, equatorial plasma fountain, equatorial (Appleton) anomaly, additional layers, plasma bubbles, and spread-F. These equatorial characteristic properties of the ionosphere have been studied observationally and theoretically for many years (see, for example, review papers presented by Moffett, 1979; Anderson, 1981; Walker, 1981; Rishbeth, 2000; Abdu, 1997, 2001, and references therein). Many theoretical models of the plasmasphere and low-latitude ionosphere were constructed and have been applied to study a wide variety of equatorial ionosphere characteristic properties. Among these models, it is necessary to point out the following major sophisticated plasmaspheric and low-latitude ionospheric models: the Sheffeld University plasmasphere-ionosphere model (Bailey and Sellec, 1990; Bailey and Balan, 1996), the coupled thermosphere-ionosphere-plasmasphere model (CTIP) (Fuller-Rowell et al., 1988; Millward et al., 1996), a coupled thermosphere-ionosphere model (CTIM) (Fuller-Rowell et al., 1996), the global theoretical ionospheric model (GTIM) (Anderson, 1973; Anderson et al., 1996), and the global numerical self-consistent and time-dependent model of the thermosphere, ionosphere, and protonosphere (Namgaladze et al., 1988). These models include transport of plasma by geomagnetic field-aligned diffusion and neutral windinduced plasma drift of ions and electrons, and plasma motion perpendicular to the geomagnetic field, $\boldsymbol{B}$, due to an electric field, $\boldsymbol{E}$, which is generated in the E-region. This electric field affects F-region plasma causing both ions and electrons to drift in the same direction with an drift velocity, $\boldsymbol{V}^{\boldsymbol{E}}=\boldsymbol{E} \times \boldsymbol{B} / \mathrm{B}^{2}$.

In a Lagrangian method, the finite-difference grid moves with the local plasma drift velocity $\boldsymbol{V}^{\boldsymbol{E}}$ perpendicular to the magnetic and electric fields. The rate of change of electron and ion number densities and temperatures in a moving frame of reference is much easier to compute because the convective terms in the continuity and energy equations are absent in the moving frame. As a result, it is needed to solve only one-dimensional, time dependent ion and electron continuity and energy equations along magnetic field lines in this moving frame of reference.
Contrary to a Lagrangian computational grid, an Eulerian computational grid is fixed in space coordinates. The main aim of our work is to elaborate a new approach which includes the advantages of both approaches in solving electron and ion continuity and energy equations in the ionosphere and plasmasphere. Our new approach is a combination of the Eulerian and Lagrangian approaches in model simulations. This new method is used to construct a new model of the plasmasphere and ionosphere which will be used to calculate electron and ion densities and temperature in the plasmasphere and ionosphere at low and middle latitudes.

In the present work we investigate the equatorial anomaly using the constructed new model of the plasmasphere and ionosphere and the progress in understanding the F2-layer physics that has come from the development of models of the thermosphere and ionosphere. Our purpose is to discuss the models' success in reproducing the equatorial anomaly phenomenon. In contrast to previous studies of the equatorial anomaly, the model of the ionosphere and plasmasphere used in this work includes the fundamental laboratory rate coefficient measurements of $\mathrm{O}^{+}\left({ }^{4} \mathrm{~S}\right)$ ions with vibrationally excited $\mathrm{N}_{2}$ and $\mathrm{O}_{2}$ given by Hierl et al. (1997), the quenching rate coefficients for $\mathrm{O}^{+}\left({ }^{2} \mathrm{D}\right)$ and $\mathrm{O}^{+}\left({ }^{2} \mathrm{D}\right)$ by $\mathrm{N}_{2}$ measured by $\mathrm{Li}$ et al. (1997), the updated Einstein coefficients for the $\mathrm{O}^{+}\left({ }^{2} \mathrm{P}\right) \rightarrow \mathrm{O}^{+}\left({ }^{4} \mathrm{~S}\right)+\mathrm{h} v$ and $\mathrm{O}^{+}\left({ }^{2} \mathrm{P}\right) \rightarrow \mathrm{O}^{+}\left({ }^{2} \mathrm{D}\right)+\mathrm{h} v$ transitions given by Kaufman and Sugar (1986), and the updated photoionization and photoabsorption cross sections for the $\mathrm{N}_{2}, \mathrm{O}_{2}$, and $\mathrm{O}$ photoionization reactions which form $\mathrm{N}_{2}^{+}$, $\mathrm{O}_{2}^{+}, \mathrm{O}^{+}\left({ }^{4} \mathrm{~S}\right), \mathrm{O}^{+}\left({ }^{2} \mathrm{D}\right), \mathrm{O}^{+}\left({ }^{2} \mathrm{P}\right), \mathrm{O}^{+}\left({ }^{4} \mathrm{P}\right)$, and $\mathrm{O}^{+}\left({ }^{2} \mathrm{P}^{*}\right)$ ions (Richards et al., 1994; Schaphorst et al., 1995; Berkowitz, 1997).

There is a strong dependence of the equatorial anomaly characteristics (i.e. crest latitudes and magnitudes) on the vertical drift velocity of the equatorial F-layer, and the theoretically modeled low-latitude distributions of the electron density are very sensitive to input drift velocities (Klobuchar et al., 1991). The present work reports the attempt to study some features of this relationship in the case study in which $N m \mathrm{~F} 2$ electron densities are observed at the anomaly crest and close to the geomagnetic equator simultaneously, near approximately the same geomagnetic meridian by the Panama, Bogota, Talara, Chiclayo, and Huancayo ionospheric sounders during the 7 October 1957 time period. The model wishes to look at the effects of changing $\boldsymbol{V}^{\boldsymbol{E}}$.

The model of the ionosphere and plasmasphere uses the solar EUV flux and the neutral temperature and densities as the model inputs. As a result, the model/data discrepancies arise due to uncertainties in EUV fluxes and a possible inability of the neutral atmosphere model to accurately predict the thermospheric response to the studied time period in the upper atmosphere. Over the years, testing and modification of the MSIS neutral atmosphere model has continued, and it has led to improvements through several main versions of this neutral atmosphere model: MSIS-77 (Hedin et al., 1977 a, b), MSIS-86 (Hedin, 1987), and NRLMSISE-00 (Picone et al., 2000, 2002). In the present work we investigate 
how well the Panama, Bogota, Talara, Chiclayo, and Huancayo ionospheric sounder measurements of electron densities taken during the geomagnetically quiet period of 7 October 1957 agree with those calculated by the model of the ionosphere and plasmasphere using the MSIS-86 or NRLMSISE00 neutral temperature and densities. The model of the ionosphere and plasmasphere has an option to use the solar EUV fluxes from the EUVAC model (Richards et al., 1994) or the EUV97 model (Tobiska and Eparvier, 1998). As a result, the model/data agreement can be better or worse when we use NRLMSISE-00, as opposed to MSIS-86 and EUVAC, as opposed to EUV97. One objective of the model/data comparison which is carried out in this work is to present an evaluation of uncertainties in model calculations of electron and ion densities and temperatures from the comparison between neutral atmosphere models and between the solar flux models as input model parameters.

The $\mathrm{O}^{+}\left({ }^{4} \mathrm{~S}\right)$ ions that predominate at ionospheric $\mathrm{F} 2$ region altitudes are lost in the reactions of $\mathrm{O}^{+}\left({ }^{4} \mathrm{~S}\right)$ with unexcited $\mathrm{N}_{2}(v=0)$ and $\mathrm{O}_{2}(v=0)$ and vibrationally excited $\mathrm{N}_{2}(v)$ and $\mathrm{O}_{2}(v)$ molecules at vibrational levels, $v>$ 0 . Vibrationally excited $\mathrm{N}_{2}$ and $\mathrm{O}_{2}$ react more strongly with $\mathrm{O}^{+}\left({ }^{4} \mathrm{~S}\right)$ ions in comparison with unexcited $\mathrm{N}_{2}$ and $\mathrm{O}_{2}$ (Schmeltekopf et al., 1968, Hierl et al., 1997). As a result, an additional reduction in the electron density is caused by the reactions of $\mathrm{O}^{+}\left({ }^{4} \mathrm{~S}\right)$ ions with vibrationally excited $\mathrm{N}_{2}$ and $\mathrm{O}_{2}$. Numerical simulations of the ionosphere show that the daytime mid-latitude electron density of the F2-region should be reduced by a factor of $1.5-2.5$, due to enhanced vibrational excitation of $\mathrm{N}_{2}$ at high solar activity during geomagnetically quiet and storm periods (see Pavlov and Foster, 2001, and references therein). The reduction to two-thirds of its value due to vibrationally excited $\mathrm{N}_{2}$ is found in the low-latitude F-region electron density at the location of the equatorial trough at solar maximum (Jenkins et al., 1997). The increase in the $\mathrm{O}^{+}+\mathrm{O}_{2}$ loss rate due to vibrationally excited $\mathrm{O}_{2}$ decreases the simulated daytime $\mathrm{F} 2$ peak density by up to a factor of 1.7 at high solar activity (Pavlov, 1998b; Pavlov et al., 1999, 2000; 2001; Pavlov and Foster, 2001). In this paper we examine the latitude dependence of the effects of vibrationally excited $\mathrm{N}_{2}$ and $\mathrm{O}_{2}$ on the electron density and temperature at solar maximum during geomagnetically quiet conditions of 7 October 1957, to investigate the role of vibrationally excited $\mathrm{N}_{2}$ and $\mathrm{O}_{2}$ in the formation of the observed electron density equatorial anomaly variations.

\section{Theoretical model}

We present a new model of the middle-and low-latitude ionosphere and plasmasphere. This model uses a dipole approximation to the Earth's magnetic field and takes into account the offset between the geographic and geomagnetic axes. The horizontal components of the neutral wind, which are used in calculations of the wind-induced plasma drift velocity along the magnetic field, are specified using the HWW90 wind model of Hedin et al. (1991). In the model, time- dependent ion continuity equations for the three major ions, $\mathrm{O}^{+}\left({ }^{4} \mathrm{~S}\right), \mathrm{H}^{+}$, and $\mathrm{He}^{+}$and for the minor ions, $\mathrm{NO}^{+}, \mathrm{O}_{2}^{+}$, and $\mathrm{N}_{2}^{+}$are solved by taking into account the production and loss rates of ions, transport of plasma by geomagnetic fieldaligned diffusion and neutral wind-induced plasma drift of ions and electrons and plasma motion perpendicular to the geomagnetic field due to an electric field which is generated in the E-region. The approach of the local chemical equilibrium is used to calculate steady-state number densities of $\mathrm{O}^{+}\left({ }^{2} \mathrm{D}\right), \mathrm{O}^{+}\left({ }^{2} \mathrm{P}\right), \mathrm{O}^{+}\left({ }^{4} \mathrm{P}\right)$, and $\mathrm{O}^{+}\left({ }^{2} \mathrm{P}^{*}\right)$ ions. Timedependent electron and ion energy balance equations are solved in the model. These equations include heating and cooling rates of electron and ions and a term due to the $\boldsymbol{E} \times \boldsymbol{B}$ drift of electrons and ions. Modelled electron heating caused by collisions between thermal electrons and photoelectrons is provided by a solution of the Boltzmann equation for photoelectron flux along a centered - dipole magnetic field line, the same field line used for solving for number densities of electron and ions, and electron and ion temperatures at the same grid point. The model uses Boltzmann distributions of $\mathrm{N}_{2}(v)$ and $\mathrm{O}_{2}(v)$ to calculate $\left[\mathrm{N}_{2}(v)\right]$ and $\left[\mathrm{O}_{2}(v)\right]$ which are included in the model loss rate of $\mathrm{O}^{+}\left({ }^{4} \mathrm{~S}\right)$ ions and cooling rates of thermal electrons, due to vibrational excitation of $\mathrm{N}_{2}$ and $\mathrm{O}_{2}$. The chemistry, physics, and solution procedure have been described in detail in Appendix A.

The coordinate system considered in this work is presented in Appendix A. Orthogonal curvilinear coordinates are: $q, U$, and a geomagnetic longitude, $\Lambda$. The important properties of these coordinates are that $q$ is aligned with, and $U$ and $\Lambda$ are perpendicular to, the magnetic field, the $U$ and $\Lambda$ coordinates are constant along a dipole magnetic field line, and the McIlwain parameter $L$ can be presented as $L=U^{-1}$. The model takes into account that the plasma $\boldsymbol{E} \times \boldsymbol{B}$ drift velocity can be presented as $\boldsymbol{V}^{\boldsymbol{E}}=$ $V^{E}{ }_{\Lambda} \boldsymbol{e}_{\boldsymbol{\Lambda}}+V^{E}{ }_{U} \boldsymbol{e}_{U}$, where $V^{E}{ }_{\Lambda}=E_{U} / B$ is the zonal component of $V^{E}, V^{E}{ }_{U}=-E_{\Lambda} / B$ is the meridional component of $V^{E}, \boldsymbol{E}=E_{\Lambda} \boldsymbol{e}_{\Lambda}+E_{U} \boldsymbol{e}_{U}, E_{\Lambda}$ is the $\Lambda$ (zonal) component of $\boldsymbol{E}$ in the dipole coordinate system, $E_{U}$ is the $U$ (meridional) component of $\boldsymbol{E}$ in the dipole coordinate system, $\boldsymbol{e}_{\boldsymbol{\Lambda}}$ and $\boldsymbol{e}_{U}$ are unit vectors in $\Lambda$ and $U$ directions, respectively.

The zonal component, $V^{E} \Lambda$, of the $\boldsymbol{E} \times \boldsymbol{B}$ drift is not included in the our model calculations (see Appendix A) as it is believed that this $\boldsymbol{E} \times \boldsymbol{B}$ drift component has a negligible effect on the electron density profiles (Anderson, 1981). It should be noted that, as far as the author knows, possible effects of the zonal component of the $\boldsymbol{E} \times \boldsymbol{B}$ drift on electron and ion densities and temperatures are not included in the published model calculations of the ionospheric equatorial anomaly variations (see, for example, Bailey and Sellec, 1990; Bailey and Balan, 1996; Su et al., 1997).

The equatorial magnitude of the meridional component of the $\boldsymbol{E} \times \boldsymbol{B}$ drift velocity has been found to vary greatly from day to day, and these drift velocities have large seasonal and solar cycle variations (Woodman, 1970; Fejer et al., 1989, 1995; Scherliess and Fejer, 1999). It is also known to be longitude dependent (Schieldge et al., 1973; Fejer et al., 1995). 


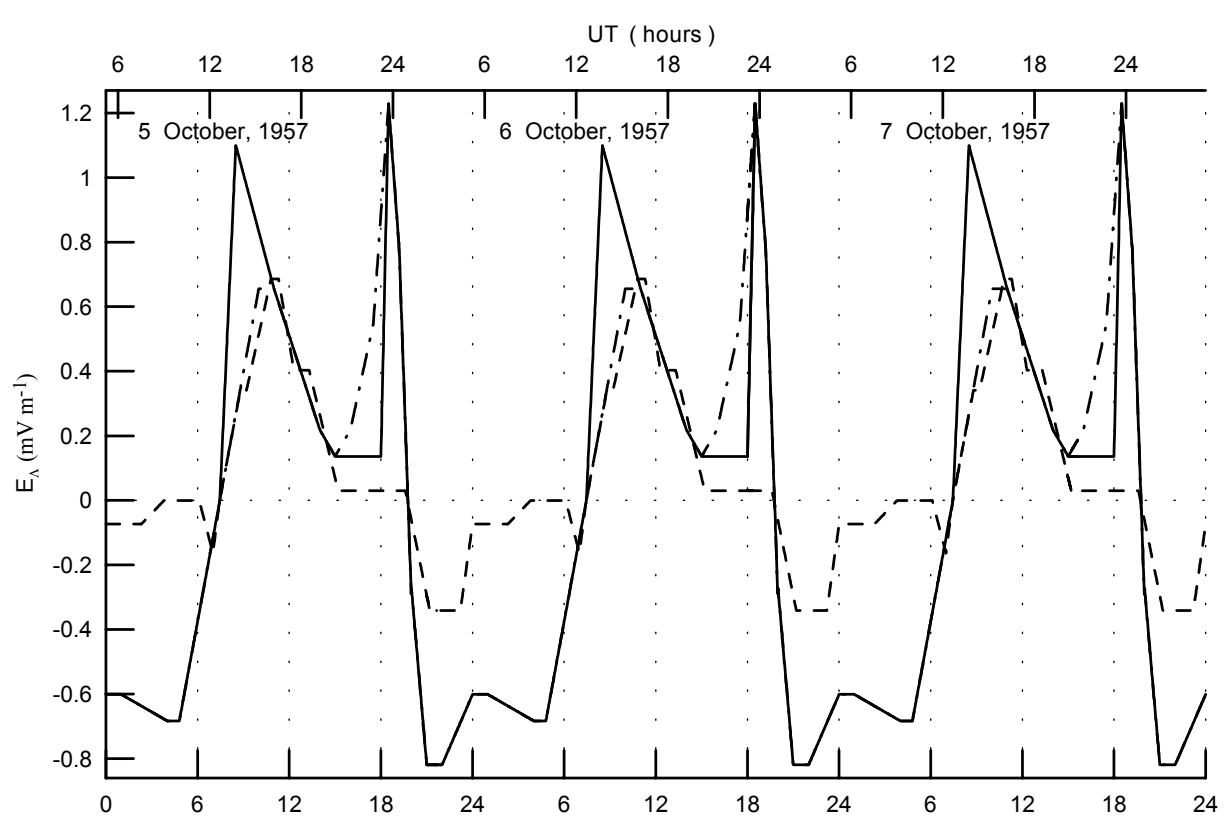

Fig. 1. Diurnal variations of $E_{\Lambda}$ on 7 October 1957. The empirical F-region quiet time vertical drift velocity over the geomagnetic equator presented in Fig. 8 of Scherliess and Fejer (1999) for high solar activity and equinox conditions was used to find the equatorial value of $E_{\Lambda}$ (dash-dotted line). Solid line shows the empirical equatorial electric field which was modified in the time range between 07:27 LT and 11:00 LT and between 15:00 LT and 18:30 LT by the use of the comparison between the measured and modelled values of $N m \mathrm{~F} 2$ and $h m \mathrm{~F} 2$ at 00:00 UT and 16:00 UT. The average quiet time value of $E_{\Lambda}$ at the F-region altitudes over Arecibo (dashed line) is found from the average quiet time perpendicular/northward F-region plasma drifts for equinox conditions presented in Fig. 2 of Fejer (1993).

There is evidence that the vertical $\boldsymbol{E} \times \boldsymbol{B}$ drift velocity varies with altitude at the geomagnetic equator (Pingree and Fejer, 1987). In the present study, the simplistic approach is used to calculate the dependence of $E_{\Lambda}$ on $t_{g e}$, where $t_{g e}$ is the local time at the geomagnetic equator for the magnetic longitude of each ionosonde station.

In the model, the value of $E_{\Lambda}\left(t_{g e}\right)$ over the geomagnetic equator given by the dash-dotted line in Fig. 1 is obtained from the empirical F-region quiet time equatorial vertical drift velocity presented in Fig. 8 of Scherliess and Fejer (1999) for high solar activity and equinox conditions. As it will be discussed later in Sect. 4, this empirical equatorial electric field is modified in the time range between 07:27 LT and 11:00 LT and between 15:0 LT and 18:30 LT by the use of the comparison between the measured and modelled nighttime values of $h m \mathrm{~F} 2$. The resulting equatorial magnitude of $E_{\Lambda}\left(t_{g e}\right)$, which is used in the model calculations is shown by the solid line in Fig. 1. The average quiet time value of $E_{\Lambda}$ at the F-region altitudes over Arecibo (dashed line in Fig. 1) is found from Fig. 2 of Fejer (1993), where the average quiet time perpendicular/northward F-region plasma drifts for high solar activity and equinox conditions is presented.

Equations (A11), (A12), and (A15) determine the trajectory of the ionospheric plasma perpendicular to magnetic field lines and the moving coordinate system. It follows from Eq. (A11) that time variations of $U$ caused by the existence of the $E_{\Lambda}$ component of the electric field are determined by time variations of the $\Lambda$ component, $E_{\Lambda}$ eff , of the effective electric field given by Eq. (A12). We have to take into account that the magnetic field lines are "frozen" in the ionospheric plasma (see Sect. A2.5.1 of Appendix A). As a result, $E_{\Lambda}{ }^{e f f}(t)$ is not changed along magnetic field lines (see Eq. A15). The equatorial and Arecibo values of $E_{\Lambda}\left(t_{g e}\right)$ are used to find the equatorial and Arecibo values of $E_{\Lambda}$ eff $\left(t_{g e}\right)$ from Eqs. (A12) and (A15). The equatorial value of $E_{\Lambda}$ eff $\left(t_{g e}\right)$ (the equatorial $E_{\Lambda}\left(t_{g e}\right)$ is given by the solid line in Fig. 1) is used for magnetic field lines with an apex altitude, $h_{a p}=R_{e q}-R_{E}$, less than $600 \mathrm{~km}$, where $R_{e q}$ is the equatorial radial distance of the magnetic field line from the Earth's center and $R_{E}$ is the Earth's radius. The Arecibo value of $E_{\Lambda}{ }^{\text {eff }}\left(t_{g e}\right)$ (the Arecibo $E_{\Lambda}\left(t_{g e}\right)$ is given by the dashed line in Fig. 1) is used if the apex altitude is greater than $2126 \mathrm{~km}$. Linear interpolation of the equatorial and Arecibo values of $E_{\Lambda}^{e f f}\left(t_{g e}\right)$ is employed at the intermediate apex altitudes.

The model starts at 15:12 UT on 5 October 1957. This UT corresponds to 10:00 LT at the geomagnetic equator and $351.9^{\circ}$ of the geomagnetic longitude (see explanations of the value of the geomagnetic longitude in Sect. 3). First of all, the steady-state $N_{i}, N_{e}, T_{i}$, and $T_{e}$ are found by the use of the model of the ionosphere and plasmasphere with $E_{\Lambda}=0$ (i.e. without the $\boldsymbol{E} \times \boldsymbol{B}$ drift velocity). It means that the onedimensional time dependent Eqs. (A1), (A6), and (A7) of Appendix A are solved along each computational grid dipole magnetic field line at 10:00 UT on 5 October 1957, to obtain the $N_{i}, N_{e}, T_{i}$, and $T_{e}$ initial conditions. These steadystate daytime values of $N_{i}, N_{e}, T_{i}$, and $T_{e}$ are used as initial conditions to solve the two-dimensional, time dependent 


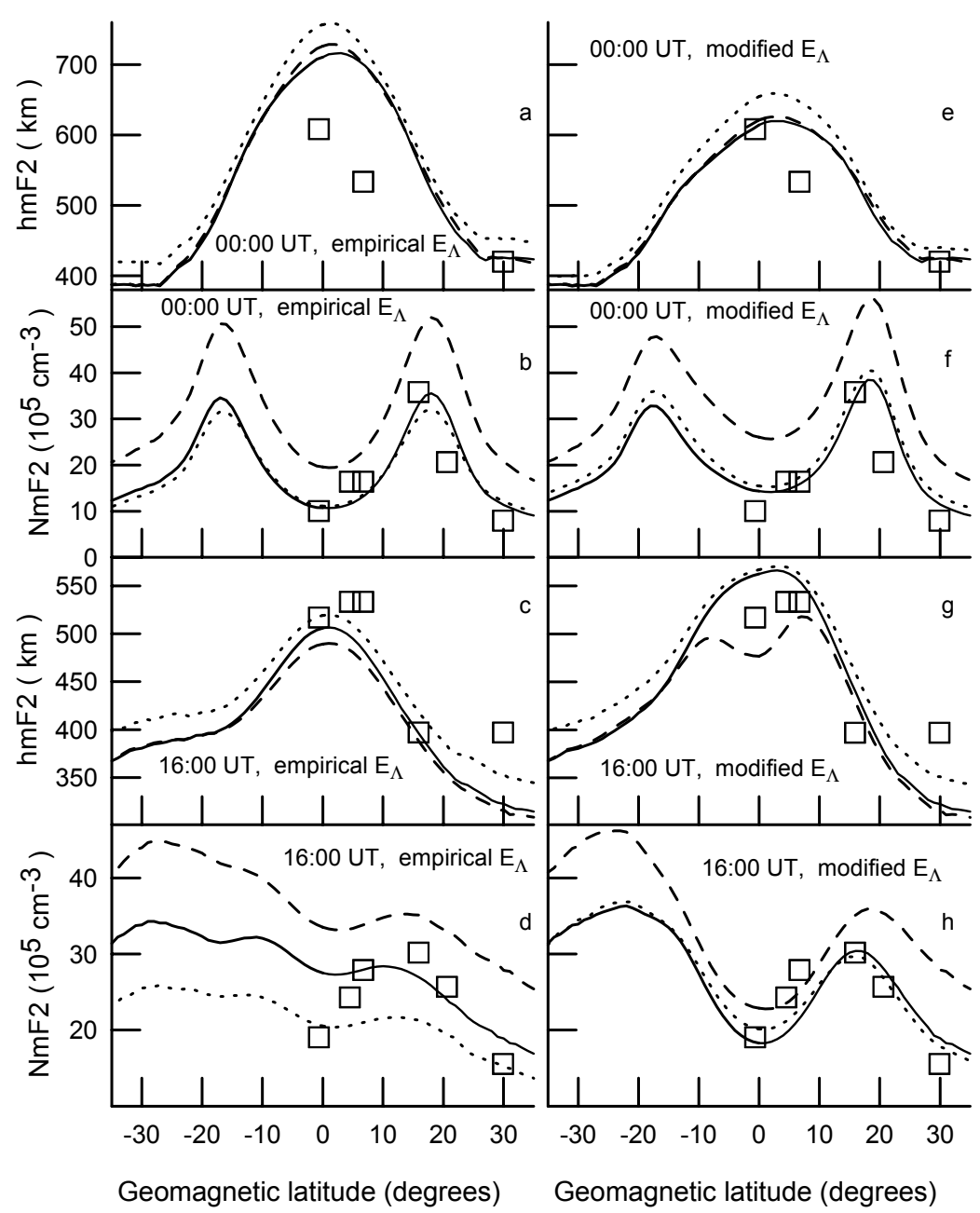

Fig. 2. Observed (squares) and calculated (lines) $h m \mathrm{~F} 2$ and $N m \mathrm{~F} 2$ at 00:00 UT (Panels a, b, e, f) and 16:00 UT (Panels c, d, g, h) on 7 October 1957. Left panels (a), (b), (c), (d) show the model results when the original equatorial perpendicular plasma drift of Scherliess and Fejer (1999) given by the dash-dotted line in Fig. 1 is used. Right panels (e), (f), (g), (h) show the model results when the empirical equatorial electric field found the equatorial perpendicular plasma drift velocity of Scherliess and Fejer (1999) was modified in the time range between 07:27 LT and 11:00 LT and between 15:00 LT and 18:30 LT (this modified equatorial electric field is shown by a solid line in Fig. 1). Dashed lines show the model results when the original NRLMSISE-00 neutral temperature and densities are used. Solid lines show the model results when the NRLMSISE-00 model [O] was decreased by a factor of 1.7 from 16:12 UT to 23:12 UT (from 11:00 LT to 18:00 LT, where LT is the local time at the geomagnetic equator and $351.9^{\circ}$ of the geomagnetic longitude) during all model simulation period. Dotted lines show the model results when the NRLMSISE-00 model $\left[\mathrm{N}_{2}\right]$ and $\left[\mathrm{O}_{2}\right]$ were increased by a factor of 2.1 from 16:12 UT to 23:12 UT during all model simulation period. The vibrationally excited $\mathrm{N}_{2}(v>0)$ and $\mathrm{O}_{2}(v>0)$ are included in the model and the EUVAC solar flux model is used as the input model parameter in all model calculations presented in Fig. 2. The difference between UT and the local time at the geomagnetic equator is $05: 12$.

Eqs. (A1), (A6), and (A7) of Appendix A with the model value of $E_{\Lambda}$. The model is run from 15:12 UT on 5 October 1957 to 24:00 UT on 6 October 1957 before model results are used.

\section{Solar geophysical conditions and data}

The value of the geomagnetic $K_{p}$ index was between 0 and 2 for the studied time period of 7 October 1957. It should be noted that when the thermosphere is disturbed, it takes time for it to relax back to its initial state, and this thermosphere relaxation time determines the time for the disturbed ionosphere to relax back to the quiet state. It means that not every time period with $K_{p} \leq 3$ can be considered as a magnetically quiet time period. The characteristic time of the neutral composition recovery after a storm impulse event ranges from 7 to 12 hours, on average (Hedin, 1987), while it may need up to days for all altitudes down to $120 \mathrm{~km}$ in the atmosphere to recover completely back to the undisturbed state of the atmosphere (Richmond and $\mathrm{Lu}, 2000$ ). The value of $K_{p}$ was between 0 and 3 for the previous 4-6 October 1957 time period, i.e. the studied time period of 7 October 1957 can be 
considered as a magnetically quiet time period. The F10.7 solar activity index was 254 on 7 October 1957, while the 81-day averaged F10.7 solar activity index was 234.

Our study is based on hourly critical frequencies fof2, and $f o \mathrm{E}$, of the $\mathrm{F} 2$ and E-layers, and the maximum usable frequency parameter, $\mathrm{M}(3000) \mathrm{F} 2$, data from the Huancayo, Chiclayo, Talara, Bogota, Panama, and, Puerto Rico ionospheric sounder stations available on the Ionospheric Digital Database of the National Geophysical Data Center, Boulder, Colorado. Locations of these ionospheric sounder stations are shown in Table 1. The first five sounders at low latitude are within $\pm 3.5^{\circ}$ geomagnetic longitude of one another. As a result, all model simulations are carried out for the geomagnetic longitude of $351.9^{\circ}$. To complete the picture of the latitude dependence of $N m \mathrm{~F} 2$ and $h m \mathrm{~F} 2$ variations, we compare the modeled $N m \mathrm{~F} 2$ and $h m \mathrm{~F} 2$ at the geomagnetic longitude of $351.9^{\circ}$ with $\mathrm{Nmf} 2$ and $h m \mathrm{~F} 2$ measured by the Puerto Rico ionosonde station with geomagnetic longitude $2.8^{\circ}$. The Puerto Rico sounder departs slightly from the near conjugacy of the Huancayo, Chiclayo, Talara, Bogota, and Panama ionospheric sounder stations, but this geomagnetic longitude deviation is nonsignificant for our study because the equatorial anomaly effects are less pronounced at the Puerto Rico sounder in comparison with those at the first five sounders. The values of the peak density, $N m \mathrm{~F} 2$, of the F2-layer is related to the critical frequencies fof 2 as $N m \mathrm{~F} 2=1.24 \cdot 10^{10} f o f 2^{2}$, where the unit of $N m \mathrm{~F} 2$ is $\mathrm{m}^{-3}$, the unit of fof 2 is $\mathrm{MHz}$. To determine the ionosonde values of $h m \mathrm{~F} 2$, we use the relation between $h m \mathrm{~F} 2$ and the values of $\mathrm{M}(3000) \mathrm{F} 2$, fof 2 , and $f o \mathrm{E}$ recommended by Dudeney (1983) from the comparison of different approaches as $h m \mathrm{~F} 2=1490 /[\mathrm{M}(3000) \mathrm{F} 2+\Delta \mathrm{M}]-176$, where $\Delta \mathrm{M}=$ $0.253 /(f \circ f 2 / f o \mathrm{E}-1.215)-0.012$. If there are no $f o \mathrm{E}$ data, then it is suggested that $\Delta \mathrm{M}=0$, i.e. the $h m \mathrm{~F} 2$ formula of Shimazaki (1955) is used.

\section{Results}

\subsection{Equatorial perpendicular electric field modification}

In Fig. 2, geomagnetic latitude plots are shown of $h m \mathrm{~F} 2$ and $N m$ F2 at 00:00 UT (panels (a), (b), (e), and (f)) and 16:00 UT (panels (c), (d), (g), and (h)) on 7 October 1957 from the ionospheric sounder station measurements (squares) and model calculations (solid, dotted, and dashed lines). Four left panels (a), (b), (c), and (d) show the model results when the original equatorial perpendicular plasma drift of Scherliess and Fejer (1999), given by the dash-dotted line in Fig. 1, is used. Four right panels (e), (f), (g), and (h) show the model results when the empirical equatorial electric field, found from the equatorial perpendicular plasma drift velocity of Scherliess and Fejer (1999), was modified in the time range between 07:27 LT and 11:00 LT and between 15:00 LT and 18:30 LT (this modified equatorial electric field is shown by a solid line in Fig. 1). Dashed lines show the model results when the original NRLMSISE-00 neutral temperature and densities are used. Solid lines show the model results when the NRLMSISE-00 model [O] was decreased by a factor of 1.7 from 16:12 UT to 23:12 UT (from 11:00 LT to 18:00 LT, where LT is the local time at the geomagnetic equator and $351.9^{\circ}$ of the geomagnetic longitude) during all model simulation periods. Dotted lines show the model results when the NRLMSISE-00 model $\left[\mathrm{N}_{2}\right]$ and $\left[\mathrm{O}_{2}\right]$ were increased by a factor of 2.1 from 16:12 UT to 23:12 UT during all model simulation periods. The vibrationally excited $\mathrm{N}_{2}(v>0)$ and $\mathrm{O}_{2}(v>0)$ are included in the model, and the EUVAC solar flux model is used as the input model parameter in all model calculations presented in Fig. 2.

The comparison between the results shown in the two upper panels (a) and (e) of Fig. 2 clearly indicates that there is a large disagreement between the measured and modelled $h m \mathrm{~F} 2$ at 00:00 UT on 7 October 1957, if the equatorial upward $\boldsymbol{E} \times \boldsymbol{B}$ drift given by Scherliess and Fejer (1999) is used. The results presented in panels (a) and (b) of Fig. 2 provide evidence that we can match the measured and modeled $N m F 2$ using the corrected neutral densities. However, the corrections of the NRLMSISE-00 model [O], $\left[\mathrm{N}_{2}\right]$, or $\left[\mathrm{O}_{2}\right]$ do not bring the measured and modeled $h m \mathrm{~F} 2$ into agreement. We conclude that this disagreement in $h m \mathrm{~F} 2$ is caused by the long time duration of the pre-reversal strengthening of the equatorial upward $\boldsymbol{E} \times \boldsymbol{B}$ drift given by Scherliess and Fejer (1999). The high estimate of this pulse duration in $E_{\Lambda}$ leads to unreal, high-modeled F2 peak altitudes at 00:00 UT. Our calculations presented in the panels (e) and (f) of Fig. 2 provide evidence that, to bring the measured and modeled F2-region main peak altitudes into agreement, the magnitude of $E_{\Lambda}$ has to be approximately constant in the time range between 15:00 LT and 18:00 LT with the following peak in $E_{\Lambda}$, which has a shorter time width in comparison with the time duration of the pre-reversal strengthening of the original equatorial perpendicular plasma drift given by Scherliess and Fejer (1999). Fejer et al. (1989) show solar maximum ion vertical drifts over Jicamarca, which is very close to Huancayo, near the magnetic equator. The pre-reversal enhancements during quiet equinox periods can begin as late as 18:00 LT and peak after 19:00 LT, although the average enhancements are earlier and broader. In addition, Batista et al. (1986) estimate the pre-reversal enhancement at Huancayo to peak between 18:00 LT and 19:00 LT based on $h m \mathrm{~F} 2$ changes during equinox solar maximum conditions. Thus, our delay of the pre-reversal enhancement until 18:00 LT is in agreement with the observed day-to-day variability at Jicamarca, and previous estimates for Huancayo.

The principal feature of the equatorial anomaly is that the crest-to-trough ratio is increased with increasing upward $\boldsymbol{E} \times \boldsymbol{B}$ drift (Dunford, 1967; Su et al., 1997; Rishbeth, 2000). The measurements show that, by mid-afternoon (15:00 UT), the equatorial anomaly crests are forming away from the geomagnetic equator, while the model calculations with the equatorial $E_{\Lambda}\left(t_{g e}\right)$, given by the dash-dotted line in Fig. 1, produce the onset of the equatorial anomaly crest formation close to 16:00 UT (see lines in panels (c) and (d) of Fig. 2). The disagreement between the sizes of the equato- 
Table 1. Ionosonde station names and locations

\begin{tabular}{lrrrr}
\hline $\begin{array}{l}\text { Ionosonde } \\
\text { station }\end{array}$ & $\begin{array}{r}\text { Geographic } \\
\text { latitude }\end{array}$ & $\begin{array}{r}\text { Geographic } \\
\text { longitude }\end{array}$ & $\begin{array}{r}\text { Geomagnetic } \\
\text { latitude }\end{array}$ & $\begin{array}{r}\text { Geomagnetic } \\
\text { longitude }\end{array}$ \\
\hline Huancayo & -12.0 & 284.6 & -0.65 & 354.5 \\
Chiclayo & -6.7 & 280.1 & 4.5 & 349.9 \\
Talara & -4.5 & 278.6 & 6.7 & 348.4 \\
Bogota & 4.5 & 285.8 & 15.9 & 355.4 \\
Panama & 9.4 & 280.1 & 20.6 & 349.3 \\
Puerto Rico & 18.5 & 292.8 & 29.9 & 2.8 \\
\hline
\end{tabular}

rial trough in the measured (squares in panel (d) of Fig. 2) and modeled (lines in panel (d) of Fig. 2) $N m$ F2 at 16:00 UT can be explained by disagreements between the chosen and unknown real values of $E_{\Lambda}\left(t_{g e}\right)$ on 7 October 1957. The results presented in panel (d) of Fig. 2 provide evidence that we cannot match the measured and modeled $N m \mathrm{~F} 2$ and the sizes of the measured and modeled equatorial troughs using the corrections of the NRLMSISE-00 model [O], $\left[\mathrm{N}_{2}\right]$, or $\left[\mathrm{O}_{2}\right]$.

Our calculations show that a strengthening of the equatorial upward $\boldsymbol{E} \times \boldsymbol{B}$ drift before 17:00 UT on 7 October 1957 leads to an increase in the northern and southern depths of the equatorial $N m \mathrm{~F} 2$ trough (these depths can be expressed as ratios of $N m \mathrm{~F} 2$ at $\mathrm{F} 2$-region northern and southern crests to an equatorial $N m \mathrm{~F} 2$ ) at 17:00 UT on 7 October 1957. The modification of $E_{\Lambda}\left(t_{g e}\right)$ is shown by a solid line in Fig. 1. This modification, which was carried out in the time range between 07:27 LT and 11:00 LT, includes the strengthening of $E_{\Lambda}$ and the time shift of the peak in $E_{\Lambda}\left(t_{g e}\right)$ relative to the peak in $E_{\Lambda}\left(t_{g e}\right)$, shown by the dash-dotted line in Fig. 1. The first maximum $\left(E_{\Lambda}=1.1 \mathrm{mVm}^{-1}\right)$ of the modified $E_{\Lambda}\left(t_{g e}\right)$ occurs at 08:30 LT while the first maximum $\left(E_{\Lambda}=0.66 \mathrm{mVm}^{-1}\right)$ of $E_{\Lambda}\left(t_{g e}\right)$, given by the dash-dotted line in Fig. 1, is located between 10:00 LT and 11:00 LT. It should be noted that the revised magnitude of the first peak in $E_{\Lambda}$ is close to the magnitude of the second peak in $E_{\Lambda}$, although the second peak is expected to be about double the size of the first peak in solar maximum (Fesen et al., 2000). However, the Fejer et al. (1995) quiet-time equinox model from the AE-E satellite observations during moderate to high solar flux conditions at $260^{\circ} \mathrm{E}$ suggest a morning peak at 09:30 LT, which is nearly equal to the sharper evening reversal peak, similar to our proposed changes. The comparison between the squares and solid line in panel (h) of Fig. 2 shows that the northern depth of the equatorial $N m \mathrm{~F} 2$ trough in the calculated $N m \mathrm{~F} 2$ is approximately consistent with the measured depth, if the modified $E_{\Lambda}\left(t_{g e}\right)$ is used. The model $N m \mathrm{~F} 2$ is higher than the observations with the anomaly crest shifted poleward, if the original NRLMSISE00 model is used (see dashed line in panel (h) of Fig. 2). Panel (g) of Fig. 2 shows that the agreement between measured and modeled $h m \mathrm{~F} 2$ is somewhat worse. It should be noted that the model with the modified value of $E_{\Lambda}\left(t_{g e}\right)$ produces the onset of the equatorial anomaly crest formation close to 15:00 UT, in agreement with the measured onset of the equatorial anomaly crest formation given by ionosonde stations.

As a result, the equatorial electric field, shown by the solid line in Fig. 1, and the Arecibo value of $E_{\Lambda}\left(t_{g e}\right)$, shown by the dashed line in Fig. 1, are used in all subsequent model calculations presented in this paper, as described in Sect. 2.

4.2 Evaluation of uncertainties in model calculations of $N m \mathrm{~F} 2$ and $h m \mathrm{~F} 2$ from the comparison between neutral atmosphere models and between the solar flux models as input model parameters

The measured (squares) and calculated (lines) $N m \mathrm{~F} 2$ and $h m \mathrm{~F} 2$ are displayed in the two lower panels of Figs. 3-8 for the 7 October 1957 time period above the Huancayo (Fig. 3), Chiclayo (Fig. 4), Talara (Fig. 5), Bogota (Fig. 6), Panama (Fig. 7), and Puerto Rico (Fig. 8) ionosonde stations. The results obtained from the model of the ionosphere and plasmasphere, using the combinations of the original NRLMSISE00 or MSIS-86 neutral temperature and density models and the EUVAC or EUV97 solar flux models as the input model parameters, are shown by solid lines (the NRLMSISE-00 model in combination with the EUVAC model), dotted lines (the NRLMSISE-00 model in combination with the EUV97 model), dash-dotted lines (the MSIS-86 model in combination with the EUVAC model), and dashed lines (the MSIS-86 model in combination with the EUV97 model).

The differences in original neutral densities and temperatures from the NRLMSISE-00 and MSIS-86 models result in the differences between solid and dash-dotted lines (the EUVAC solar flux model is used) and between dotted and dashed lines (the EUV97 solar flux model is used). We found that the use of the NRLMSISE-00 model, as opposed to the MSIS-86 model, leads to the highest possible increase in the calculated $N m \mathrm{~F} 2$ by a maximum factor of $1.29,1.23,1.22$, $1.28,1.30$, and 1.39 and to the highest possible decrease in the calculated $h m \mathrm{~F} 2$ by $38,42,40,22,22$ and $23 \mathrm{~km}$ above the Huancayo, Chiclayo, Talara, Bogota, Panama, and Puerto Rico ionosonde stations, respectively. The use of the EUV97 solar flux model as opposed to the EUVAC solar flux model leads to the increase in the calculated $N m \mathrm{~F} 2$ by a factor of $1.13-1.34$ and to the highest possible variations in calculated $h m \mathrm{~F} 2$ of $12 \mathrm{~km}$. 


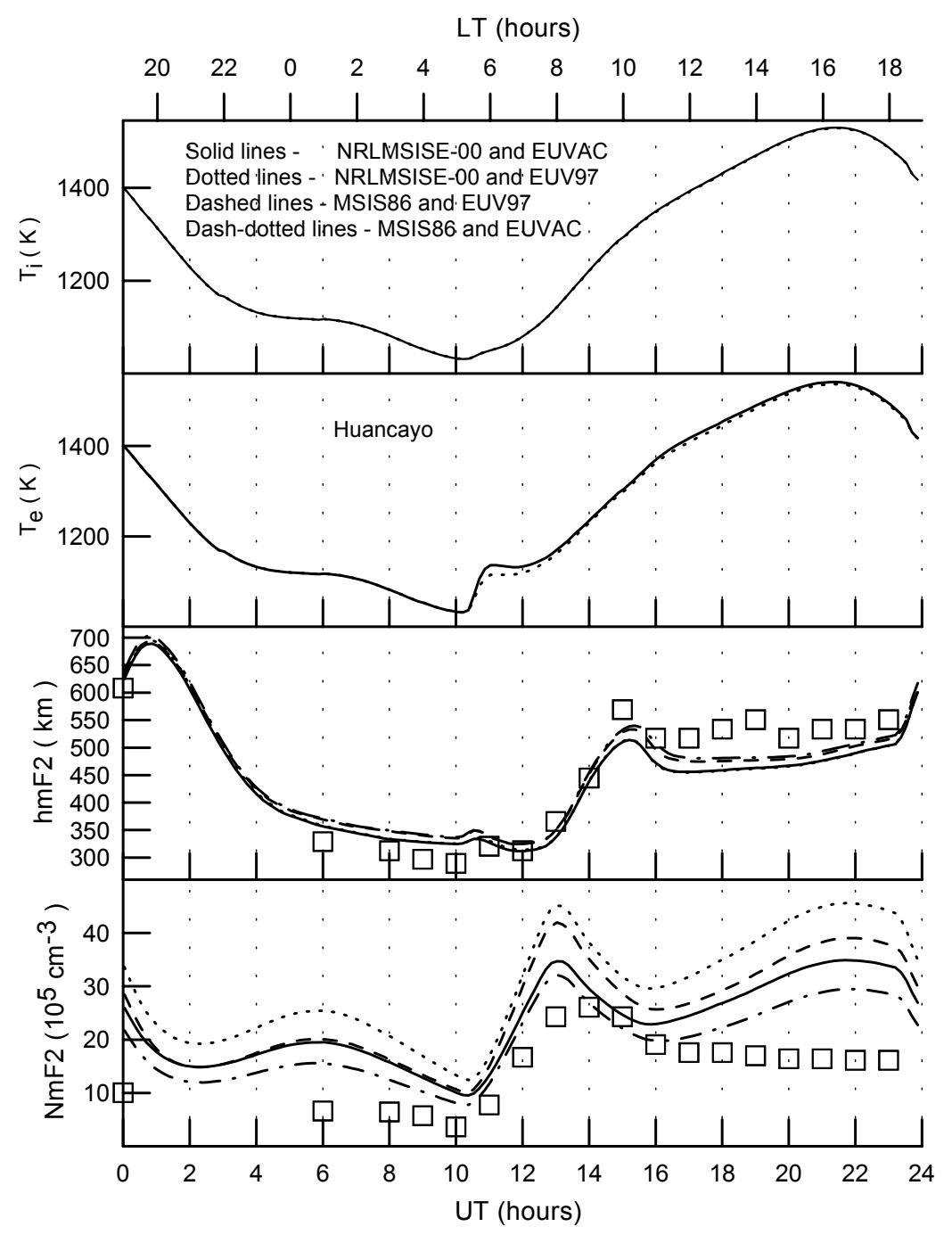

Fig. 3. Observed (squares) and calculated (lines) $N m \mathrm{~F} 2$ and $h m \mathrm{~F} 2$ (two lower panels), and electron and $\mathrm{O}^{+}$ion temperatures (two upper panels) at the F2-region main peak altitude above the Huancayo ionosonde station on 7 October 1957. The results obtained from the model of the ionosphere and plasmasphere using the combinations of the original NRLMSISE-00 or original MSIS-86 neutral temperature and densities model and the EUVAC or EUV97 solar flux models as the input model parameters are shown by solid lines (the NRLMSISE-00 model in combination with the EUVAC model), dotted lines (the NRLMSISE-00 model in combination with the EUV97 model), dashdotted lines (the MSIS-86 model in combination with the EUVAC model), dashed lines (the MSIS-86 model in combination with the EUV97 model). LT is the local time at the Huancayo ionosonde station.
Our calculations clearly show that the best agreement between the measured and modeled electron densities is obtained if the MSIS-86 neutral densities and temperature in combination with the EUVAC solar flux (dash-dotted lines in Figs. 3-8) are used as the input model parameters. At the same time, the NRLMSISE-00 model is the outgrowth of the MSIS- 86 model, and we have a right to expect that the NRLMSISE-00 model describes real neutral temperature and densities variations more accurately in comparison to the MSIS-86 model. Therefore, the NRLMSISE-00 neutral temperature and density model of Picone et al. (2000, 2002), and the EUVAC solar flux model of Richards et al. (1994) are used in the further model calculations presented in this work.

\subsection{Electron and ion temperature variations}

Two upper panels of Figs. 3-8 show the electron, $T_{e}$, and ion, $T_{i}$, temperatures at the F2-region main peak altitude calculated for the 7 October 1957 time period above the Huancayo (Fig. 3), Chiclayo (Fig. 4), Talara (Fig. 5), Bogota (Fig. 6), Panama (Fig. 7), and Puerto Rico (Fig. 8) ionosonde stations.
The results obtained from the model of the ionosphere and plasmasphere, using the combinations of the NRLMSISE00 or MSIS- 86 neutral temperature and density models and the EUVAC or EUV97 solar flux models as the input model parameters, are shown by solid lines (the NRLMSISE-00 model in combination with the EUVAC model), dotted lines (the NRLMSISE-00 model in combination with the EUV97 model), dash-dotted lines (the MSIS-86 model in combination with the EUVAC model), and dashed lines (the MSIS-86 model in combination with the EUV97 model). It is evident from Figs. 3-8 that the electron and ion temperature changes created by the difference between the NRLMSISE-00 and MSIS-86 neutral temperatures and number densities or by the difference between the EUV97 and EUVAC solar fluxes are negligible.

The electron and ion temperatures start to increase from their night-time values close to 10:12 UT. The electron temperature reaches a morning peak at about 10:52-11:12 UT, above the ionosonde stations of Table 1, while the ion temperatures above all the ionosonde stations presented in Table 1 have no morning peaks at $h m \mathrm{~F} 2$. Following the morn- 


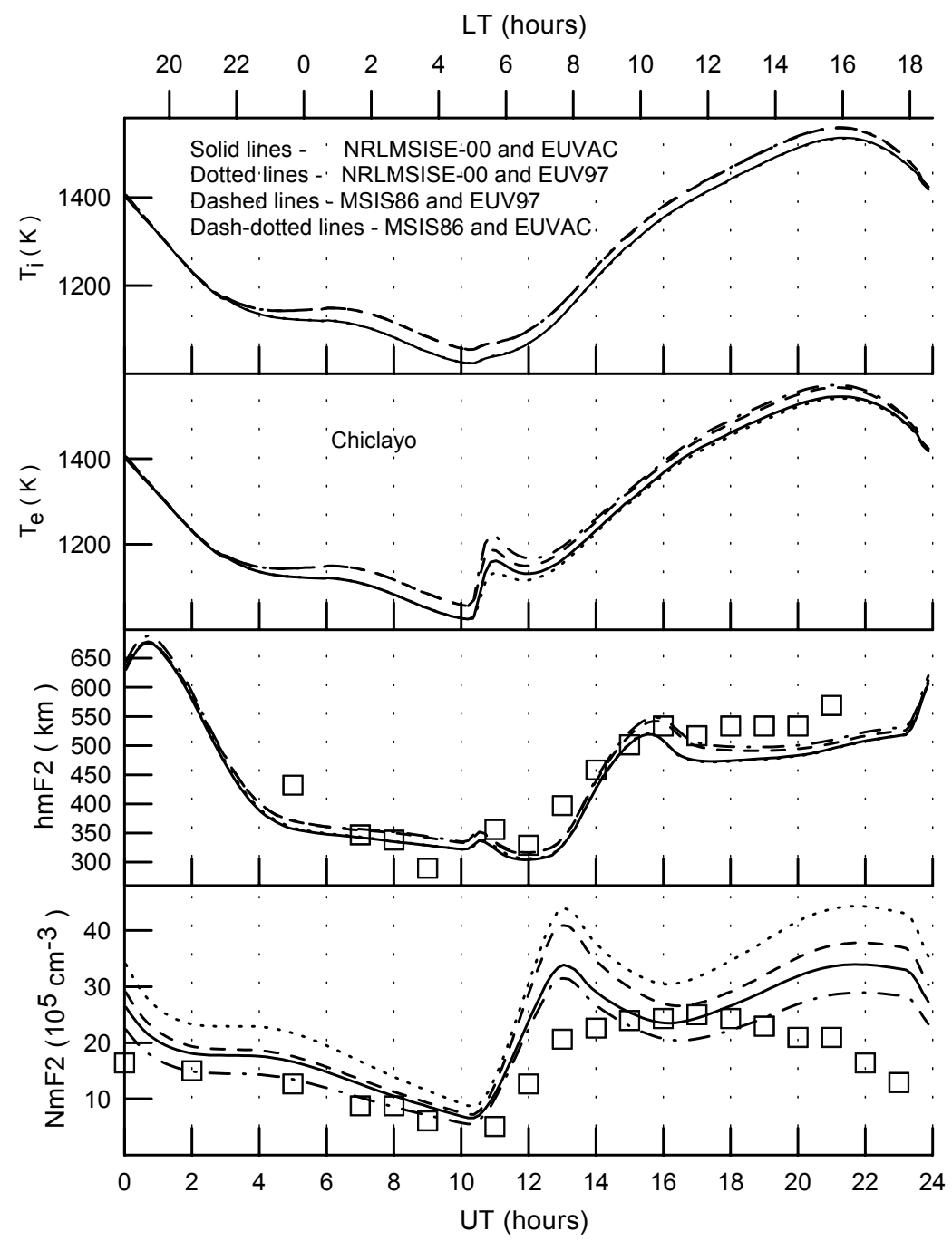

Fig. 4. From bottom to top, observed (squares) and calculated (lines) of $N m \mathrm{~F} 2, h m \mathrm{~F} 2$, electron temperatures and $\mathrm{O}^{+}$ion temperatures at the $\mathrm{F} 2$ region main peak altitude above the Chiclayo ionosonde station on 7 October 1957. LT is the local time at the Chiclayo ionosonde station. The curves are the same as in Fig. 3. ing peak, there is a rapid decrease in the electron temperature, which reaches a minimum at around 11:32-13:12 UT. After the electron temperature minimum, the electron temperature increases again above the ionosonde stations.

The peak values in the electron and ion temperatures above all the ionosonde stations presented in Table 1 occur at about 20:32-21:22 UT. Our calculations show that the magnitudes of the electron and ion temperatures at $h m \mathrm{~F} 2$ are close to the neutral temperature at $h m \mathrm{~F} 2$ during most of the daytime conditions. As a result, the peak values in the electron and ion temperatures result from the peak in the neutral temperature at $h m \mathrm{~F} 2$, which occurs very close to the time of the peaks in the electron and ion temperatures above the ionosonde stations presented in Table 1.

It is well known that in the ionospheric F-region, there is an inverse relationship between electron temperature and electron density, i.e. greater electron densities produce lower electron temperatures. As a result, the electron temperature is close to the neutral temperature during most of the daytime period at $h m \mathrm{~F} 2$ altitudes at solar maximum, due to high magnitudes of electron cooling rates in comparison with the input of the electron heat flow along the magnetic field line in the daytime electron temperature variations.

Electron and ion temperatures profiles measured at Jicamarca close to the geomagnetic equator between June 1965 and November 1966 are such that $T_{e}>T_{i}$ between about $200 \mathrm{~km}$ and $300 \mathrm{~km}$ during daytime conditions, $T_{e} \approx T_{i} \approx$ const between about $300 \mathrm{~km}$ and $500 \mathrm{~km}$, and the value of $T_{e}$ is close to the neutral temperature in this daytime isothermal altitude region (McClure, 1969; Schunk and Nagy, 1978). This daytime electron and ion isothermal region can come up to $600 \mathrm{~km}$ (Bailey et al., 1975). Throughout this region the electron thermal conduction term in the thermal balance equation of electrons is negligible in comparison with cooling of electrons due to collisions of thermal electrons with ions and neutral gases (Bailey et al., 1975; Schunk and Nagy, 1978). Our calculations show that the values of the electron temperatures at F2-region altitudes become almost independent of the electron heat flow along the magnetic field line above the Huancayo (Fig. 3), Chiclayo (Fig. 4), and Talara (Fig. 5) ionosonde stations because the near-horizontal magnetic field inhibits this heat flow of electrons. The increase 


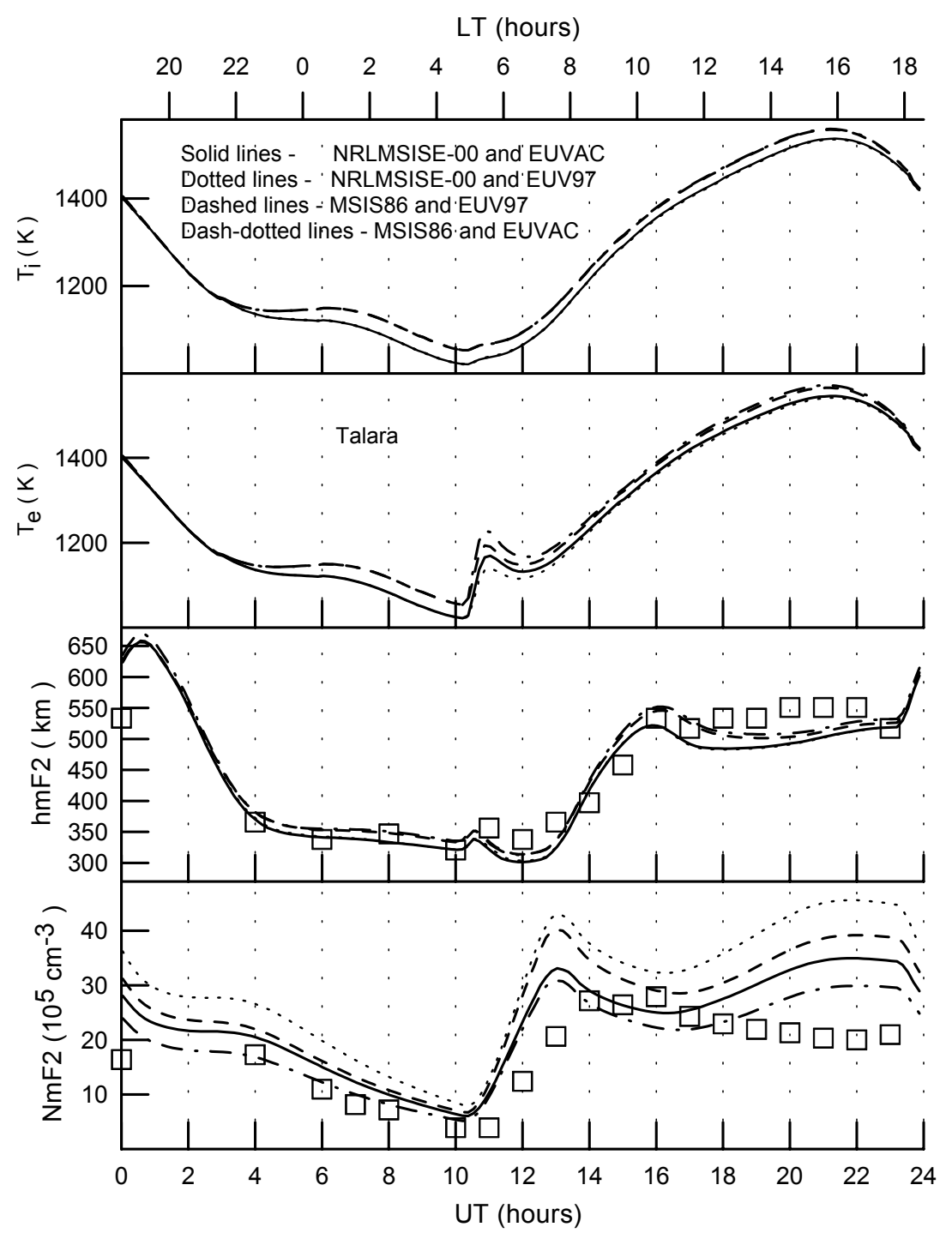

Fig. 5. From bottom to top, observed (squares) and calculated (lines) of $N m \mathrm{~F} 2, h m \mathrm{~F} 2$, electron temperatures and $\mathrm{O}^{+}$ion temperatures at the $\mathrm{F} 2$ region main peak altitude above the Talara ionosonde station on 7 October 1957. LT is the local time at the Talara ionosonde station. The curves are the same as in Fig. 3. in geomagnetic latitude leads to the increase in the effects of the electron heat flow along the magnetic field line on $T_{e}$.

It follows from the electron and ion temperatures profiles measured at Jicamarca that the enlargement of the altitude region with $T_{e}>T_{i}$ occurs at sunrise at all heights to at least $600 \mathrm{~km}$ (McClure, 1969). Our calculations show that at sunrise, there is a rapid heating of the ambient electrons by photoelectrons, and the difference between the electron and neutral temperatures could be increased because nighttime electron densities are less than those by day, and the electron cooling during morning conditions is less than that by day. This expands the altitude region at which $T_{e}>T_{i}$ near the equator, and leads to the sunrise electron temperature peaks at $h m \mathrm{~F} 2$ altitudes above the ionosonde stations. After the abrupt increase at sunrise, the electron temperature decreases, owing to the increasing electron density due to the increase in the cooling rate of thermal electrons and due to the decrease in the relative role of the electron heat flow along the magnetic field line in comparison with cooling of thermal electrons. As a result, the morning electron temperature peaks which are found above the ionosonde stations at $h m \mathrm{~F} 2$ altitudes are explained by these physical processes.

Early studies have pointed out that the radar $T_{e}$ measured at Jicamarca are lower than $T_{e}$ measured by using probes on satellites, and there was a problem with unreal night-time radar $T_{e}<T_{i}$ (McClure et al., 1973; Aponte et al., 2001). This problem was solved by Sulzer and Gonzalez (1999) and Aponte et al. (2001), who found that electron-electron and electron-ion Coulomb collisions are responsible for the additional incoherent backscatter spectral narrowing above Jicamarca, leading to the change in the measured $T_{e} / T_{i}$ ratio. Specifically, $T_{e}=T_{i}$ at night, at F-region altitudes above Jicamarca (Aponte et al., 2001). In agreement with this conclusion, our calculations show that $T_{e}=T_{i}$ at night, at F-region altitudes close to the geomagnetic equator.

The relative magnitudes of the cooling rates are of particular interest for understanding the main processes which determine the electron temperature. The model of the iono- 


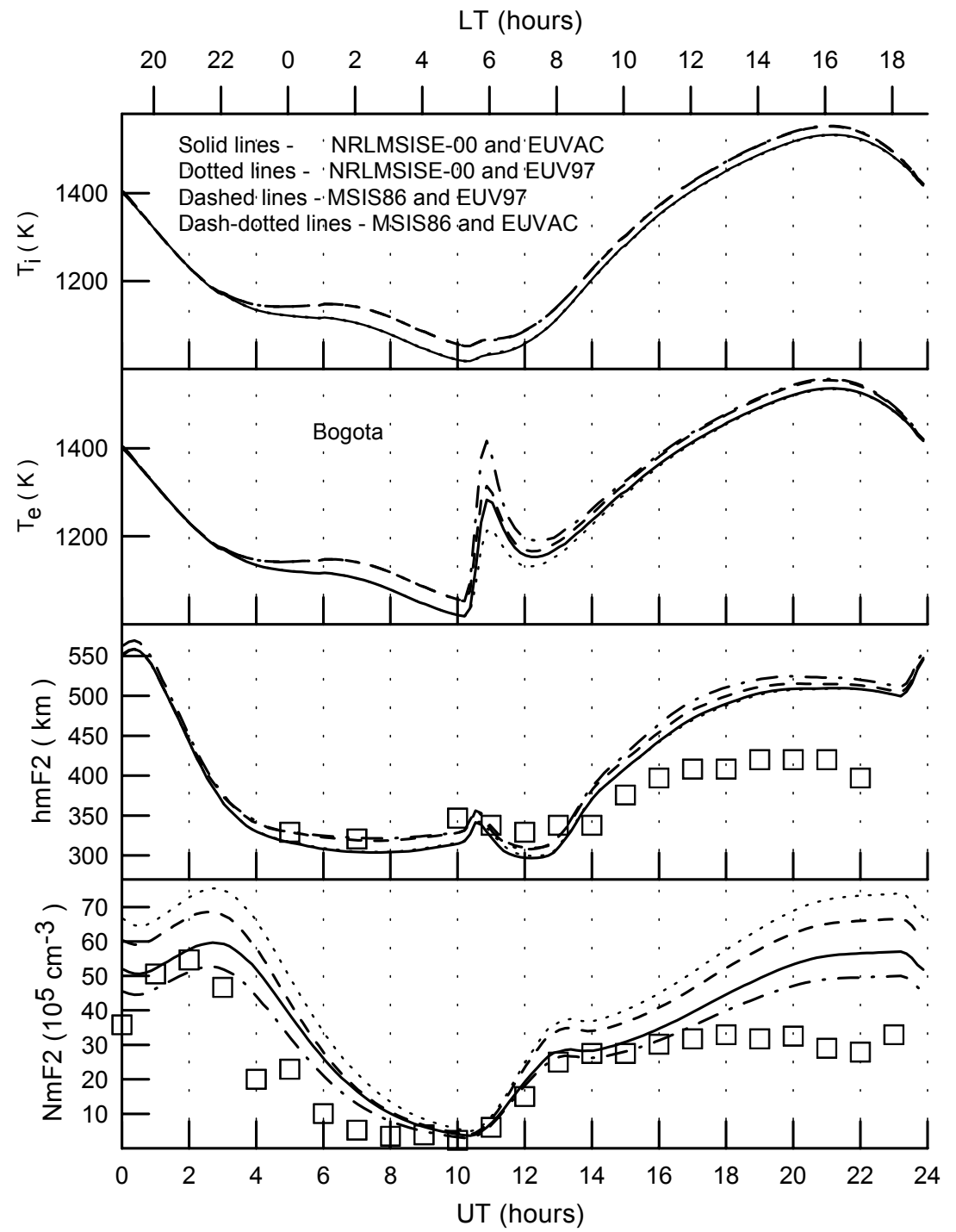

Fig. 6. From bottom to top, observed (squares) and calculated (lines) of $N m \mathrm{~F} 2, h m \mathrm{~F} 2$, electron temperatures and $\mathrm{O}^{+}$ion temperatures at the $\mathrm{F} 2$ region main peak altitude above the Bogota ionosonde station on 7 October 1957. LT is the local time at the Bogota ionosonde station. The curves are the same as in Fig. 3. sphere and plasmasphere uses the electron cooling rates due to electron-ion Coulomb collisions and elastic collisions of electrons with $\mathrm{N}_{2}, \mathrm{O}_{2}, \mathrm{O}, \mathrm{He}$ and $\mathrm{H}$, the thermal electron impact excitation of $\mathrm{O}_{2}\left(\mathrm{a}^{1} \Delta_{g}\right), \mathrm{O}_{2}\left(\mathrm{~b}^{1} \sum_{g}{ }^{+}\right)$, and the fine structure levels of the ground state of atomic oxygen, the rates of electron cooling through vibrational and rotational excitation of $\mathrm{N}_{2}$ and $\mathrm{O}_{2}$, and the electron energy loss arising from electron-impact-induced transitions ${ }^{3} \mathrm{P} \rightarrow{ }^{1} \mathrm{D}$ for atomic oxygen (see Sect. A2.2 of Appendix A). The relative role of the electron cooling rates was evaluated. We found that the main cooling rates of thermal electrons on 7 October 1957, are electron-ion Coulomb collisions, vibrational excitation of $\mathrm{N}_{2}$ and $\mathrm{O}_{2}$, and rotational excitation of $\mathrm{N}_{2}$. The relative role of the cooling rates of thermal electrons by low-lying electronic excitation of $\mathrm{O}_{2}\left(\mathrm{a}^{1} \Delta_{g}\right)$ and $\mathrm{O}_{2}\left(\mathrm{~b}^{1} \sum g^{+}\right)$, from rotational excitation of $\mathrm{O}_{2}$, in collision of $\mathrm{O}\left({ }^{3} \mathrm{P}\right)$ with thermal electrons with the $\mathrm{O}\left({ }^{1} \mathrm{D}\right)$ formation, and by the atomic oxygen fine structure excitation, is negligible in comparison with the effects of the main cooling rates on the electron temperature for the geomagnetically quiet period on 7 October 1957.

\subsection{Effects of corrections in the NRLMSISE-00 model [O] or $\left[\mathrm{N}_{2}\right]$ and $\left[\mathrm{O}_{2}\right]$ on the ionosphere.}

Figures $3-8$ show that the calculated $N m \mathrm{~F} 2$ is systematically higher than the measured one during most of the studied time period. We can expect that the neutral models have some inadequacies in predicting the number densities with accuracy, and we have to change the number densities by correction factors at all altitudes, to bring the modeled electron densities into agreement with the measurements.

The comparison between the measured (squares) and modeled (lines) $N m \mathrm{~F} 2$ and $h m \mathrm{~F} 2$ latitude variations are shown in Fig. 9, at 17:00 UT (two upper panels) and 19:00 UT (two lower panels) on 7 October 1957 and in Fig. 10 at 21:00 UT (two upper panels) and 23:00 UT (two lower panels) on 7 October 1957. Dashed lines show the model results when the original NRLMSISE-00 neutral temperature and densi- 


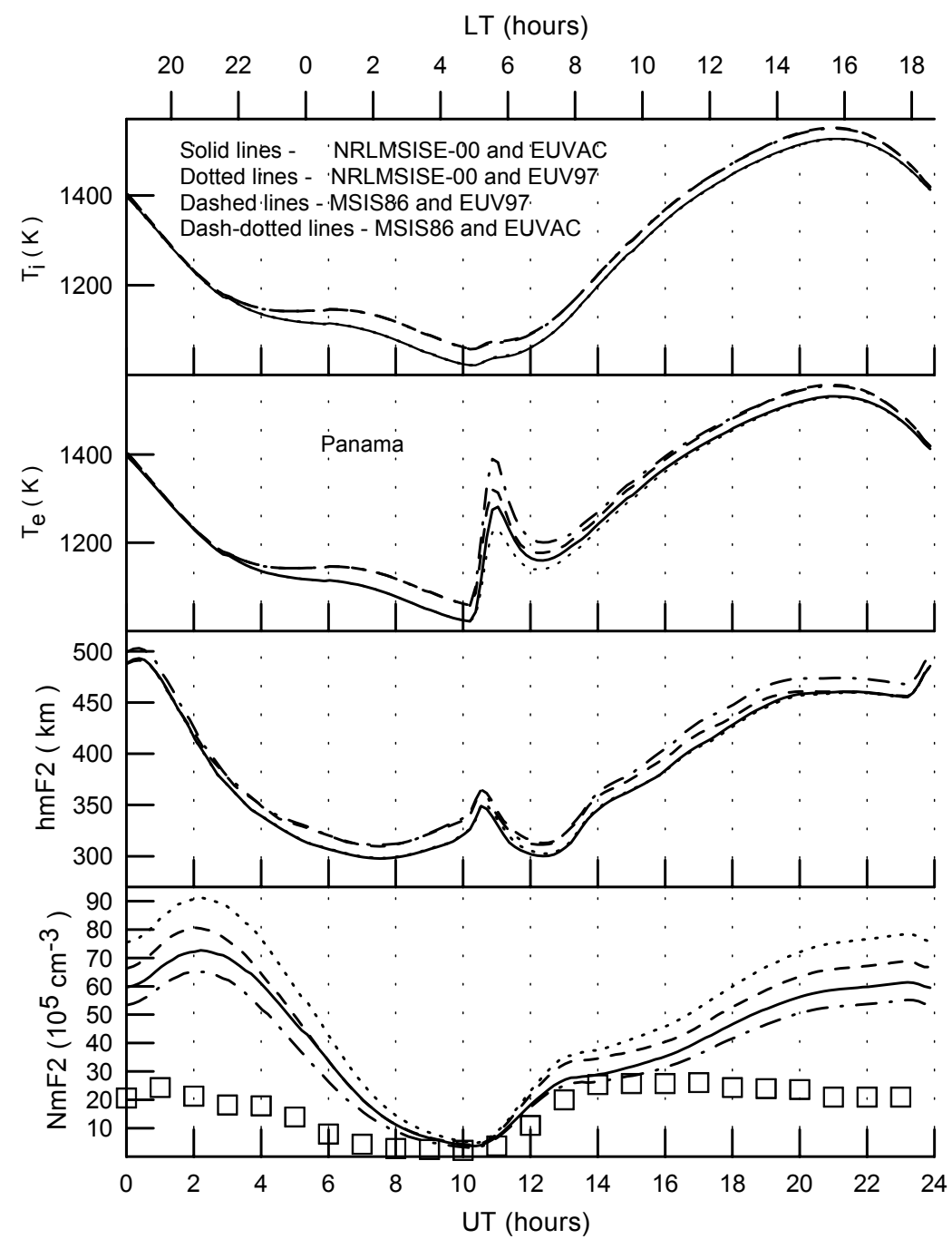

Fig. 7. From bottom to top, observed (squares) and calculated (lines) of $N m \mathrm{~F} 2, h m \mathrm{~F} 2$, electron temperatures and $\mathrm{O}^{+}$ion temperatures at the $\mathrm{F} 2$ region main peak altitude above the Panama ionosonde station on 7 October 1957. LT is the local time at the Panama ionosonde station. The curves are the same as in Fig. 3. ties are used. Solid lines show the model results when the NRLMSISE-00 model [O] was decreased by a factor of 1.7 by day, from 16:12 UT to 23:12 UT (from 11:00 LT to 18:00 LT) at all altitudes without NRLMSISE-00 $\left[\mathrm{N}_{2}\right]$ and $\left[\mathrm{O}_{2}\right]$ corrections, where LT is the local time at the geomagnetic equator and $351.9^{\circ}$ of the geomagnetic longitude) during the model simulation period. Dash-dotted and dotted lines will be explained later. One can see from Figs. 9 and 10 that the NRLMSISE-00 model with the decreased [O] improves the agreement with the measured $N m \mathrm{~F} 2$ and $h m \mathrm{~F} 2$.

We can also expect that the NRLMSISE-00 model has some inadequacies in predicting the actual $\mathrm{N}_{2}$ and $\mathrm{O}_{2}$ number densities with accuracy. The values of the NRLMSISE$00\left[\mathrm{~N}_{2}\right]$ and $\left[\mathrm{O}_{2}\right]$ were increased by a factor of 2.1 from 16:12 UT to 23:12 UT at all altitudes without NRLMSISE-00 [O] corrections to compare the effects of the NRLMSISE-00 $\left[\mathrm{N}_{2}\right]$ and $\left[\mathrm{O}_{2}\right]$ correction on $N m \mathrm{~F} 2$ and $h m \mathrm{~F} 2$ with those obtained from the NRLMSISE-00 [O] correction. The resulting model $N m \mathrm{~F} 2$ and $h m \mathrm{~F} 2$ are shown by dotted lines in Figs. 9 and 10. In general, the use of the increased NRLMSISE-00 $\mathrm{N}_{2}$ and $\mathrm{O}_{2}$ model densities brings the modeled and measured
$N m \mathrm{~F} 2$ and $h m \mathrm{~F} 2$ into satisfactory agreement.

The comparison between the NRLMSISE-00 $\left[\mathrm{N}_{2}\right]$ and $\left[\mathrm{O}_{2}\right]$ increases and the NRLMSISE-00 [O] decrease does not show similarity and consistency in their effects on $h m \mathrm{~F} 2$. Above the ionosonde stations presented in Table 1, the NRLMSISE-00 [O] decrease leads to the calculated $h m \mathrm{~F} 2$, which are less than that given by the model with the NRLMSISE-00 $\left[\mathrm{N}_{2}\right]$ and $\left[\mathrm{O}_{2}\right]$ correction, and this difference does not exceed the value of $48 \mathrm{~km}$. However, this difference in the calculated $h m \mathrm{~F} 2$ is not large enough to determine which of these two kinds of corrections of the NRLMSISE00 model are preferred by comparing the measured and modelled $h m \mathrm{~F} 2$.

The comparison between the NRLMSISE-00 $\left[\mathrm{N}_{2}\right]$ and $\left[\mathrm{O}_{2}\right]$ increases and the NRLMSISE-00 [O] decrease do show similarity and consistency in their effects on $N m \mathrm{~F} 2$. Our calculations cannot provide evidence in favor of reducing $[\mathrm{O}]$ in comparison with increasing $\left[\mathrm{N}_{2}\right]$ and $\left[\mathrm{O}_{2}\right]$. The reactions between $\mathrm{O}^{+}\left({ }^{4} \mathrm{~S}\right)$ ions and vibrationally unexcited and excited $\mathrm{N}_{2}$ provide the main input in the loss rate of $\mathrm{O}^{+}\left({ }^{4} \mathrm{~S}\right)$ ions at F-region altitudes, in comparison with that given by the reac- 


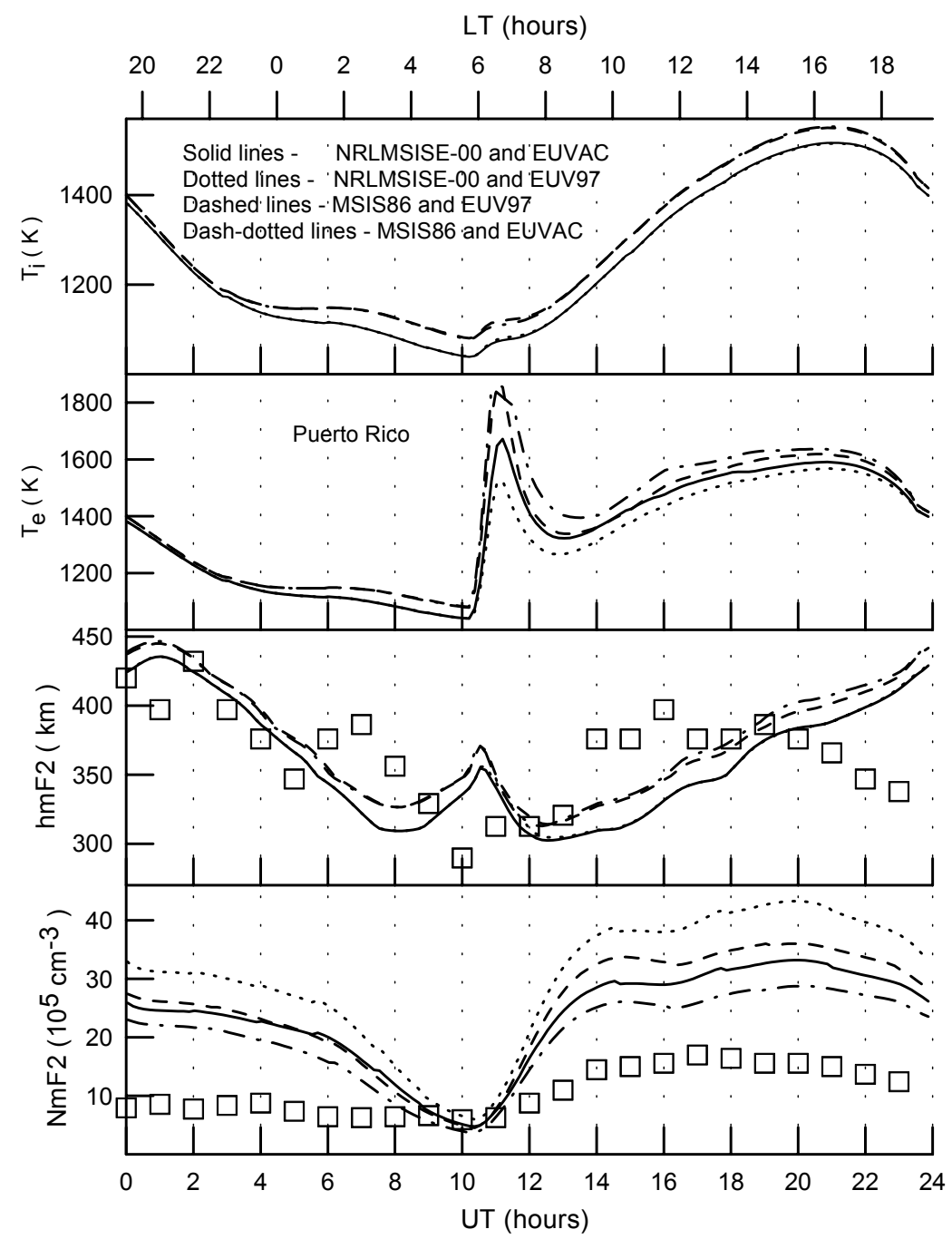

Fig. 8. From bottom to top, observed (squares) and calculated (lines) of $N m \mathrm{~F} 2, h m \mathrm{~F} 2$, electron temperatures and $\mathrm{O}^{+}$ion temperatures at the $\mathrm{F} 2$ region main peak altitude above the Puerto Rico ionosonde station on 7 October 1957. LT is the local time at the Puerto Rico ionosonde station. The curves are the same as in Fig. 3. tions between $\mathrm{O}^{+}\left({ }^{4} \mathrm{~S}\right)$ ions and vibrationally unexcited and excited $\mathrm{O}_{2}$. It follows from the calculations that the $[\mathrm{O}] /\left[\mathrm{N}_{2}\right]$ ratio determines the value of $N m \mathrm{~F} 2$. Therefore, we can only conclude from our results that it is necessary to decrease the NRLMSISE-00 model $[\mathrm{O}] /\left[\mathrm{N}_{2}\right]$ ratio by a factor of $1.7-2.1$, to bring the modeled and measured $h m \mathrm{~F} 2$ and $N m \mathrm{~F} 2$ on 7 October 1957 into agreement.

\subsection{Effects of vibrationally excited oxygen and nitrogen on $N m \mathrm{~F} 2$ and $h m \mathrm{~F} 2$}

Dash-dotted lines in Figs. 9 and 10 display the calculated $N m \mathrm{~F} 2$ and $h m \mathrm{~F} 2$ on 7 October 1957, when vibrationally excited $\mathrm{N}_{2}(v>0)$ and $\mathrm{O}_{2}(v>0)$ are not included in the model calculations of the loss rate of $\mathrm{O}^{+}\left({ }^{4} \mathrm{~S}\right)$ ions, and the original NRLMSISE-00 neutral temperature and density model and the EUVAC solar flux model are used. The heating rate of electrons due to the de-excitation of vibrationally excited $\mathrm{N}_{2}$ and $\mathrm{O}_{2}$ is taken into account in all model calculations (for more details, see Pavlov, 1998a, c; Pavlov and Foster, 2001).

As Figs. 9 and 10 show, there is a large increase in the modeled $N m \mathrm{~F} 2$ and a large decrease in the modeled $h m \mathrm{~F} 2$ without the vibrational excited nitrogen and oxygen molecules. Both the measured $N m \mathrm{~F} 2$ and $h m \mathrm{~F} 2$ are not reproduced by the model without $\mathrm{N}_{2}(v>0)$ and $\mathrm{O}_{2}(v>0)$ in the loss rate of $\mathrm{O}^{+}\left({ }^{4} \mathrm{~S}\right)$ ions, and the inclusion of vibrationally excited $\mathrm{N}_{2}$ and $\mathrm{O}_{2}$ in the loss rate of $\mathrm{O}^{+}\left({ }^{4} \mathrm{~S}\right)$ ions brings the model and data into better agreement.

Dashed lines in Figs. 9 and 10 represent the results obtained from the model with the effects of vibrationally excited $\mathrm{N}_{2}(v>0)$ and $\mathrm{O}_{2}(v>0)$ on the $\mathrm{O}^{+}\left({ }^{4} \mathrm{~S}\right)$ loss rate when the original NRLMSISE-00 neutral temperature and density model, and the EUVAC solar flux model are used. Therefore, the comparison between dashed and dash-dotted lines show the effects of vibrationally excited oxygen and nitrogen on $N m \mathrm{~F} 2$ and $h m \mathrm{~F} 2$. It follows from the model calculations that the increase in the loss rate of $\mathrm{O}^{+}\left({ }^{4} \mathrm{~S}\right)$ ions, due to the vibrational excited $\mathrm{N}_{2}$ and $\mathrm{O}_{2}$, leads to the decrease in the calculated $N m \mathrm{~F} 2$ by a factor of $1.06-1.44$ and to the increase in the calculated $h m \mathrm{~F} 2$, up to the maximum value of $32 \mathrm{~km}$ in the low-latitude ionosphere between $-30^{\circ}$ and $+30^{\circ}$ of the geomagnetic latitude. 


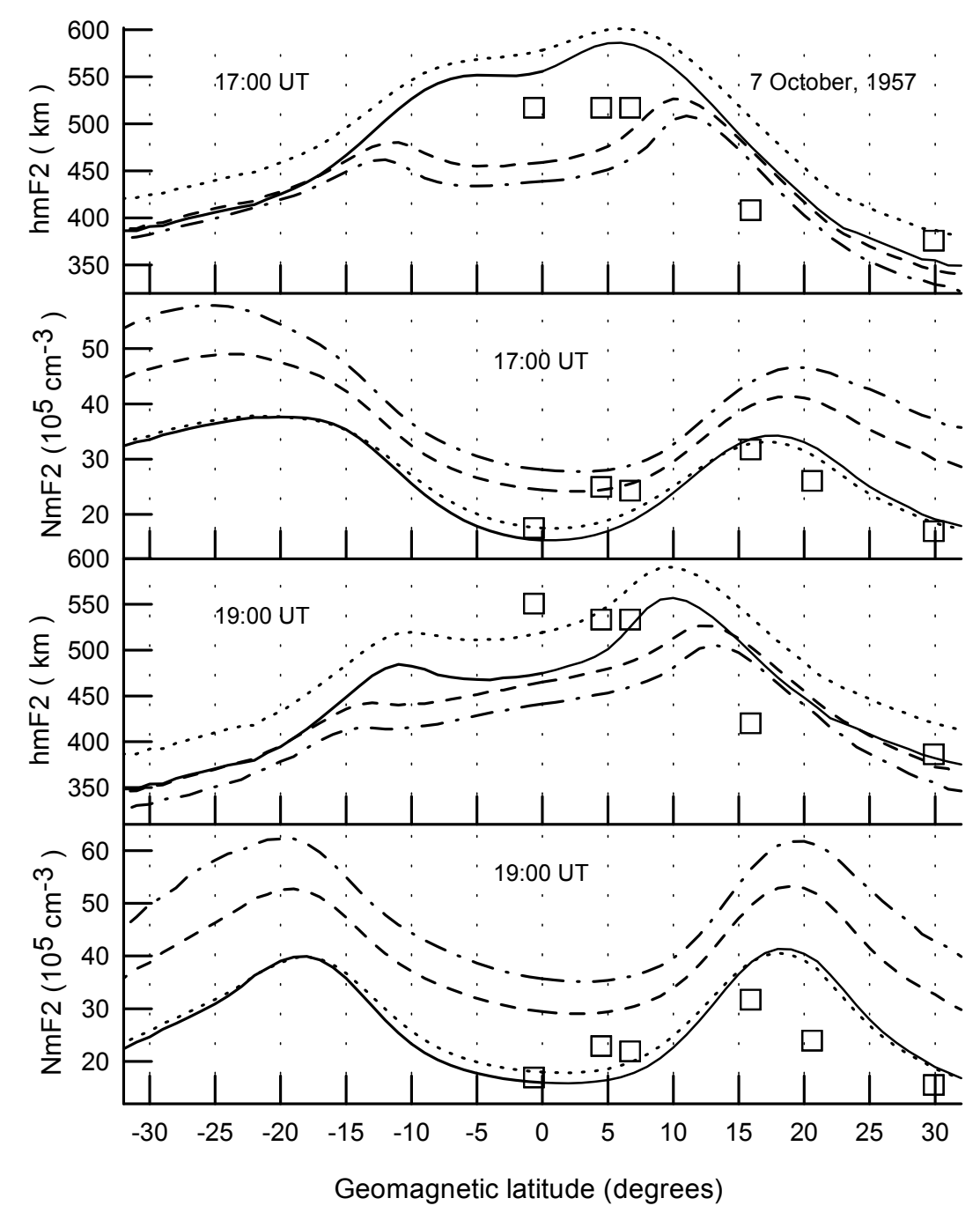

Fig. 9. Observed (squares) and calculated (lines) $h m \mathrm{~F} 2$ and $N m \mathrm{~F} 2$ at 17:00 UT (two upper panels) and 19:00 UT (two lower panels) on 7 October 1957. The measured $h m \mathrm{~F} 2$ and $N m \mathrm{~F} 2$ are taken from the ionospheric sounder station shown in Table 1 . The results obtained from the model of the ionosphere and plasmasphere using the EUVAC solar flux model as the input model parameter. Dashed lines show the model results when the original NRLMSISE-00 neutral temperature and densities are used. Solid lines show the model results when the NRLMSISE-00 model [O] was decreased by a factor of 1.7 from 16:12 UT to 23:12 UT (from 11:00 LT to 18:00 LT, where LT is the local time at the geomagnetic equator and $351.9^{\circ}$ of the geomagnetic longitude) during all model simulation period. Dotted lines show the model results when the NRLMSISE-00 model $\left[\mathrm{N}_{2}\right]$ and $\left[\mathrm{O}_{2}\right]$ were increased by a factor of 2.1 from 16:12 UT to 23:12 UT during all model simulation period. The vibrationally excited $\mathrm{N}_{2}(v>0)$ and $\mathrm{O}_{2}(v>0)$ are included in the model results shown by solid, dashed, and dotted lines. Dash-dotted lines show the model results when $\mathrm{N}_{2}(v>0)$ and $\mathrm{O}_{2}(v>0)$ are not included in the calculations of the $\mathrm{O}^{+}\left({ }^{4} \mathrm{~S}\right)$ loss rate and the original NRLMSISE-00 model temperature and number densities were used. The difference between the universal time and the local time at the geomagnetic equator is 05:12.

It is found from numerical simulations of the mid-latitude ionosphere that the daytime magnitude of $N m \mathrm{~F} 2$ should be reduced by about a factor of 2-3, due to enhanced vibrational excitation of $\mathrm{N}_{2}$ and $\mathrm{O}_{2}$ at high solar activity during geomagnetically quiet and storm periods (see Pavlov and Foster, 2001 and references therein). It is apparent from the results of our calculations that the $N m \mathrm{~F} 2$ decrease caused by the reactions of $\mathrm{O}^{+}\left({ }^{4} \mathrm{~S}\right)$ ions with vibrationally excited $\mathrm{N}_{2}$ and $\mathrm{O}_{2}$ is less at low geomagnetic latitudes, in comparison with that at middle geomagnetic latitudes at solar maximum.

The excitation of $\mathrm{N}_{2}$ and $\mathrm{O}_{2}$ by thermal electrons pro- vides the main contribution to the values of $\mathrm{N}_{2}$ and $\mathrm{O}_{2}$ vibrational excitations, if the electron temperature is higher than about 1600-1800 K at F-region altitudes (Pavlov, 1988, 1997, 1998b; Pavlov and Namgaladze, 1988; Pavlov and Buonsanto, 1997; Pavlov and Foster, 2001). The difference between the vibrational temperature, $T_{N 2 V}$, of $\mathrm{N}_{2}$ and the neutral temperature, $T_{n}$, and the difference between the vibrational temperature, $T_{O 2 V}$, of $\mathrm{O}_{2}$ and the neutral temperature increase with increasing electron temperature, and the noticeable differences $T_{N 2 V} T_{n}>50-200 \mathrm{~K}$ and $T_{O 2 V}-T_{n}>50-200 \mathrm{~K}$, are realized at $h m \mathrm{~F} 2$, if $T_{e}>1700-$ 


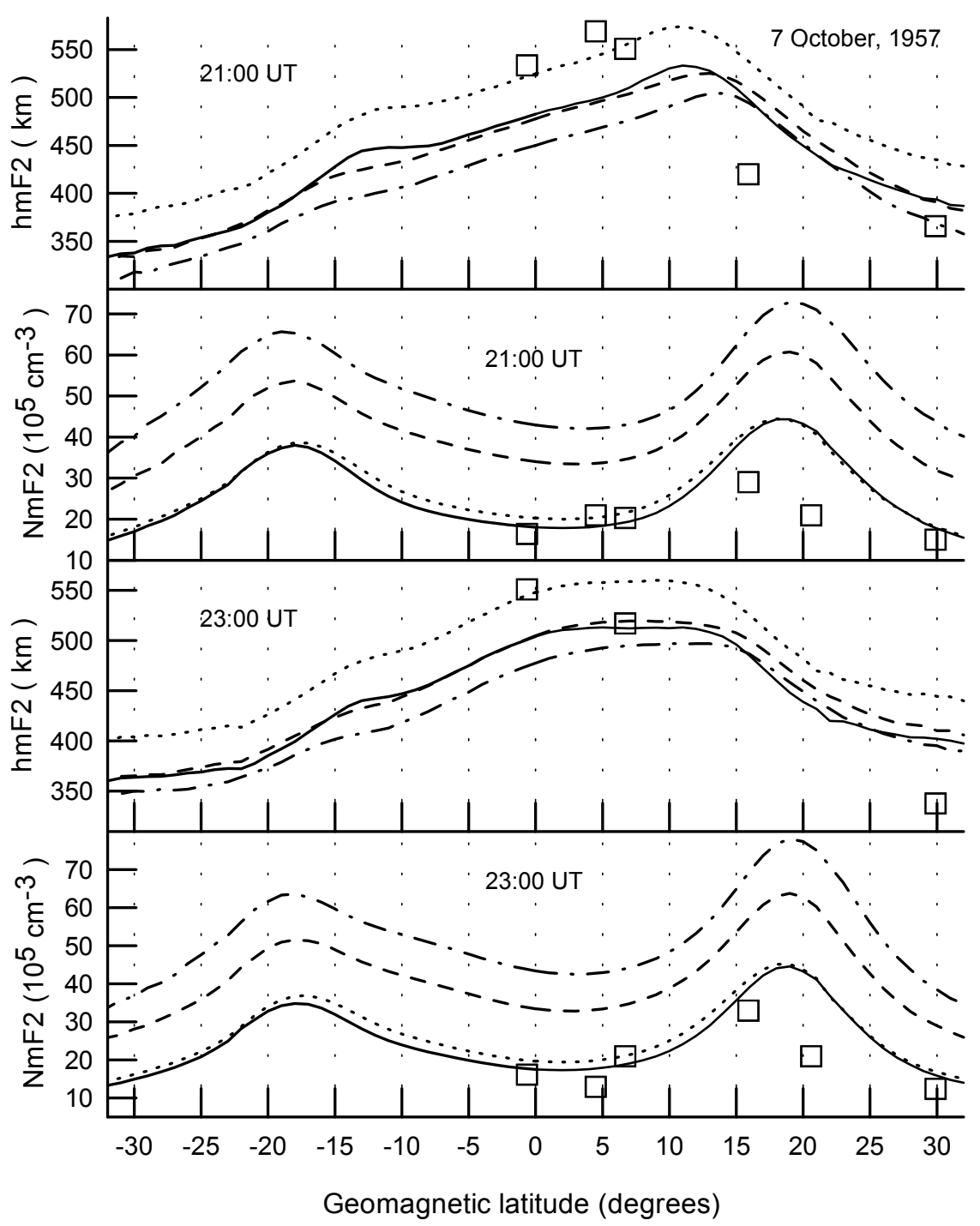

Fig. 10. Observed (squares) and calculated (lines) $h m \mathrm{~F} 2$ and $N m \mathrm{~F} 2$ at 21:00 UT (two upper panels) and 23:00 UT (two lower panels) on 7 October 1957. The difference between the universal time and the local time at the geomagnetic equator is 05:12. The curves are the same as in Fig. 9.

$1800 \mathrm{~K}$ at F-region altitudes. Thus, as a result of low electron temperatures at F-region altitudes of the low latitude ionosphere on 7 October 1957, the values of $T_{N 2 V}$ and $T_{O 2 V}$ are close to $T_{n}$, while the differences between $T_{n}$ and the middle latitude $T_{N 2 V}$ and $T_{O 2 V}$ are noticeable during daytime conditions at solar maximum (see Pavlov et al., 1999; Pavlov and Foster, 2001; Pavlov et al., 2001, and references therein). This is the first reason which explains the weaker decrease in the low-latitude $\mathrm{NmF} 2$ due to $\mathrm{N}_{2}(v)$ and $\mathrm{O}_{2}(v)$, in comparison with that at middle geomagnetic latitudes.

The effects of $\mathrm{N}_{2}(v)$ and $\mathrm{O}_{2}(v)$ on middle-latitude $N m \mathrm{~F} 2$ were usually evaluated by comparing the measured and modeled $N m F 2$ using the original (Richards, 1991) or modified (Pavlov and Buonsanto, 1997) Richards method, when model plasma drift velocities, caused by neutral winds, are found from the agreement between measured and modeled $h m F 2$. As a result, the middle-latitude model, including vi- brationally excited $\mathrm{N}_{2}$ and $\mathrm{O}_{2}$ in the loss rate of $\mathrm{O}^{+}\left({ }^{4} \mathrm{~S}\right)$ ions produces $h m \mathrm{~F} 2$ values very close to $h m \mathrm{~F} 2$ produced by the middle-latitude model without including vibrationally excited $\mathrm{N}_{2}$ and $\mathrm{O}_{2}$. The low-latitude model described in Appendix A uses the HWW90 thermospheric wind model of Hedin et al. (1991) to calculate the thermospheric wind components and the corresponding plasma drift velocities along magnetic field lines. As Figs. 9 and 10 show, the lowlatitude model, including $\mathrm{N}_{2}(v)$ and $\mathrm{O}_{2}(v)$ in the loss rate of $\mathrm{O}^{+}\left({ }^{4} \mathrm{~S}\right)$ ions produces $h m \mathrm{~F} 2$ with values higher than $h m \mathrm{~F} 2$ produced by the low-latitude model without including $\mathrm{N}_{2}(v)$ and $\mathrm{O}_{2}(v)$. As a result of including $\mathrm{N}_{2}(v)$ and $\mathrm{O}_{2}(v)$ in the loss rate of $\mathrm{O}^{+}\left({ }^{4} \mathrm{~S}\right)$ ions, the equatorial $\mathrm{F} 2$-layer is lifted to great heights, where the loss rate of $\mathrm{O}^{+}\left({ }^{4} \mathrm{~S}\right)$ ions is decreased, and this leads to an increase in $N m \mathrm{~F} 2$, which is masked by the general decrease in $N m \mathrm{~F} 2$ due to vibrationally excited $\mathrm{N}_{2}$ and $\mathrm{O}_{2}$. In other words, this additional increase in $h m \mathrm{~F} 2 \mathrm{de}-$ 
creases the effects of vibrationally excited $\mathrm{N}_{2}$ and $\mathrm{O}_{2}$ on the electron density in the low-latitude ionosphere.

\section{Conclusions}

A new theoretical model of the Earth's low- and middlelatitude ionosphere and plasmasphere has been developed. The new model uses a new method in ionospheric and plasmaspheric simulations which is a combination of the Eulerian and Lagrangian approaches in model simulations. The electron and ion continuity, and energy equations, are solved in a Lagrangian frame of reference which moves with an individual parcel of plasma, with the local plasma drift velocity perpendicular to the magnetic and electric fields. As a result, only the time-dependent, one-dimensional electron and ion continuity and energy equations are solved in this Lagrangian frame of reference. The new method makes use of an Eulerian computational grid, which is fixed in space coordinates and chooses the set of the plasma parcels at every time step, so that all the plasma parcels arrive at points which are located between grid lines of the regularly spaced Eulerian computational grid at the next time step. The solution values of electron and ion densities, and temperatures at the Eulerian computational grid, are obtained by interpolation.

Dipole orthogonal curvilinear coordinates $q, U$, and $\Lambda$ are used, where $q$ is aligned with, and $U$ and $\Lambda$ are perpendicular to, the magnetic field, and the $U$ and $\Lambda$ coordinates are constant along a dipole magnetic field line. Equations A11A14, and Eqs. A15-A17, which determine the trajectory of the ionospheric plasma perpendicular to magnetic field lines and the moving coordinate system, are derived. It follows from these equations that time variations of $U$, caused by the existence of the $E_{\Lambda}$ component of the electric field, are determined by time variations of the $\Lambda$ component, $E_{\Lambda}$ eff , of the effective electric field and time variations of $\Lambda$, caused by the existence of the $E_{U}$ component of the electric field, are determined by time variations of the $U$ component, $E_{U}$ eff , of the effective electric field. It is shown that the magnetic field lines are "frozen" in the ionospheric plasma, if the values of $E_{\Lambda}{ }^{\text {eff }}$ and $E_{U}$ eff are not changed along magnetic field lines, and there is the interdependency given by Eq. A17 between changes in $E_{U}$ eff in the $\Lambda$ direction and changes in $E_{\Lambda}$ eff in the $U$ direction.

The Eulerian computational grid used consists of a distribution of the dipole magnetic field lines in the ionosphere and plasmasphere. One hundred dipole magnetic field lines are used in the model for each fixed value of the geomagnetic longitude. The number of the fixed nodes taken along each magnetic field line is 191. For each fixed value of the geomagnetic longitude, the region of study is a $(q, U)$ plane which is bounded by two dipole magnetic field lines. The low boundary dipole magnetic field line has the apex altitude of $150 \mathrm{~km}$. The upper boundary dipole magnetic field line has the apex altitude of $4491 \mathrm{~km}$ and intersects the Earth's surface at two geomagnetic latitudes: $\pm 40^{\circ}$. The Eulerian computational grid dipole magnetic field lines are distributed between these two boundary lines.

The model takes into account the offset between the geographic and geomagnetic poles. The horizontal components of the neutral wind, which are used in calculations of the wind-induced plasma drift velocity along the magnetic field, are specified using the HWW90 wind model of Hedin et al. (1991). In the model, time-dependent ion continuity equations for the three major ions, $\mathrm{O}^{+}\left({ }^{4} \mathrm{~S}\right), \mathrm{H}^{+}$and $\mathrm{He}^{+}$ and for the minor ions, $\mathrm{NO}^{+}, \mathrm{O}_{2}{ }^{+}$, and $\mathrm{N}_{2}{ }^{+}$, are solved, and the approach of local chemical equilibrium is used to calculate steady-state number densities of $\mathrm{O}^{+}\left({ }^{2} \mathrm{D}\right), \mathrm{O}^{+}\left({ }^{2} \mathrm{P}\right)$, $\mathrm{O}^{+}\left({ }^{4} \mathrm{P}\right)$, and $\mathrm{O}^{+}\left({ }^{2} \mathrm{P}^{*}\right)$ ions. The model includes the solution of time-dependent electron and ion energy balance equations. The model uses Boltzmann distributions of $\mathrm{N}_{2}(v)$ and $\mathrm{O}_{2}(v)$ to calculate $\left[\mathrm{N}_{2}(v)\right]$ and $\left[\mathrm{O}_{2}(v)\right]$, which are included in the model loss rate of $\mathrm{O}^{+}\left({ }^{4} \mathrm{~S}\right)$ ions and cooling rates of thermal electrons due to vibrational excitation of $\mathrm{N}_{2}$ and $\mathrm{O}_{2}$.

We have presented a comparison between the modeled $N m \mathrm{~F} 2$ and $h m \mathrm{~F} 2$, and $N m \mathrm{~F} 2$ and $h m \mathrm{~F} 2$ which were observed at the anomaly crest and close to the geomagnetic equator simultaneously by the Panama, Bogota, Talara, Chiclayo, and Huancayo ionospheric sounders during the 7 October 1957 geomagnetically quiet time period at solar maximum, near approximately the same geomagnetic meridian of $351.9^{\circ}$. To complete the picture of the latitude dependence of $\mathrm{NmF} 2$ and $N m \mathrm{~F} 2$ variations, we compare the modeled $N m \mathrm{~F} 2$ and $h m \mathrm{~F} 2$ at the geomagnetic longitude of $351.9^{\circ}$ with $N m \mathrm{~F} 2$ and $h m \mathrm{~F} 2$ measured by the Puerto Rico ionosonde station with geomagnetic longitude of $2.8^{\circ}$.

A two-peaked structure in the time dependence of the equatorial vertical $\boldsymbol{E} \times \boldsymbol{B}$ drift velocity is given by the model of Scherliess and Fejer (1999) at solar maximum during quiet daytime equinox conditions. It leads to a two-peaked structure in the time dependence of the equatorial value of $E_{\Lambda}$. The model results highlight the relationship between local time variations of the low-latitude electron densities and the equatorial value of $E_{\Lambda}$. The model calculations show that there is a need to revise the model dependence of the equatorial $E_{\Lambda}$ in local time by elevating and displacing the morning peak to earlier times, and by compressing the time of the pre-reversal peak. It is found that the large disagreement between the measured and modelled $h m \mathrm{~F} 2$ at 00:00 UT on 7 October 1957 (at 18:48 LT on 6 October 1957) is caused by the long time duration of the prereversal strengthening of the equatorial upward $\boldsymbol{E} \times \boldsymbol{B}$ drift given by Scherliess and Fejer (1999). The long period of the pre-reversal enhancement in $E_{\Lambda}$ leads to unreal high modeled F2 peak altitudes at 00:00 UT. Our calculations provide evidence that, to bring the measured and modeled F2-region main peak altitudes into agreement, the magnitude of $E_{\Lambda}$ has to be approximately constant in the time range between 15:00 LT and 18:00 LT with the following peak in $E_{\Lambda}$, which has a shorter time width in comparison to the time duration of the pre-reversal strengthening of the original equatorial perpendicular plasma drift given by Scherliess and Fejer (1999). The modification of $E_{\Lambda}\left(t_{g e}\right)$ was carried out in the time 
range between 07:27 LT and 11:00 LT, to mimic the depth of the anomaly crest and trough in the modeled and measured $N m \mathrm{~F} 2$. This modification includes the strengthening of $E_{\Lambda}$ and the time shift of the first peak in $E_{\Lambda}\left(t_{g e}\right)$ relative to the first peak in the original equatorial $E_{\Lambda}\left(t_{g e}\right)$ found from the equatorial perpendicular plasma drift of Scherliess and Fejer (1999). The first maximum $\left(E_{\Lambda}=1.1 \mathrm{mVm}^{-1}\right)$ of the modified $E_{\Lambda}\left(t_{g e}\right)$ occurs at 08:30 LT, while the first maximum $\left(E_{\Lambda}=0.66 \mathrm{mVm}^{-1}\right)$ of the original equatorial $E_{\Lambda}\left(t_{g e}\right)$ is located between 10:00 LT and 11:00 LT. The northern depth of the equatorial $N m \mathrm{~F} 2$ trough in the calculated $N m \mathrm{~F} 2$ is approximately consistent with the measured depth, if the modified $E_{\Lambda}\left(t_{g e}\right)$ is used. The model with the modified value of $E_{\Lambda}\left(t_{g e}\right)$ produces the onset of the equatorial anomaly crest formation close to 15:00 UT, in agreement with the measured onset of the equatorial anomaly crest formation given by the ionosonde stations.

Electron and ion densities and temperature uncertainties resulting from the difference between the NRLMSISE-00 and MSIS-86 neutral temperatures and densities, and from the difference between the EUV97 and EUVAC solar fluxes, are evaluated. Our calculations show that the best agreement between the measured and modeled electron densities is obtained if the MSIS- 86 neutral densities and temperature model is used, in combination with the EUVAC solar flux model. We found that the electron and ion temperature uncertainties caused by these differences are negligible.

The thermal electron energy budget in the low-latitude ionosphere at solar maximum was examined. It is shown that the daytime peak values in the electron and ion temperatures, which occur at about 20:32 UT-21:22 UT above the ionosonde stations, result from the peak in the neutral temperature at F2-region altitudes, which occurs very close to the time of the peaks in the electron and ion temperatures. Our calculations show that the values of the electron temperatures at F2-region altitudes become almost independent of the electron heat flow along the magnetic field lines above the Huancayo, Chiclayo, and Talara ionosonde stations because the near-horizontal magnetic field inhibits this heat flow of electrons. The increase in geomagnetic latitude leads to an increase in the effects of the electron heat flow along the magnetic field line on $T_{e}$.

At sunrise, there is a rapid heating of the ambient electrons by photoelectrons, and the difference between the electron and neutral temperatures could be increased because nighttime electron densities are less than those by day, and the electron cooling during morning conditions is less than that by day. This expands the altitude region at which $T_{e}>T_{i}$ near the equator and leads to the sunrise electron temperature peaks at $h m \mathrm{~F} 2$ altitudes above the ionosonde stations. After the abrupt increase at sunrise, the electron temperature decreases, owing to the increasing electron density, due to the increase in the cooling rate of thermal electrons and due to the decrease in the relative role of the electron heat flow along the magnetic field line, in comparison with cooling of thermal electrons. As a result, the morning electron temperature peaks, which are found above the ionosonde stations at $h m \mathrm{~F} 2$ altitudes, are explained by these physical processes.

The relative role of the electron cooling rates was evaluated. We found that the main cooling rates of thermal electrons on 7 October 1957 are electron-ion Coulomb collisions, vibrational excitation of $\mathrm{N}_{2}$ and $\mathrm{O}_{2}$, and rotational excitation of $\mathrm{N}_{2}$. The relative role of the cooling rates of thermal electrons by low-lying electronic excitation of $\mathrm{O}_{2}\left(\mathrm{a}^{1} \Delta_{g}\right)$ and $\mathrm{O}_{2}\left(\mathrm{~b}^{1} \sum g^{+}\right)$, from rotational excitation of $\mathrm{O}_{2}$, in collision of $\mathrm{O}\left({ }^{3} \mathrm{P}\right)$ with thermal electrons with the $\mathrm{O}\left({ }^{1} \mathrm{D}\right)$ formation, and by the atomic oxygen fine structure excitation, is negligible, in comparison with the effects of the main cooling rates on the electron temperature for the geomagnetically quiet period on 7 October 1957.

The model of the ionosphere and plasmasphere was able to reproduce F-region main peak electron densities and altitudes observed on 7 October, if modified NRLMSISE-00 [O] or $\left[\mathrm{N}_{2}\right]$ and $\left[\mathrm{O}_{2}\right]$ are used. We found that it is necessary to decrease the NRLMSISE- 00 model $[\mathrm{O}] /\left[\mathrm{N}_{2}\right]$ ratio by a factor of 1.7-2.1 from 16:12 UT to 23:12 UT, to bring the modeled and measured $N m \mathrm{~F} 2$ and $h m \mathrm{~F} 2$ into satisfactory agreement. This result indicates that the NRLMSISE-00 model may need improvements during geomagnetically quiet periods in equinox at solar maximum at low latitudes.

The increase in the loss rate of $\mathrm{O}^{+}\left({ }^{4} \mathrm{~S}\right)$ ions due to the vibrationally excited $\mathrm{N}_{2}$ and $\mathrm{O}_{2}$ leads to the decrease in the calculated $N m \mathrm{~F} 2$ by a factor of $1.06-1.44$ and to the increase in the calculated $h m \mathrm{~F} 2$, up to the maximum value of $32 \mathrm{~km}$ in the low-latitude ionosphere between $-30^{\circ}$ and $+30^{\circ}$ of geomagnetic latitude. Inclusion of vibrationally excited $\mathrm{N}_{2}$ and $\mathrm{O}_{2}$ brings the model and data into better agreement.

\section{Appendix A Theoretical model description}

\section{A1.1 Ion continuity equations}

The model used is a three-dimensional, time-dependent model of the ionosphere and plasmasphere that uses a dipole approximation to the Earth's magnetic field and takes into account the offset between the geographic and geomagnetic axes. The model includes the coupled ion continuity equations for the three major ions, $\mathrm{O}^{+}\left({ }^{4} \mathrm{~S}\right), \mathrm{H}^{+}$, and $\mathrm{He}^{+}$, and the ion continuity equations for the minor ions, $\mathrm{NO}^{+}, \mathrm{O}_{2}^{+}$, and $\mathrm{N}_{2}^{+}$, which can be written as:

$$
\begin{aligned}
& \frac{d}{d t} \mathrm{~N}_{\mathrm{i}}+B \frac{\partial}{\partial S} C_{i} N_{i} B^{-1}= \\
& Q_{i}+\Delta Q_{i}+P_{i}-L_{i}-N_{i} \operatorname{div} \boldsymbol{V}^{\boldsymbol{E}},
\end{aligned}
$$

where $N_{i}$ is the ion concentration, $B=|\mathbf{B}|$ is the absolute value of the geomagnetic field whose magnitude can be calculated as $B=B_{O}\left(R_{E} / R\right)^{3}\left(1+3 \cos ^{2} \Theta\right)^{1 / 2}, \Theta=90^{\circ}-\varphi$ is the geomagnetic co-latitude, $\varphi$ is the geomagnetic latitude, $R_{E}$ is the Earth's radius, $R$ is the radial distance from the Earth's center, $B_{0}$ is the equatorial value of $B$ for $R=R_{E}$ and $\Theta=0, t$ is a local time, $S$ is the distance along the magnetic field line, 
positive in the direction north to south, $P_{i}$ and $L_{i}$ are the production rates and the ion loss rates by the chemical reactions, $Q_{i}$ and $\Delta Q_{i}$ are the production rates of ions by photoionization and due to photoelectrons, $C_{i}=V_{i}+W, V_{i}$ is the field-aligned diffusion velocity, $W$ is the field-aligned windinduced plasma drift velocity, with the total time-derivative is defined by

$$
\frac{d}{d t} \mathrm{~N}_{\mathrm{i}}=\frac{\partial}{\partial t} \mathrm{~N}_{\mathrm{i}}+\boldsymbol{V}^{E} \cdot \operatorname{grad} \mathrm{N}_{\mathrm{i}}, \boldsymbol{V}^{E}=\boldsymbol{E} \times \boldsymbol{B} / \mathrm{B}^{2} .
$$

The model also includes $\mathrm{O}^{+}\left({ }^{2} \mathrm{D}\right), \mathrm{O}^{+}\left({ }^{2} \mathrm{P}\right), \mathrm{O}^{+}\left({ }^{4} \mathrm{P}\right)$, and $\mathrm{O}^{+}\left({ }^{2} \mathrm{P}^{*}\right)$ ions whose number densities are obtained from local chemical equilibrium (see Sect. 2.2). The value of the electron number density is calculated as the sum of the ion number densities: $N_{e}=\sum_{i} N_{i}$.

The ion diffusion velocities are calculated by solving the system of equations given by Pavlov (1997). The windinduced plasma drift velocity along the magnetic field is determined as $W=U_{\Theta} \cos I$, where $U_{\Theta}$ is the magnetic meridianal component of the thermospheric wind in spherical polar geomagnetic coordinates $(R, \Theta, \Lambda), \Lambda$ is the geomagnetic longitude, $I$ is the magnetic field dip angle, $\cos I=$ $\sin \Theta\left(1+3 \cos ^{2} \Theta\right)^{-1 / 2}$. The model takes into account the offset between the geographic and geomagnetic poles and calculates $\mathrm{U}_{\Theta}=\mathrm{U}_{\Theta(g)} \cos \mathrm{D}-\mathrm{U}_{\Lambda(g)} \sin \mathrm{D}$ (see Bailey and Balan, 1996), where $D$ is the magnetic declination angle, $\Theta(g)=90^{\circ}-\varphi(g)$ is the geographic co-latitude, $\varphi(g)$ is the geographic latitude, $\Lambda(g)$ is the geographic longitude, $U_{\Theta(g)}$ and $U_{\Lambda(g)}$ are the horizontal components of thermospheric wind in spherical polar geographic coordinates, which are positive in the southward and eastward directions, respectively. The magnitudes of $U_{\Theta(g)}$ and $U_{\Lambda(g)}$ are obtained from the thermospheric wind components given by the HWW90 thermospheric wind model (Hedin et al., 1991). To calculate the magnetic declination angle, we use the approach described in detail by Bailey and Balan (1996).

The model includes the production and loss rates of $\mathrm{O}^{+}\left({ }^{4} \mathrm{~S}\right), \mathrm{NO}^{+}, \mathrm{O}_{2}{ }^{+}, \mathrm{N}_{2}{ }^{+}, \mathrm{H}^{+}$, and $\mathrm{He}^{+}$ions by the chemical reactions described in detail by Pavlov and Foster (2001), except for the dissociative recombination rate coefficient for $\mathrm{O}_{2}^{+}$ions, whose value is taken from Peverall et al. (2001). The reactions of photoionization and ionization by photoelectrons of $\mathrm{N}_{2}, \mathrm{O}_{2}, \mathrm{O}$, and $\mathrm{He}$, which form $\mathrm{N}_{2}^{+}, \mathrm{O}_{2}^{+}, \mathrm{O}^{+}\left({ }^{4} \mathrm{~S}\right), \mathrm{O}^{+}\left({ }^{2} \mathrm{D}\right), \mathrm{O}^{+}\left({ }^{2} \mathrm{P}\right)$, and $\mathrm{He}^{+}$ions, are included in the model (see details in Appendix A of Pavlov, 1998b) using the photoionization and photoabsorption cross sections of $\mathrm{N}_{2}, \mathrm{O}_{2}$, and $\mathrm{O}$ compiled by Richards et al. (1994) and the photoionization cross section for He presented by Samson et al. (1994). The total and partial atomic oxygen photoionization cross sections of Richards et al. (1994) were updated using the measurements of these cross sections given by Schaphorst et al. (1995), and Berkowitz (1997) and compiled by Avakyan et al. (2000). Additional production rates of $\mathrm{O}^{+}\left({ }^{4} \mathrm{~S}\right), \mathrm{O}^{+}\left({ }^{2} \mathrm{D}\right)$ and $\mathrm{O}^{+}\left({ }^{2} \mathrm{P}\right)$ ions are obtained in the model by inclusion of $\mathrm{O}^{+}\left({ }^{4} \mathrm{P}\right)$ and $\mathrm{O}^{+}\left({ }^{2} \mathrm{P}^{*}\right)$ ions using photoionization cross sections given by Richards et al. (1994). The $\mathrm{O}^{+}\left({ }^{4} \mathrm{P}\right)$ state decays to $\mathrm{O}^{+}\left({ }^{4} \mathrm{~S}\right)$ ions and
$\mathrm{O}^{+}\left({ }^{2} \mathrm{P}^{*}\right)$ ions decay to either $\mathrm{O}^{+}\left({ }^{2} \mathrm{D}\right)$ or $\mathrm{O}^{+}\left({ }^{2} \mathrm{P}\right)$ with a branching ratio of 2:1 for $\mathrm{O}^{+}\left({ }^{2} \mathrm{D}\right.$ ): $\mathrm{O}^{+}\left({ }^{2} \mathrm{D}\right.$ ) (Pavlov and Foster, 2001). Ionization of $\mathrm{O}$ by photoelectrons produces little extra $\mathrm{O}^{+}$ions. The electronically excited oxygen ions are converted to unexcited $\mathrm{O}^{+}\left({ }^{4} \mathrm{~S}\right)$ ions, and $\mathrm{N}_{2}^{+}$and $\mathrm{O}_{2}^{+}$ ions, by chemical reactions that are included in the model of the ionosphere and plasmasphere (see Table A1). As a result, the total production rate of unexcited $\mathrm{O}^{+}\left({ }^{4} \mathrm{~S}\right)$ ions $\left(\mathrm{Q}_{t o t}\left({ }^{4} S\right)\right.$ $\left.=\mathrm{Q}_{\mathrm{i}}+\Delta \mathrm{Q}_{\mathrm{i}}+\mathrm{P}_{\mathrm{i}}, \mathrm{i}=\mathrm{O}^{+}\left({ }^{4} \mathrm{~S}\right)\right)$ is calculated in the model of the ionosphere and plasmasphere as $\mathrm{Q}_{t o t}\left({ }^{4} \mathrm{~S}\right)=\mathrm{Q}\left({ }^{4} \mathrm{~S}\right)+$ $\left(\mathrm{K}_{1}[\mathrm{O}]+\mathrm{K}_{3}+\mathrm{K}_{5} \mathrm{~N}_{\mathrm{e}}\right)\left[\mathrm{O}^{+}\left({ }^{2} \mathrm{P}\right)\right]+\left(\mathrm{K}_{7}+\mathrm{K}_{10} \mathrm{~N}_{\mathrm{e}}\right)\left[\mathrm{O}^{+}\left({ }^{2} \mathrm{D}\right)\right]+$ $\mathrm{Q}\left({ }^{4} \mathrm{P}\right)+\Delta \mathrm{Q}\left({ }^{4} \mathrm{P}\right)+\left(\mathrm{K}_{11}\left[\mathrm{~N}_{2}^{+}\right]+\mathrm{K}_{12}\left[\mathrm{H}^{+}\right]\right)[\mathrm{O}]$, where $\mathrm{Q}\left({ }^{4} \mathrm{~S}\right)$ and $\Delta \mathrm{Q}\left({ }^{4} \mathrm{~S}\right)$ are the production rates of $\mathrm{Q}\left({ }^{4} S\right)$ ions by photoionization and due to photoelectrons, $\mathrm{Q}\left({ }^{4} \mathrm{P}\right)$ and $\Delta \mathrm{Q}\left({ }^{4} \mathrm{P}\right)$ are the production rates of $\mathrm{Q}\left({ }^{4} \mathrm{P}\right)$ ions by photoionization and due to photoelectrons, $\mathrm{K}_{1}, \mathrm{~K}_{3}, \mathrm{~K}_{5}, \mathrm{~K}_{7}, \mathrm{~K}_{10}$ are the rate coefficients of the chemical reactions displayed in Table A1, $\mathrm{K}_{11}$ and $\mathrm{K}_{12}$ are the rate coefficients of the chemical reactions $\mathrm{N}_{2}^{+}+\mathrm{O} \rightarrow \mathrm{O}^{+}\left({ }^{4} \mathrm{~S}\right)+\mathrm{N}_{2}$ and $\mathrm{O}+\mathrm{H}^{+} \rightarrow \mathrm{O}^{+}\left({ }^{4} \mathrm{~S}\right)$ $+\mathrm{H}$ given by McFarland et al. (1974) and Park and Banks (1974), respectively.

A1.2 Number densities of $\mathrm{O}^{+}\left({ }^{2} \mathrm{D}\right), \mathrm{O}^{+}\left({ }^{2} \mathrm{P}\right), \mathrm{O}^{+}\left({ }^{4} \mathrm{P}\right)$ and $\mathrm{O}^{+}\left({ }^{2} \mathrm{P}^{*}\right)$ ions

A1.2.1 Rate coefficients of the $\mathrm{O}^{+}\left({ }^{2} \mathrm{P}\right)+\mathrm{N}_{2}, \mathrm{O}^{+}\left({ }^{2} \mathrm{D}\right)+\mathrm{N}_{2}$ and $\mathrm{O}^{+}\left({ }^{2} \mathrm{D}\right)+\mathrm{O}_{2}$ reactions

The difficulty of preparing $\mathrm{O}^{+}\left({ }^{2} \mathrm{D}\right)$ and $\mathrm{O}^{+}\left({ }^{2} \mathrm{P}\right)$ metastable states leads to the difficulty in the determination of the rate coefficients of the reactions involving these ions. In the experiment by Johnsen and Biondi $(1980 \mathrm{a}, \mathrm{b})$, metastable $\mathrm{O}^{+}\left({ }^{2} \mathrm{D}\right)$ and $\mathrm{O}^{+}\left({ }^{2} \mathrm{D}\right)$ ions are prepared by dissociative charge transfer: $\mathrm{He}^{+}+\mathrm{O}_{2} \rightarrow \mathrm{He}+$ $\mathrm{O}+\mathrm{O}^{+}\left({ }^{4} \mathrm{~S},{ }^{2} \mathrm{D},{ }^{2} \mathrm{P}\right)$. Johnsen and Biondi (1980 a, b) reported rate constants of $8 \cdot 10^{-10} \mathrm{~cm}^{3} \mathrm{~s}^{-1}$ and $7 \cdot 10^{-10} \mathrm{~cm}^{3} \mathrm{~s}^{-1}$ for chemical reactions 8 and 9 of Table A1, respectively, assuming that the reaction $\mathrm{He}^{+}+\mathrm{O}_{2}$ produces only $\mathrm{O}^{+}\left({ }^{4} \mathrm{~S}\right)$ and $\mathrm{O}^{+}\left({ }^{2} \mathrm{D}\right)$ ions with the predominance of $\mathrm{O}^{+}\left({ }^{2} D\right)$ ions. The branching ratios for $\mathrm{O}^{+}\left({ }^{4} \mathrm{~S}\right), \mathrm{O}^{+}\left({ }^{2} \mathrm{D}\right)$, and $\mathrm{O}^{+}\left({ }^{2} \mathrm{P}\right)$ ions formed in the reaction $\mathrm{He}^{+}+\mathrm{O}_{2}$ have been measured as a function of the center-of-mass kinetic energy, $E$, by Bischof and Linder (1986) and by Gerlich (1991). Contrary to the assumption of Johnsen and Biondi (1980a, b), more than $60 \%$ of the $\mathrm{O}^{+}$ions formed at thermal energies are found to be in the $\mathrm{O}^{+}\left({ }^{2} \mathrm{D}\right)$ state (Bischof and Linder, 1986; Gerlich, 1991). As a result, the rate coefficients of the $\mathrm{O}^{+}\left({ }^{2} \mathrm{D}\right)+\mathrm{N}_{2}$ and $\mathrm{O}^{+}\left({ }^{2} \mathrm{D}\right)+\mathrm{O}_{2}$ reactions given by Johnsen and Biondi (1980 a, b) include a large error.

$\mathrm{Li}$ et al. (1997) have measured the dependence of the cross sections for reactions 2 and 8 of Table $\mathrm{A} 1$ on $E$, in the energy range $0.006-40 \mathrm{eV}$, employing the differential retarding potential method. They found that these cross sections are nearly independent of $E$, and estimated the values of the charge transfer rate constants of reactions 2 and 8 of Table A1 at thermal energies as $2.0 \cdot 10^{-10} \mathrm{~cm}^{3} \mathrm{~s}^{-1}$ and 


\section{$1.5 \cdot 10^{-10} \mathrm{~cm}^{3} \mathrm{~s}^{-1}$, respectively.}

The rate coefficient for an ion-neutral chemical reaction can be calculated from the measured cross section, $\sigma(E)$, using the relation (St.-Maurice and Torr, 1978)

$\mathrm{K}(\mathrm{T})=\int_{0}^{\infty} \sigma(\mathrm{u}) \mathrm{uf}(\mathrm{u}) \mathrm{du}$

where $u$ is the relative speed between the reactants, the Maxwellian distribution of relative speeds is calculated as $f(u)=4 \pi u^{2}\left\{\mu(2 \pi k T)^{-1}\right\}^{1.5} \exp \left\{-\mu u^{2}(2 k T)^{-1}\right\}, k$ is the Boltzmann's coefficient, $\mu=m_{i} m_{n}\left(m_{i}+m_{n}\right)^{-1}, m_{i}$ and $m_{n}$ denote the masses of the ion and neutral reactants, respectively, $T=\left(m_{i} T_{n}+m_{n} T_{i}\right)\left(m_{i}+m_{n}\right)^{-1}+\mu V_{d}^{2}(3 k)^{-1}, V_{d}$ is a relative drift velocity between ion and neutral reactants.

It follows from Eq. A2, that if the cross section for a reaction is approximately constant, then this reaction rate coefficient is approximated by the relation of $K(T)=$ $\sigma\left\{8 k T(\pi \mu)^{-1}\right\}^{0.5}$. The measured cross sections of reactions 2 and 8 of Table A1 are nearly independent of $E$ in the energy range $0.006-40 \mathrm{eV}$ ( $\mathrm{Li}$ et al., 1997). As a result, we can find the rate coefficients $K_{2}$ and $K_{8}$ of reactions 2 and 8 of Table A1 as $K_{2}=2.0 \cdot 10^{-10}(T / 300)^{0.5} \mathrm{~cm}^{3} \mathrm{~s}^{-1}, K_{8}=$ $1.5 \cdot 10^{-10}(T / 300)^{0.5} \mathrm{~cm}^{3} \mathrm{~s}^{-1}$. These values of $K_{2}$ and $K_{8}$ were used by Pavlov and Foster (2001) without the explanations presented above.

The rate coefficients $K_{8}$ and $K_{9}$ of the $\mathrm{O}^{+}\left({ }^{2} \mathrm{D}\right)+\mathrm{N}_{2}$ and $\mathrm{O}^{+}\left({ }^{2} \mathrm{D}\right)+\mathrm{O}_{2}$ reactions (the reactions 8 and 9 of Table A1) given by Johnsen and Biondi (1980a, b) include the same error due to the same source of $\mathrm{O}^{+}\left({ }^{2} \mathrm{D}\right)$ ions in the reaction $\mathrm{He}^{+}+\mathrm{O}_{2}$, and, therefore, it is possible to assume that the $K_{9} / K_{8}$ ratio given by Johnsen and Biondi (1980a, b) as $7 / 8$ is close to the correct value. As a result, we believe that $K_{9}$ $=1.3 \cdot 10^{-10}(T / 300)^{0.5} \mathrm{~cm}^{3} \mathrm{~s}^{-1}$.

\section{A1.2.2 Quenching of $\mathrm{O}^{+}\left({ }^{2} \mathrm{D}\right)$ and $\mathrm{O}^{+}\left({ }^{2} \mathrm{P}\right)$ by electrons}

The metastable $\mathrm{O}^{+}\left({ }^{2} \mathrm{D}\right)$ and $\mathrm{O}^{+}\left({ }^{2} \mathrm{P}\right)$ electron quenching rate coefficients have not been measured in the laboratory. The rate coefficients for these chemical reactions can be calculated as $K_{i j}\left(T_{e}\right)=\int_{0}^{\infty} \sigma_{i j}(u) u f(u) d u$, where $\sigma_{i j}$ is the cross section for the transition $i \rightarrow j, u$ is the relative speed between $\mathrm{O}^{+}\left({ }^{2} \mathrm{D}\right)$ or $\mathrm{O}^{+}\left({ }^{2} \mathrm{D}\right)$ ions and electrons, the Maxwellian distribution of relative speeds is calculated as $f(u)=4 \pi u^{2}\left\{m_{e}\left(2 \pi k T_{e}\right)^{-1}\right\}^{1.5} \exp \left\{-m_{e} u^{2}(2 k T)^{-1}\right\}$.

The value of $\sigma_{i j}$ is related to the collision strength, $\Omega_{i j}$, through $\sigma_{i j}(E)=\pi a_{0}^{2} R_{y} \Omega_{i j}(E)\left(g_{i} E\right)^{-1}$, where $E=$ $m_{e} u^{2} / 2, g_{i}=2 i+1$ is the statistical weight of the i-th level, $a_{0}$ is the Bohr radius, and $R_{y}$ is the Rydberg constant. The effective collision strength, $Q_{i j}\left(T_{e}\right)$, is determined as $Q_{i j}\left(T_{e}\right)=\int_{0}^{\infty} \Omega_{i j}(x) \exp (-x) d x$, where $x=E\left(k T_{e}\right)^{-1}$. As a result, the rate coefficients for quenching of $\mathrm{O}^{+}\left({ }^{2} \mathrm{D}\right)$ and $\mathrm{O}^{+}\left({ }^{2} \mathrm{P}\right)$ by electrons may be obtained from the effective collision strengths as $K_{i j}\left(T_{e}\right)=$ $Q_{i j}\left(T_{e}\right) a_{0}^{2} R_{y}\left(g_{i}\right)^{-1}(8 \pi)^{1 / 2}\left(m_{e} k T_{e}\right)^{-1 / 2}$. The values of $Q_{i j}\left(T_{e}\right)$ are nearly independent of $T_{e}$ in the thermal en- ergy range of electrons (Henry et al., 1969, McLaughlin and Bell, 1998), and we conclude that $K_{i j}\left(T_{e}\right) \approx$ const $T_{e}^{-0.5}$. The updated rate coefficients can be calculated from the updated effective collision strengths of McLaughlin and Bell (1998) as $K_{5}=2.5 \cdot 10^{-8}\left(300 / T_{e}\right)^{0.5} \mathrm{~cm}^{3} \mathrm{~s}^{-1}$, $K_{6}=7.0 \cdot 10^{-8}\left(300 / T_{e}\right)^{0.5} \mathrm{~cm}^{3} \mathrm{~s}^{-1}, K_{10}=4.0$. $10^{-8}\left(300 / T_{e}\right)^{0.5} \mathrm{~cm}^{3} \mathrm{~s}^{-1}$.

It should be noted that the rate coefficients $K_{5}, K_{6}$, and $K_{10}$ of reactions 5, 6 and 10 of Table A1, which are used in the current models of the ionosphere and plasmasphere (e.g. Pavlov and Foster, 2001), were presented by Torr and Torr (1982). These rate coefficients were found using the effective collision strengths of metastable $\mathrm{O}^{+}$ions calculated by Henry et al. (1969). The updated rate coefficients are less than those given by Torr and Torr (1982) by a factor of 1.9-2.1.

A1.2.3 Steady-state number density of $\mathrm{O}^{+}\left({ }^{4} \mathrm{P}\right), \mathrm{O}^{+}\left({ }^{2} \mathrm{P}^{*}\right)$ and $\mathrm{O}^{+}\left({ }^{2} \mathrm{P}\right)$ ions

The $\mathrm{O}^{+}\left({ }^{4} \mathrm{P}\right)$ state decays very promptly to $\mathrm{O}^{+}\left({ }^{4} \mathrm{~S}\right)$ ions with the measured radiative lifetime of $\mathrm{O}^{+}\left({ }^{4} \mathrm{P}\right)$ ions as $\tau\left({ }^{4} \mathrm{P}\right)=(1.26 \pm 0.10) \cdot 10^{-9} \mathrm{~s}$ (Smith et al., 1971). The radiative lifetime of $\mathrm{O}^{+}\left({ }^{2} \mathrm{P}^{*}\right)$ ions is found by Tayal and Richardson (2000) as $\tau\left({ }^{2} \mathrm{P}^{*}\right)=1.4 \cdot 10^{-10} \mathrm{~s}$. Using the measured oscillator strengths of transitions among states of $\mathrm{O}^{+}$ ions and measured excitation energies of $\mathrm{O}^{+}$states, compiled by Tayal and Richardson (2000), Pavlov and Foster (2001) found that $\mathrm{O}^{+}\left({ }^{2} \mathrm{P}^{*}\right)$ ions decay to either $\mathrm{O}^{+}\left({ }^{2} \mathrm{D}\right)$ or $\mathrm{O}^{+}\left({ }^{2} \mathrm{D}\right)$ with a branching ratio of $2: 1$ for $\mathrm{O}^{+}\left({ }^{2} \mathrm{D}\right): \mathrm{O}^{+}\left({ }^{2} \mathrm{P}\right)$. The value of $\tau\left({ }^{4} \mathrm{P}\right)$ or $\tau\left({ }^{2} \mathrm{P}^{*}\right)$ is much less than the studied characteristic times of changes in densities of ions and electrons in the ionosphere and plasmasphere. As a result, the model of the ionosphere and plasmasphere uses the steady-state number densities of $\mathrm{O}^{+}\left({ }^{4} \mathrm{P}\right)$ and $\mathrm{O}^{+}\left({ }^{2} \mathrm{P}^{*}\right)$ as

$$
\begin{aligned}
& {\left[\mathrm{O}^{+}\left({ }^{4} \mathrm{P}\right)\right]=\left\{\mathrm{Q}\left({ }^{4} \mathrm{P}\right)+\Delta \mathrm{Q}\left({ }^{4} \mathrm{P}\right)\right\} \tau\left({ }^{4} \mathrm{P}\right),} \\
& {\left[\mathrm{O}^{+}\left({ }^{2} \mathrm{P}^{*}\right)\right]=\left\{\mathrm{Q}\left({ }^{2} \mathrm{P}^{*}\right)+\Delta \mathrm{Q}\left({ }^{2} \mathrm{P}^{*}\right)\right\} \tau\left({ }^{2} \mathrm{P}^{*}\right) .}
\end{aligned}
$$

The loss rate of $\mathrm{O}^{+}\left({ }^{2} \mathrm{D}\right)$ ions is determined by the reactions (1)-(6) of Table A1. The characteristic time, $\tau\left({ }^{2} \mathrm{P}\right)$, of $\mathrm{O}^{+}\left({ }^{2} \mathrm{D}\right)$ number density changes in these chemical reactions is given as $\tau\left({ }^{2} \mathrm{P}\right)=\left\{\mathrm{K}_{1}[\mathrm{O}]+\mathrm{K}_{2}\left[\mathrm{~N}_{2}\right]+\mathrm{K}_{3}+\mathrm{K}_{4}+\left(\mathrm{K}_{5}+\mathrm{K}_{6}\right) \mathrm{N}_{\mathrm{e}}\right\}^{-1}$, where $\mathrm{K}_{1}-\mathrm{K}_{6}$ are the rate coefficients of the chemical reactions (1)-(6), respectively, displayed in Table A1. The value of $\tau\left({ }^{2} \mathrm{P}\right)$ is less than $2.78 \mathrm{~s}$, i.e. this time constant is much less than the studied characteristic times of changes in densities of ions and electrons in the ionosphere and plasmasphere. As a result, the steady-state number density of $\mathrm{O}^{+}\left({ }^{2} \mathrm{D}\right)$ ions is used in the model calculations as

$$
\left[\mathrm{O}^{+}\left({ }^{2} \mathrm{P}\right)\right]=\left\{\mathrm{Q}\left({ }^{2} \mathrm{P}\right)+\Delta \mathrm{Q}\left({ }^{2} \mathrm{P}\right)+\frac{1}{3} \mathrm{Q}\left({ }^{2} \mathrm{P}^{*}\right)+\frac{1}{3} \Delta \mathrm{Q}\left({ }^{2} \mathrm{P}^{*}\right)\right\}
$$

$\tau\left({ }^{2} \mathrm{P}\right)$,

where $\mathrm{Q}\left({ }^{2} \mathrm{P}\right)$ and $\Delta \mathrm{Q}\left({ }^{2} \mathrm{P}\right)$ are the production rates of $\mathrm{O}^{+}\left({ }^{2} \mathrm{P}\right)$ ions by photoionization and due to photoelectrons, respec- 
Table A1. Chemistry of $\mathrm{O}^{+}\left({ }^{2} \mathrm{D}\right)$ and $\mathrm{O}^{+}\left({ }^{2} \mathrm{D}\right)$ ions $\left({ }^{a}\right.$ The effective temperature $\mathrm{T}=\left(\mathrm{m}_{\mathrm{i}} \mathrm{T}_{\mathrm{n}}+\mathrm{m}_{\mathrm{n}} \mathrm{T}_{\mathrm{i}}\right)\left(\mathrm{m}_{\mathrm{i}}+\mathrm{m}_{\mathrm{n}}\right)^{-1}+\mathrm{m}_{\mathrm{i}} \mathrm{m}_{\mathrm{n}} \mathrm{V}_{\mathrm{d}}^{2}\left\{3 \mathrm{k}\left(\mathrm{m}_{\mathrm{i}}+\mathrm{m}_{\mathrm{n}}\right)\right\}^{-1}$, where $\mathrm{m}_{i}$ and $\mathrm{m}_{n}$ denote the masses of ion and neutral reactants, respectively, $\mathrm{V}_{d}$ is a plasma drift velocity)

\begin{tabular}{llll}
\hline No. & Reaction & $\begin{array}{l}\text { Rate coefficient }\left(\mathrm{m}^{3} \mathrm{~s}^{-1}\right) \\
\text { or rate }\left(\mathrm{s}^{1}\right)\end{array}$ & Reference \\
\hline 1. & $\mathrm{O}^{+}\left({ }^{2} \mathrm{P}\right)+\mathrm{O} \rightarrow \mathrm{O}^{+}\left({ }^{4} \mathrm{~S}\right)+\mathrm{O}$ & $4 \cdot 10^{-10}$ & Chang et al.(1993) \\
2. & $\mathrm{O}^{+}\left({ }^{2} \mathrm{P}\right)+\mathrm{N}_{2} \rightarrow \mathrm{O}+\mathrm{N}_{2}^{+}$ & $2 \cdot 10^{-10}(\mathrm{~T} / 300)^{0.5}$ & Li et. al. (1997) $)^{\mathrm{a}}$, see text \\
3. & $\mathrm{O}^{+}\left({ }^{2} \mathrm{P}\right) \rightarrow \mathrm{O}^{+}\left({ }^{4} \mathrm{~S}\right)+\mathrm{h} v$ & 0.0833 & Kaufman and Sugar (1986) \\
4. & $\mathrm{O}^{+}\left({ }^{2} \mathrm{P}\right) \rightarrow \mathrm{O}^{+}\left({ }^{2} \mathrm{D}\right)+\mathrm{h} v$ & 0.277 & Kaufman and Sugar (1986) \\
5. & $\mathrm{O}^{+}\left({ }^{2} \mathrm{P}\right)+\mathrm{e} \rightarrow \mathrm{O}^{+}\left({ }^{4} \mathrm{~S}\right)+\mathrm{e}$ & $2.5 \cdot 10^{-8}\left(300 / \mathrm{T}_{e}\right)^{0.5}$ & McLaughlin and Bell (1998), see text \\
6. & $\mathrm{O}^{+}\left({ }^{2} \mathrm{P}\right)+\mathrm{e} \rightarrow \mathrm{O}^{+}\left({ }^{2} \mathrm{D}\right)+\mathrm{e}$ & $7.0 \cdot 10^{-8}\left(300 / \mathrm{T}_{e}\right)^{0.5}$ & McLaughlin and Bell (1998), see text \\
7. & $\mathrm{O}^{+}\left({ }^{2} \mathrm{D}\right)+\mathrm{O} \rightarrow \mathrm{O}^{+}\left({ }^{4} \mathrm{~S}\right)+\mathrm{O}$ & $5 \cdot 10^{-12}$ & Abdou et al. (1984) \\
8. & $\mathrm{O}^{+}\left({ }^{2} \mathrm{D}\right)+\mathrm{N}_{2} \rightarrow \mathrm{N}_{2}^{+}+\mathrm{O}$ & $1.5 \cdot 10^{-10}(\mathrm{~T} / 300)^{0.5}$ & Li et. al. (1997) $)^{\mathrm{a}}$, see text \\
9. & $\mathrm{O}^{+}\left({ }^{2} \mathrm{D}\right)+\mathrm{O}_{2} \rightarrow \mathrm{O}_{2}^{+}+\mathrm{O}$ & $1.3 \cdot 10^{-10}(\mathrm{~T} / 300)^{0.5}$ & see text a \\
10. & $\mathrm{O}^{+}\left({ }^{2} \mathrm{D}\right)+\mathrm{e} \rightarrow \mathrm{O}^{+}\left({ }^{4} \mathrm{~S}\right)+\mathrm{e}$ & $4.0 \cdot 10^{-8}\left(300 / \mathrm{T}_{e}\right)^{0.5}$ & McLaughlin and Bell (1998), see text \\
\hline
\end{tabular}

tively, and $\mathrm{Q}\left({ }^{2} \mathrm{P}^{*}\right)$ and $\Delta \mathrm{Q}\left({ }^{2} \mathrm{P}^{*}\right)$ are the production rates of $\mathrm{O}^{+}\left({ }^{2} \mathrm{P}^{*}\right)$ ions by photoionization and due to photoelectrons, respectively.

\section{A1.2.4. Steady-state number density of $\mathrm{O}^{+}\left({ }^{2} \mathrm{D}\right)$ ions}

The steady-state number density of $\mathrm{O}^{+}\left({ }^{2} \mathrm{D}\right)$ ions can be calculated as

$$
\left[\mathrm{O}^{+}\left({ }^{2} \mathrm{D}\right)\right]=\left\{\mathrm{Q}\left({ }^{2} \mathrm{D}\right)+\Delta \mathrm{Q}\left({ }^{2} \mathrm{D}\right)+\frac{2}{3} \mathrm{Q}\left({ }^{2} \mathrm{P}^{*}\right)+\frac{2}{3} \Delta \mathrm{Q}\left({ }^{2} \mathrm{P}^{*}\right)+\right.
$$$$
\left.\left(\mathrm{K}_{4}+\mathrm{K}_{6} \mathrm{~N}_{\mathrm{e}}\right)\left[\mathrm{O}^{+}\left({ }^{2} \mathrm{P}\right)\right]\right\} \tau\left({ }^{2} \mathrm{D}\right)
$$

where $\mathrm{Q}\left({ }^{2} \mathrm{D}\right)$ and $\Delta \mathrm{Q}\left({ }^{2} \mathrm{D}\right)$ are the production rates of $\mathrm{O}^{+}\left({ }^{2} \mathrm{D}\right)$ ions by photoionization and by photoelectrons, and $\tau\left({ }^{2} \mathrm{D}\right)$ is the characteristic time of $\mathrm{O}^{+}\left({ }^{2} \mathrm{D}\right)$ number density changes in chemical reactions that is determined as $\tau\left({ }^{2} \mathrm{D}\right)=\left\{\mathrm{K}_{7}[\mathrm{O}]+\mathrm{K}_{8}\left[\mathrm{~N}_{2}\right]+\mathrm{K}_{9}\left[\mathrm{O}_{2}\right]+\mathrm{K}_{10} \mathrm{~N}_{\mathrm{e}}\right\}^{-1}, \mathrm{~K}_{4}$, $\mathrm{K}_{6}-\mathrm{K}_{10}$ are the rate coefficients of the chemical reactions (4) and (6)-10), respectively, displayed in Table A1.

\section{A2.2. Energy balance equations}

To determine the temperatures $T_{i}$ and $T_{e}$ of ions and electrons, we use the energy balance equations for ions and electrons given by Pavlov (1997) and add in these equations the terms which take into account the drift of plasma perpendicular to the magnetic field line (see, for example, Bailey and Balan, 1996):

$1.5 \mathrm{kN}_{\mathrm{i}}\left(\frac{\mathrm{d}}{\mathrm{dt}} \mathrm{T}_{\mathrm{i}}+\mathrm{C}_{\mathrm{i}} \frac{\partial}{\partial \mathrm{S}} \mathrm{T}_{\mathrm{i}}\right)=\mathrm{B} \frac{\partial}{\partial \mathrm{S}} \lambda_{\mathrm{i}} \mathrm{B}^{-1} \frac{\partial}{\partial \mathrm{S}} \mathrm{T}_{\mathrm{i}}-$

$$
\begin{aligned}
& \mathrm{kN}_{\mathrm{i}} \mathrm{T}_{\mathrm{i}}\left(\mathrm{B} \frac{\partial}{\partial \mathrm{S}} \mathrm{C}_{\mathrm{i}} \mathrm{B}^{-1}+\operatorname{div} V^{\mathrm{E}}\right)+3 \mathrm{kN}_{\mathrm{i}} v_{\mathrm{ie}}\left(\mathrm{T}_{\mathrm{e}}-\mathrm{T}_{\mathrm{i}}\right)+ \\
& 3 \mathrm{kN}_{\mathrm{i}} \mathrm{m}_{\mathrm{i}}\left(\mathrm{T}_{\mathrm{n}}-\mathrm{T}_{\mathrm{i}}\right) \sum_{\mathrm{n}} v_{\mathrm{in}}\left(\mathrm{m}_{\mathrm{i}}+\mathrm{m}_{\mathrm{n}}\right)^{-1}+ \\
& \mathrm{m}_{\mathrm{i}} \mathrm{N}_{\mathrm{i}} \mathrm{V}_{\mathrm{d}}^{2} \sum_{\mathrm{n}} v_{\mathrm{in}}\left(\mathrm{m}_{\mathrm{i}}+\mathrm{m}_{\mathrm{n}}\right)^{-1}
\end{aligned}
$$

$1.5 \mathrm{kN}_{\mathrm{e}}\left(\frac{\mathrm{d}}{\mathrm{dt}} \mathrm{T}_{\mathrm{e}}+\mathrm{C}_{\mathrm{e}} \frac{\partial}{\partial \mathrm{S}} \mathrm{T}_{\mathrm{e}}\right)=\mathrm{B} \frac{\partial}{\partial \mathrm{S}} \lambda_{\mathrm{e}} \mathrm{B}^{-1} \frac{\partial}{\partial \mathrm{S}} \mathrm{T}_{\mathrm{e}}-$

$\mathrm{kN}_{\mathrm{e}} \mathrm{T}_{\mathrm{e}}\left(\mathrm{B} \frac{\partial}{\partial \mathrm{S}} \mathrm{C}_{\mathrm{e}} \mathrm{B}^{-1}+\operatorname{div} \boldsymbol{V}^{\mathrm{E}}\right)+\mathrm{P}_{\mathrm{e}}+\mathrm{P}_{\mathrm{re}}-\sum_{1} \mathrm{~L}_{\mathrm{el}}$,

where $k$ is the Boltzmann's coefficient, $m_{i}$ denotes the mass of the $\mathrm{i}$-th ion, mn denotes the mass of the nth neutral component of the atmosphere, $v_{i e}$ and $v_{i n}$ are the collision frequencies for momentum transfer between ions and electrons and between ions and neutrals, $\mathrm{V}_{\mathrm{d}}^{2}=\mathrm{W}^{2}+\left(\mathrm{E}_{\perp} \mathrm{B}^{-1}\right)^{2}\left\{1+\omega_{\mathrm{i}}^{-2}\left(\sum_{\mathrm{n}} v_{\mathrm{in}}\right)^{2}\right\}^{-1}, \omega_{i}$ is the ion cyclotron frequency, $E_{\perp}$ is the perpendicular component of the electric field with respect to the geomagnetic field, $\lambda_{i}$ and $\lambda_{e}$ are the thermal conductivities of ions and electrons, $L_{e l}$ is the electron cooling rate in the process " $l$ ", $P_{e}$ is the heating rate of the electron gas by photoelectrons, $P_{r c}$ is an additional heating rate of the electron gas due to Coulomb collisions between ring current ions and plasmaspheric electrons and wave-electron interactions (the value of $P_{r c}=0$ is used in the calculations presented in this work), the total timederivatives are defined by $\frac{\mathrm{d}}{\mathrm{dt}} \mathrm{T}_{\mathrm{i}}=\frac{\partial}{\partial \mathrm{t}} \mathrm{T}_{\mathrm{i}}+\boldsymbol{V}^{\mathrm{E}} \cdot \operatorname{grad} \mathrm{T}_{\mathrm{i}}$ and by $\frac{\mathrm{d}}{\mathrm{dt}} \mathrm{T}_{\mathrm{e}}=\frac{\partial}{\partial \mathrm{t}} \mathrm{T}_{\mathrm{e}}+V^{\mathrm{E}} \cdot \operatorname{grad} \mathrm{T}_{\mathrm{e}}$, the value of $C_{i}$ is the same as in Eq. (A1), and to calculate the field-aligned electron velocity, $C_{e}$, we assume that there are no field-aligned currents, i.e. $\mathrm{C}_{\mathrm{e}}=\sum_{\mathrm{i}} \mathrm{C}_{\mathrm{i}} \mathrm{N}_{\mathrm{i}} / \mathrm{N}_{\mathrm{e}}$.

We use the same equations for $v_{i e}$ and $v_{i n}$ as given by Bailey and Balan (1996), except for the $\mathrm{O}^{+}-\mathrm{O}$ frequency, 
whose value is taken from Pesnell et al. (1993). The model uses the generally accepted electron cooling rates due to electron-ion Coulomb collisions and elastic collisions of electrons with $\mathrm{N}_{2}, \mathrm{O}_{2}, \mathrm{O}, \mathrm{He}$ and $\mathrm{H}$ presented by Schunk and Nagy (1978), and the thermal electron impact excitation of $\mathrm{O}_{2}\left(\mathrm{a}^{1} \Delta_{\mathrm{g}}\right)$ and $\mathrm{O}_{2}\left(\mathrm{~b}^{1} \sum_{\mathrm{g}}^{+}\right)$given by Prasad and Furman (1973). The revised electron cooling rates by vibrational and rotational excitation of $\mathrm{O}_{2}$ and $\mathrm{N}_{2}$ of Pavlov (1998 a, c), the expression for atomic oxygen fine structure cooling rate of thermal electrons derived by Pavlov and Berrington (1999), and the thermal electron cooling rate due to electron-impactinduced transitions ${ }^{3} \mathrm{P} \rightarrow{ }^{1} \mathrm{D}$ for atomic oxygen (Lobzin et al., 1999) are included in the model. The model uses the updated expression for $\lambda_{e}$ given by Pavlov et al. $(2000,2001)$ and the expression for $\lambda_{i}$ given by Hochstim (1969).

The heating rate of electrons by photoelectrons is calculated by the use of the approach of Hoegy (1984) (the same approach was derived from the kinetic equation by Krinberg and Tachilin (1984)). The value of $P_{e}$ is a function of the photoelectron flux.

We split the studied ionosphere and plasmasphere region into two regions. The first region includes the plasmasphere and ionosphere with the magnetic field lines which intersect the point $\mathrm{S}=0$ above $1500 \mathrm{~km}$, i.e. the magnetic field lines have the apex altitudes $h_{a p} \geq 1500 \mathrm{~km}$ in the first region. Modelled electron heating due to photoelectrons is provided by a solution of the Boltzmann equation for photoelectron flux along a centered-dipole magnetic field line, using the method of Krinberg and Tachilin (1984) on the same field line grid which is used in solving for the electron and ion temperatures. In the altitude range $130-700 \mathrm{~km}$ in the Northern and Southern Hemispheres, the model solves the Boltzmann equation for photoelectron flux using the method of Krinberg and Tachilin (1984) and the updated elastic and inelastic cross sections of the neutral components of the atmosphere described by Lobzin et al. (1999) and calculates the value of $P_{e}$. In the approach of Krinberg and Tachilin (1984), photoelectron transport and loss processes due to the elastic and inelastic collisions of electrons with neutral components of the atmosphere and Coulomb electron-electron collisions are taken into account. Their technique is based on the solution of simpler transport flux equations derived from the Boltzmann equation and determines the ionospheric electron heating rate with an accuracy of about $10 \%$, in comparison with that obtained by the numerical solution of the kinetic equation (Krinberg and Tachilin, 1984). Above $700 \mathrm{~km}$, the energy lost by photoelectrons in heating the plasma is calculated using the analytical equation for the plasmaspheric transparency, $P(E)$, (Krinberg and Matafonov, 1978; Krinberg and Tachilin, 1984) that determines the probability of the magnetically trapped photoelectrons with an energy, $E$, of entering the magnetically conjugated ionosphere. The transparency depends mainly on a single parameter proportional to the Coulomb cross section and the total content of electrons in the plasmasphere magnetic flux tube (the transparency approaches unity as photoelectrons pass through the plasmasphere without significant absorption, and $\mathrm{P}(\mathrm{E})=0$, if photoelectrons are absorbed by the plasmasphere). This analytical transparency approach determines the plasmaspheric heating rate with an accuracy of about $10-20 \%$ in comparison with that obtained by the numerical solution of the kinetic equation (Krinberg and Matafonov, 1978; Krinberg and Tachilin, 1984). Below $700 \mathrm{~km}$, the photoelectron transfer equations, which were derived by Krinberg and Taschilin (1984) from the kinetic equation for the photoelectron flux, are solved in both hemispheres. This approach is used in the models of the plasmasphere and ionosphere (Krinberg and Taschilin, 1984; Pavlov and Foster, 2001; Korenkov et al., 1996).

The second region is the ionosphere region with the magnetic field lines that intersect the apex altitudes below $1500 \mathrm{~km}$. To calculate the value of $P_{e}$ in the second region, we solve the equations which were derived by Krinberg and Taschilin (1984) from the kinetic equation for the photoelectron flux below the points $S=0$ in both hemispheres, i.e. the transparency approach is not used.

A2.3 Energy equations for vibrationally excited nitrogen and oxygen molecules

The loss rate of $\mathrm{O}^{+}\left({ }^{4} \mathrm{~S}\right)$ ions and cooling rates of thermal electrons due to vibrational excitation of $\mathrm{N}_{2}$ and $\mathrm{O}_{2}$ depend on number densities, $\left[\mathrm{N}_{2}(\mathrm{v})\right]$ and $\left[\mathrm{O}_{2}(\mathrm{v})\right]$, of vibrationally excited nitrogen, $\mathrm{N}_{2}(\mathrm{v})$, and oxygen, $\mathrm{O}_{2}(\mathrm{v})$, molecules at vibrational levels, $v$ (Pavlov, 1988, 1994, 1997, 1998a, b, c; Pavlov and Namgaladze, 1988; Pavlov et al., 1999, 2000, 2001; Pavlov and Foster, 2001).

Time dependent continuity and energy equations, which determine $\left[\mathrm{N}_{2}(\mathrm{v})\right]$ and $\left[\mathrm{O}_{2}(\mathrm{v})\right]$, are presented by Pavlov (1997) and Pavlov (1998b). The model uses Boltzmann distributions of $\mathrm{N}_{2}(\mathrm{v})$ and $\mathrm{O}_{2}(\mathrm{v})$ as

$$
\begin{aligned}
& {\left[\mathrm{N}_{2}(\mathrm{v})\right]=\left[\mathrm{N}_{2}(0)\right] \exp \left(-\mathrm{vE}_{1} \mathrm{~T}_{\mathrm{N} 2 \mathrm{v}}^{-1}\right),} \\
& {\left[\mathrm{O}_{2}(\mathrm{v})\right]=\left[\mathrm{O}_{2}(0)\right] \exp \left(-\mathrm{vE}_{1}{ }^{\prime} \mathrm{T}_{\mathrm{O} 2 \mathrm{v}}^{-1}\right),}
\end{aligned}
$$

where $E_{1}{ }^{\prime}=3353 \mathrm{~K}$ is the energy of the first level of $\mathrm{N}_{2}$ given by Radzig and Smirnov (1980), $\mathrm{E}_{1}=2239 \mathrm{~K}$ is the energy of the first level of $\mathrm{O}_{2}$ given by Radzig and Smirnov (1980), $T_{N 2 v}$ and $T_{O 2 v}$ are the vibrational temperatures of $\mathrm{N}_{2}$ and $\mathrm{O}_{2}$.

The vibrational quanta, $\alpha$ and $\beta$, of $\mathrm{N}_{2}$ and $\mathrm{O}_{2}$ are determined as $\alpha=\sum_{\mathrm{v}} \mathrm{v}\left[\mathrm{N}_{2}(\mathrm{v})\right] /\left[\mathrm{N}_{2}\right]$ and $\beta=\sum_{\mathrm{v}} \mathrm{v}\left[\mathrm{O}_{2}(\mathrm{v})\right] /\left[\mathrm{O}_{2}\right]$, where $\left[\mathrm{N}_{2}\right]=\sum_{\mathrm{v}}\left[\mathrm{N}_{2}(\mathrm{v})\right]$ and $\left[\mathrm{O}_{2}\right]=\sum_{\mathrm{v}}\left[\mathrm{O}_{2}(\mathrm{v})\right]$ are the total number densities of $\mathrm{N}_{2}$ and $\mathrm{O}_{2}$. It follows from Eq. (A25) that

$$
\begin{aligned}
& {\left[\mathrm{N}_{2}(\mathrm{v})\right]=\left[\mathrm{N}_{2}(0)\right]\left(\frac{\alpha}{1+\alpha}\right)^{\mathrm{v}},} \\
& \left.\left[\mathrm{O}_{2}(\mathrm{v})\right]=\left[\mathrm{O}_{2}(0)\right]\left(\frac{\beta}{1+\beta}\right)^{\mathrm{v}}\right], \\
& \mathrm{T}_{\mathrm{N} 2 \mathrm{v}}=-\mathrm{E}_{1} / \ln \frac{\alpha}{1+\alpha}, \\
& \mathrm{T}_{\mathrm{O} 2 \mathrm{v}}=-\mathrm{E}_{1}^{\prime} / \ln \frac{\beta}{1+\beta},
\end{aligned}
$$


where the values of $\left[\mathrm{N}_{2}(0)\right]$ and $\left[\mathrm{O}_{2}(0)\right]$ are calculated from $\left[\mathrm{N}_{2}\right]$ and $\left[\mathrm{O}_{2}\right]$ (whose values are given by the MSIS-86 model of Hedin (1987) or by the NRLMSISE-00 model of Picone et al. $(2000,2002))$ by $\left[\mathrm{N}_{2}(0)\right]=\left[\mathrm{N}_{2}\right] /(1+\alpha)$ and $\left[\mathrm{O}_{2}(0)\right]=\left[\mathrm{O}_{2}\right] /(1+\beta)$.

The values of $\alpha$ and $\beta$ are determined by solving the time-dependent, one dimensional quanta energy equations given by Pavlov (1997, 1998b). The quanta energy equation solution procedure is described in detail by Pavlov (1997, 1998b).

\section{A2.4 Neutral temperature and densities and solar EUV fluxes}

The model of the ionosphere and plasmasphere includes an option to use two sets of the models of the neutral temperature and densities. First, one uses the NRLMSISE00 neutral temperature and densities given by Picone et al. $(2000,2002)$, and second, one uses the MSIS-86 neutral temperature and densities model of Hedin (1987). Both neutral temperature and density models are run using 3-h geomagnetic Ap indices. To calculate the density of NO, the model given by Titheridge (1997) is used. The model of the ionosphere and plasmasphere can use the solar EUV fluxes from the EUVAC model (Richards et al., 1994) or the EUV97 model (Tobiska and Eparvier, 1998). At night our model includes the neutral ionization by scattered solar 121.6, 102.6 and $58.4 \mathrm{~nm}$ fluxes, as described by Pavlov (1997).

\section{A2.5 Solution of continuity and energy equations}

\section{A2.5.1 Dipole coordinates}

The coordinate system considered here is similar to that of Anderson (1973) and Rasmussen et al. (1993). Orthogonal curvilinear coordinates are: $q=\left(R_{E} / R\right)^{2} \cos \Theta, U=$ $\left(R_{E} / R\right) \sin ^{2} \Theta$, and a geomagnetic longitude, $\Lambda$. The important properties of these coordinates are that $q$ is aligned with, and $U$ and $\Lambda$ are perpendicular to, the magnetic field, the $U$ and $\Lambda$ coordinates are constant along a dipole magnetic field line, and the Mcllwain parameter $L=R /\left(R_{E} \sin ^{2} \Theta\right)$ can be presented as $L=U^{-1}$. Also, for a dipole magnetic field line $\frac{\partial}{\partial S}=\eta_{0} \frac{\partial}{\partial q}$, where $\eta_{0}=-\left(1+3 \cos ^{2} \Theta\right)^{0.5} R_{E}^{2} / R^{3}$ (Bailey and Balan, 1996). We take into account that the plasma $\boldsymbol{E} \times \boldsymbol{B}$ drift velocity can be presented as $\boldsymbol{V}^{E}=$ $V_{\Lambda}^{E} \boldsymbol{e}_{\Lambda}+V_{U}^{E} \boldsymbol{e}_{U}$, where $V_{\Lambda}^{E}=E_{U} / B, V_{U}^{E}=-E_{\Lambda} / B$, $\boldsymbol{E}=E_{\Lambda} \boldsymbol{e}_{\Lambda}+E_{U} \boldsymbol{e}_{U}, E_{\Lambda}$ is the $\Lambda$ component of $\boldsymbol{E}$ in the dipole coordinate system, $E_{U}$ is the $U$ component of $\boldsymbol{E}$ in the dipole coordinate system, $\boldsymbol{e}_{\Lambda}$ and $\boldsymbol{e}_{U}$ are unit vectors in $\Lambda$ and $\mathrm{U}$ directions, respectively.

For the plasma trajectory tracking, the definition of the velocity vector can be used as follows:

$\mathrm{V}_{\mathrm{U}}^{\mathrm{E}}=\mathrm{h}_{\mathrm{U}} \frac{\partial}{\partial \mathrm{t}} \mathrm{U}, \mathrm{V}_{\Lambda}^{\mathrm{E}}=\mathrm{h}_{\Lambda} \frac{\partial}{\partial \mathrm{t}} \Lambda$,

where the coordinate scale factors, $h_{U}$ and $h_{\Lambda}$, are given by Rasmussen et al. (1993) as $h_{U}=R L \cos I$ and $\mathrm{h}_{\Lambda}=\mathrm{R} \sin \Theta$, $\mathrm{I}$ is the magnetic field dip angle, $\cos I=\sin \Theta\left(1+3 \cos ^{2} \Theta\right)^{-1 / 2}$.

Taking into account that $B=B_{0}\left(R_{E} / R\right)^{3}\left(1+3 \cos ^{2} \Theta\right)^{1 / 2}$, Eq. (A10) which determines the trajectory of the ionospheric plasma and the moving coordinate system can be rewritten as

$$
\begin{aligned}
& \frac{\partial}{\partial \mathrm{t}} \mathrm{U}=-\mathrm{E}_{\Lambda}^{\mathrm{eff}} \mathrm{R}_{\mathrm{E}}^{-1} \mathrm{~B}_{0}^{-1}, \\
& \mathrm{E}_{\Lambda}^{\mathrm{eff}}=\mathrm{E}_{\Lambda} \mathrm{h}_{\Lambda} \mathrm{R}_{\mathrm{E}}^{-1},
\end{aligned}
$$

$$
\frac{\partial}{\partial \mathrm{t}} \Lambda=\mathrm{E}_{\mathrm{U}}^{\mathrm{eff}} \mathrm{R}_{\mathrm{E}}^{-1} \mathrm{~B}_{0}^{-1}
$$

$\mathrm{E}_{\mathrm{U}}^{\mathrm{eff}}=\mathrm{E}_{\mathrm{U}} h_{\mathrm{U}} \mathrm{R}_{\mathrm{E}}^{-1}$.

If the $\mathrm{E}_{\Lambda}^{\mathrm{eff}}$ and $\mathrm{E}_{\mathrm{U}}^{\mathrm{eff}}$ components of the effective electric field are changed along magnetic field lines (i.e. the values of $E_{\Lambda} \sin ^{3} \Theta$ and $E_{U} \sin ^{3} \Theta\left(1+3 \cos ^{2} \Theta\right)^{-1 / 2}$ are changed along magnetic field lines), then the values of $\frac{\partial}{\partial t} U$ (i.e. $\frac{\partial}{\partial \mathrm{t}} \mathrm{L}$ ) and $\frac{\partial}{\partial \mathrm{t}} \Lambda$ are not constants, and magnetic field lines are not "frozen" in the ionospheric plasma. However, the ionospheric plasma is assumed to be with a magnetic field "frozen" in above about $150 \mathrm{~km}$, where the drift velocities of ions and electrons perpendicular to the geomagnetic and electric fields are approximately the same (Ratcliffe, 1956). To overcome this difficulty, it is necessary to prove that the values of $E_{\Lambda} h_{\Lambda}$ and $E_{U} h_{U}$ are not changed along magnetic field lines. To understand the physics, there must first be a clear understanding of the concept of "magnetic line" preservation. The concept of magnetic line preservation or moving magnetic field lines gives rise to the mnemonic of magnetic field lines as entities with an integrity that is locally convected by plasma flow fields, which are locally orthogonal to magnetic field lines (Alfven and Fälthammer, 1963). Magnetic field lines are carried about with any plasma flow fields whose motions are perpendicular to magnetic field lines. For the magnetic field line to be "frozen" to the perpendicular motion of plasma, the magnetic field diffusion is assumed to be negligible, and the evolution of the magnetic field is governed by the induction equation as (Alfven and Fälthammer, 1963) $\frac{\partial}{\partial t} \boldsymbol{B}=\operatorname{rot} \boldsymbol{B} \times \boldsymbol{V}^{E}$. We have to take into account that $\frac{\partial}{\partial \mathrm{t}} \boldsymbol{B}=0$ and $\boldsymbol{B} \times \boldsymbol{V}^{E}=-E_{U} \boldsymbol{e}_{U}-E_{\Lambda} \boldsymbol{e}_{\Lambda}$. As a result, the electric field restrictions which follow from the fact that the magnetic field lines are frozen in the ionospheric plasma can be formulated from $\operatorname{rot} \boldsymbol{B} \times \boldsymbol{V}^{E}=0$ as

$$
\begin{aligned}
& \frac{\partial}{\partial \mathrm{q}}\left(\mathrm{E}_{\Lambda}^{\mathrm{eff}}\right)=0 \\
& \frac{\partial}{\partial \mathrm{q}}\left(\mathrm{E}_{\mathrm{U}}^{\mathrm{eff}}\right)=0 \\
& \frac{\partial}{\partial \Lambda}\left(\mathrm{E}_{\mathrm{U}}^{\mathrm{eff}}\right)=\frac{\partial}{\partial \mathrm{U}}\left(\mathrm{E}_{\Lambda}^{\mathrm{eff}}\right) .
\end{aligned}
$$

These equations yield the frozen-in-field conditions in the ionosphere and plasmasphere above about $150 \mathrm{~km}$. It follows 
from Eqs. (A15) and (A16) that the $\mathrm{E}_{\Lambda}^{\mathrm{eff}}$ and $\mathrm{E}_{\mathrm{U}}^{\mathrm{eff}}$ components of the effective electric field are not changed along magnetic field lines. Equation (A17) shows that there is the interdependency between changes in $\mathrm{E}_{\mathrm{U}}^{\mathrm{eff}}$ in the $\Lambda$ direction and changes in $\mathrm{E}_{\Lambda}^{\mathrm{eff}}$ in the $\mathrm{U}$ direction.

The zonal component $V^{E}{ }_{\Lambda}$ of the $\boldsymbol{E} \times \boldsymbol{B}$ drift is not included in the ionospheric model calculations of the ionospheric equatorial anomaly variations (see, for example, Bailey and Sellec, 1990; Bailey and Balan, 1996; Su et al., 1997) as it is believed that the $E_{U}$ component of $\boldsymbol{E}$ has a negligible effect on the electron density profiles (Anderson, 1981). Possible effects of $E_{U}$ on $N_{i}, N_{e}, T_{i}$, and $T_{e}$ are also not studied in this work. Nevertheless, up to now, there are no published theoretical calculations of possible effects of $E_{U}$ on $N_{i}, N_{e}$, $T_{i}$ and $T_{e}$. Therefore, the model, without taking into account the effects of $E_{U}$ on $N_{i}, N_{e}, T_{i}$ and $T_{e}$, can be considered as the first step in our studies of the low-latitude ionosphere, and we plan to include the zonal component of the $\boldsymbol{E} \times \boldsymbol{B}$ drift in our model and solve Eqs. (A13), (A14), (A16) and (A17) in future studies, to evaluate the possible role of $E_{U}$.

Following Murphy et al. (1980), Bailey and Balan (1996), and Millward et al. (1996), we believe that the value of div $V^{E}$ in Eq. (A1) can be presented as $\operatorname{div} V^{E}=6 V_{e q}^{\perp} \sin ^{2} \Theta(1+$ $\left.\cos ^{2} \Theta\right) R_{e q}^{-1}\left(1+3 \cos ^{2} \Theta\right)^{-2}$, where $R_{e q}$ is the equatorial radial distance of the magnetic field line from the Earth's center, and the equatorial value of $V^{\perp}\left(\boldsymbol{V}^{\perp}=V^{\perp} \boldsymbol{e}_{\perp}\right.$, $\left.\boldsymbol{e}_{\perp}=-\boldsymbol{e}_{U}, V^{\perp}=-V_{U}^{E}\right)$ is calculated as $V^{\perp}{ }_{e q}=$ $\left(R_{e q} / R_{E}\right)^{3} E_{\Lambda} / B_{0}$.

The procedure for determining the distribution of points along the magnetic field line is very important during our model calculations. Therefore, we do not use the value of $\mathrm{q}$ in our calculations. The model calculations are carried out by the use of $X=\sin (\Gamma q) / \sin \left(\Gamma q_{m}\right)$, where $\mathrm{q}_{\mathrm{m}}$ is the maximum value of $\mathrm{q}_{\mathrm{m}}$ for the considered magnetic field line, and $\Gamma$ is a point distribution parameter. As a result, for a dipole magnetic field line, $\frac{\partial}{\partial S}=\eta \frac{\partial}{\partial X}$, where $\eta=\eta_{0} \Gamma \cosh (\Gamma \mathrm{q}) / \sinh \left(\Gamma \mathrm{q}_{\mathrm{m}}\right)$. In the model, this transformation of coordinates is applied to the continuity, and energy balance equations of electrons and ions given by Eqs. (A1), (A6) and (A7), and to the system of equations for determination of the field-aligned ion diffusion velocities of ions given by Pavlov (1997). After that, the points of each magnetic field line are distributed in equal increments, $\Delta \mathrm{X}$, along the magnetic field line. The lower boundary in each hemisphere is taken to be at the $130 \mathrm{~km}$ altitude, and the fixed value of $\Gamma=10$ is used in the model calculations.

The model calculates the values of $N_{i}, N_{e}, T_{i}$ and $T_{e}$ in the fixed nodes of the fixed volume grid. This Eulerian computational grid consists of a distribution of the dipole magnetic field lines in the ionosphere and plasmasphere. One hundred dipole magnetic field lines are used in the model for each fixed value of $\Lambda$. The number of fixed nodes taken along each magnetic field line is 191 . For each fixed value of $\Lambda$, the region of study is a $(q, U)$ plane which is bounded by two dipole magnetic field lines. The low boundary dipole magnetic field line has the apex altitude, $h_{a p}=R_{e q}-R_{E}$, of $150 \mathrm{~km}$. The upper boundary dipole magnetic field line has $h_{a p}=4491 \mathrm{~km}$ and intersects the Earth's surface at two middle latitude geomagnetic latitudes: $\pm 40^{\circ}$. The computational grid dipole magnetic field lines are distributed between these two boundary lines. They have the interval, $\Delta h_{a p}$, of $20 \mathrm{~km}$ between $h_{a p}$ of the low boundary line and the nearest computational grid dipole magnetic field line. The value of $\Delta h_{a p}$ is increased from $20 \mathrm{~km}$ to $45 \mathrm{~km}$ by linear law if we go from the low computational grid boundary line to the upper computational grid dipole magnetic field line. We expect our finite-difference algorithm, which is described below, to yield approximations to $N_{i}, N_{e}, T_{i}$ and $T_{e}$ in the ionosphere and plasmasphere at discrete times $t=0, \Delta t, 2 \Delta t, \ldots$ with the time step $\Delta \mathrm{t}=$ 10 min.

\section{A2.5.2 Solution procedure}

The model calculations are carried out in two parts. In the first part, the daytime $N_{i}, N_{e}, T_{i}$ and $T_{e}$ are calculated in the model with $V^{E}=0$. It means that the one-dimensional time dependent Eqs. (A1), (A6), and (A7) are solved along each computational grid dipole magnetic field line. The numerical technique for the numerical solution of the one-dimensional, time-dependent continuity, momentum and energy equations given by Marov and Kolesnichenko (1987) is used in the model calculations. This numerical technique which we use is similar to that described by Hastings and Roble (1977). The solving patterns of such model calculations were given by Marov and Kolesnichenko (1987), Pavlov (1994, 1997, 1998b), Pavlov and Buonsanto (1997), Pavlov and Foster (2001), and Pavlov et al. $(2000,2001)$. These steady-state daytime values of $N_{i}, N_{e}, T_{i}$ and $T_{e}$ are used as initial conditions to solve the two-dimensional, time-dependent equations (A1), (A6), and (A7) with the $\boldsymbol{E} \times \boldsymbol{B}$ drift of plasma perpendicular to the magnetic field line.

In the second part, the model takes into account that, during the $\boldsymbol{E} \times \boldsymbol{B}$ plasma drift, time variations of the $U$ coordinate of each point of plasma can be described by Eqs. (A11), (A12) and (A15). The plasma move in a $(q, U)$ plane with a fixed value of $\Lambda$ along geomagnetic field lines along the $q$ coordinate and perpendicular to magnetic field lines, along the $U$ coordinate, with the dependence of $U$ on $t$ is determined by Eqs. (A11), (A12), and (A15).

In the second part, the model calculations are carried out in several steps. We describe plasma evolution based on a reference frame moving with an individual parcel of plasma like a fully Lagrangian method, but make use of an Eulerian computational grid and choose the set of plasma parcels at every time step, so that all plasma parcels arrive at grid points which are located between grid lines of the regularly spaced Eulerian computational grid at the next time step. The solution values of electron and ion densities, and temperatures at the Eulerian computational grid are obtained by interpolation.

Let us assume that the values of $N_{i}(q, U, \Lambda, t)$, $\mathrm{T}_{\mathrm{i}}(\mathrm{q}, \mathrm{U}, \Lambda, \mathrm{t})$ and $\mathrm{T}_{\mathrm{e}}(\mathrm{q}, \mathrm{U}, \Lambda, \mathrm{t})$ are known, and we calcu- 
late the values of $N_{i}(q, U, \Lambda, t+\Delta t), \mathrm{T}_{\mathrm{i}}(\mathrm{q}, \mathrm{U}, \Lambda, \mathrm{t}+\Delta \mathrm{t})$ and $\mathrm{T}_{\mathrm{e}}(\mathrm{q}, \mathrm{U}, \Lambda, \mathrm{t}+\Delta \mathrm{t})$ simultaneously for all computational grid dipole magnetic field lines. The subsequent strategy for the case when $E_{\Lambda}>0$ is different from that for the case when $\mathrm{E}_{\Lambda}<0$.

It is well known that during most of the daytime conditions, the value of $\mathrm{E}_{\Lambda}>0$, and this electric field leads to an upward drift of plasma above the geomagnetic equator, producing an equatorial plasma fountain (see, for example, Moffett, 1979; Anderson, 1981; Rishbeth, 2000; Bailey and Balan, 1996). In this case, the plasma moves along geomagnetic field lines and perpendicular to magnetic field lines along the $\mathrm{U}$ coordinate from the low boundary line (the number of this grid line is $k=1$ ) to the upper boundary line (let us assume that the number of this grid line is $\mathrm{k}=\mathrm{kk})$. We define the $(\mathrm{q}, \mathrm{U})$ coordinate at the $\mathrm{k}$-th magnetic field grid line as the $\left(\left(\mathrm{q}_{\mathrm{k}}, \mathrm{U}_{\mathrm{k}}\right)\right.$ coordinates. Using the values of $\mathrm{N}_{\mathrm{i}}\left(\mathrm{q}_{\mathrm{k}}, \mathrm{U}_{\mathrm{k}}, \Lambda, \mathrm{t}\right), \mathrm{T}_{\mathrm{i}}\left(\mathrm{q}_{\mathrm{k}}, \mathrm{U}_{\mathrm{k}}, \Lambda, \mathrm{t}\right)$ and $\mathrm{T}_{\mathrm{e}}\left(\mathrm{q}_{\mathrm{k}}, \mathrm{U}_{\mathrm{k}}, \Lambda, \mathrm{t}\right)$ at the $\mathrm{k}$-th grid line, we calculate the values of $\mathrm{N}_{\mathrm{i}}\left(\mathrm{q}_{\mathrm{k}}, \mathrm{U}_{\mathrm{k}}+\Delta \mathrm{U}_{\mathrm{k}}, \Lambda, \mathrm{t}+\Delta \mathrm{t}\right), \mathrm{T}_{\mathrm{i}}\left(\mathrm{q}_{\mathrm{k}, \mathrm{k}}+\Delta \mathrm{U}_{\mathrm{k}}, \Lambda, \mathrm{t}+\Delta \mathrm{t}\right)$ and $\mathrm{T}_{\mathrm{e}}\left(\mathrm{q}_{\mathrm{k}}, \mathrm{U}_{\mathrm{k}}+\Delta \mathrm{U}_{\mathrm{k}}, \Lambda, \mathrm{t}+\Delta \mathrm{t}\right)$ in the moving Lagrangian frame by solving the one-dimensional, time-dependent Eqs. (A1), (A6) and (A7) in this frame.

Now we want to recalculate these results to our Eulerian computational grid. The value of $\Delta \mathrm{U}_{\mathrm{k}}$ at each time step, $\Delta \mathrm{t}$, is determined from Eqs. (A11), (A12), and (A15). It follows from these equations that the value of $\Delta \mathrm{U}_{\mathrm{k}}$ is the same for different departure points of the computational grid dipole magnetic field line, i.e. the arriving points follow within the single grid magnetic field line. In addition to the first set of the calculated values of $\mathrm{N}_{\mathrm{i}}\left(\mathrm{q}_{\mathrm{k}}, \mathrm{U}_{\mathrm{k}}+\Delta \mathrm{U}_{\mathrm{k}}, \Lambda, \mathrm{t}+\Delta \mathrm{t}\right), \mathrm{T}_{\mathrm{i}}\left(\mathrm{q}_{\mathrm{k}, \mathrm{k}}+\Delta \mathrm{U}_{\mathrm{k}}, \Lambda, \mathrm{t}+\Delta \mathrm{t}\right)$ and $\mathrm{T}_{\mathrm{e}}\left(\mathrm{q}_{\mathrm{k}}, \mathrm{U}_{\mathrm{k}}+\Delta \mathrm{U}_{\mathrm{k}}, \Lambda, \mathrm{t}+\Delta \mathrm{t}\right)$, we have the second set of the calculated values of $\mathrm{N}_{\mathrm{i}}\left(\mathrm{q}_{\mathrm{k}-1}, \mathrm{U}_{\mathrm{k}-1}, \Lambda, \mathrm{t}+\Delta \mathrm{t}\right)$, $\mathrm{T}_{\mathrm{i}}\left(\mathrm{q}_{\mathrm{k}-1}, \mathrm{U}_{\mathrm{k}-1}, \Lambda, \mathrm{t}+\Delta \mathrm{t}\right)$ and $\mathrm{T}_{\mathrm{e}}\left(\mathrm{q}_{\mathrm{k}-1}, \mathrm{U}_{\mathrm{k}-1}, \Lambda, \mathrm{t}+\Delta \mathrm{t}\right)$ at the neighboring underlying computational grid dipole magnetic field line. The value of $\mathrm{q}_{\mathrm{k}-1}$ does not coincide with the value of $\mathrm{q}_{k}$ and, thus, a search-interpolation procedure is needed to calculate the third set of $\mathrm{N}_{\mathrm{i}}\left(\mathrm{q}_{\mathrm{k}}, \mathrm{U}_{\mathrm{k}-1}, \Lambda, \mathrm{t}+\Delta \mathrm{t}\right)$, $\mathrm{T}_{\mathrm{i}}\left(\mathrm{q}_{\mathrm{k}}, \mathrm{U}_{\mathrm{k}-1}, \Lambda, \mathrm{t}+\Delta \mathrm{t}\right)$ and $\mathrm{T}_{\mathrm{e}}\left(\mathrm{q}_{\mathrm{k}}, \mathrm{U}_{\mathrm{k}-1}, \Lambda, \mathrm{t}+\Delta \mathrm{t}\right)$ (these values of $N_{i}, T_{i}$ and $T_{e}$ correspond to the neighboring, underlying computational grid dipole magnetic field line as well) from the second set of the calculated $N_{i}, T_{i}$ and $T_{e}$. Using the first and the third sets of the calculated $N_{i}, T_{i}$ and $T_{e}$ and the interpolation procedure, we calculate the desired quantities of $\mathrm{N}_{\mathrm{i}}\left(\mathrm{q}_{\mathrm{k}}, \mathrm{U}_{\mathrm{k}}, \Lambda, \mathrm{t}+\Delta \mathrm{t}\right), \mathrm{T}_{\mathrm{i}}\left(\mathrm{q}_{\mathrm{k}}, \mathrm{U}_{\mathrm{k}}, \Lambda, \mathrm{t}+\Delta \mathrm{t}\right)$ and $\mathrm{T}_{\mathrm{e}}\left(\mathrm{q}_{\mathrm{k}}, \mathrm{U}_{\mathrm{k}}, \Lambda, \mathrm{t}+\Delta \mathrm{t}\right)$.

To put into practice this strategy, it is necessary to have the desired quantities of $\mathrm{N}_{\mathrm{i}}\left(\mathrm{q}_{\mathrm{k}}, \mathrm{U}_{\mathrm{k}}, \Lambda, \mathrm{t}+\Delta \mathrm{t}\right)$, $\mathrm{T}_{\mathrm{i}}\left(\mathrm{q}_{\mathrm{k}}, \mathrm{U}_{\mathrm{k}}, \Lambda, \mathrm{t}+\Delta \mathrm{t}\right)$ and $\mathrm{T}_{\mathrm{e}}\left(\mathrm{q}_{\mathrm{k}}, \mathrm{U}_{\mathrm{k}}, \Lambda, \mathrm{t}+\Delta \mathrm{t}\right)$ for $\mathrm{k}=1$ (the low boundary dipole magnetic field line). For this computational grid dipole magnetic field line with the apex altitude of $150 \mathrm{~km}$, the calculations are carried out without $\boldsymbol{E} \times \boldsymbol{B}$ drift velocity by solving the one-dimensional, timedependent Eqs. (A1), (A6), and (A7). It should be noted that there are no differences in the strategy of calculations of $N_{i}$, $T_{i}$ and $T_{e}$ for the grid line with $\mathrm{k}=\mathrm{kk}$ and for the grid lines with $1<\mathrm{k}<\mathrm{kk}$.

For each Eulerian computational grid dipole magnetic field line, we can find that $\mathrm{q}_{\mathrm{k}}(\mathrm{min}) \leq \mathrm{q}_{\mathrm{k}} \leq 0$, where $\mathrm{q}_{\mathrm{k}}(\mathrm{min})$ is a minimum value of $q_{k}$. The magnitude of $\left|\mathrm{q}_{\mathrm{k}}(\mathrm{min})\right|$ is increased if the value of $k$ is increased. It means that we cannot use our method to find the value of $N_{i}, T_{i}$ and $T_{e}$ close to both ends of each Eulerian computational grid dipole magnetic field line with $k>1$. These grid points are located below $150 \mathrm{~km}$ altitude for the Eulerian computational grid point distribution which is used in this study. The calculations of $N_{i}, T_{i}$ and $T_{e}$ for these Eulerian computational grid points are carried out without $\boldsymbol{E} \times \boldsymbol{B}$ drift velocity by solving the one-dimensional, time-dependent Eqs. (A1), (A6) and (A7).

If the value of $E_{\Lambda}<0$, then the plasma moves along geomagnetic field lines and perpendicular to magnetic field lines along the $U$ coordinate from the upper boundary grid line, with $\mathrm{k}=\mathrm{kk}$ to the low boundary grid line with $\mathrm{k}=1$. Like the previous case, we use the values of $\mathrm{N}_{\mathrm{i}}\left(\mathrm{q}_{\mathrm{k}}, \mathrm{U}_{\mathrm{k}}, \Lambda, \mathrm{t}\right), \mathrm{T}_{\mathrm{i}}\left(\mathrm{q}_{\mathrm{k}}, \mathrm{U}_{\mathrm{k}}, \Lambda, \mathrm{t}\right)$ and $\mathrm{T}_{\mathrm{e}}\left(\mathrm{q}_{\mathrm{k}}, \mathrm{U}_{\mathrm{k}}, \Lambda, \mathrm{t}\right)$ at the $\mathrm{k}$-th grid line, to calculate the values of $\mathrm{N}_{\mathrm{i}}\left(\mathrm{q}_{\mathrm{k}}, \mathrm{U}_{\mathrm{k}}+\Delta \mathrm{U}_{\mathrm{k}}, \Lambda, \mathrm{t}+\Delta \mathrm{t}\right), \mathrm{T}_{\mathrm{i}}\left(\mathrm{q}_{\mathrm{k}}, \mathrm{U}_{\mathrm{k}}+\Delta \mathrm{U}_{\mathrm{k}}, \Lambda, \mathrm{t}+\Delta \mathrm{t}\right)$ and $\mathrm{T}_{\mathrm{e}}\left(\mathrm{q}_{\mathrm{k}}, \mathrm{U}_{\mathrm{k}}+\Delta \mathrm{U}_{\mathrm{k}}, \Lambda, \mathrm{t}+\Delta \mathrm{t}\right)$ in the moving Lagrangian frame by solving the one-dimensional, time-dependent Eqs. (A1), (A6), and (A7) in this frame. After that, the model recalculates the results to our Eulerian computational grid.

Equations (A11), (A12), and (A15) are used to find the value of $\Delta \mathrm{U}_{\mathrm{k}}$. Like the previous case, the value of $\Delta \mathrm{U}_{\mathrm{k}}$ is the same for different departure points of the computational grid dipole magnetic field line, i.e. the arriving points follow within the single grid magnetic field line. In addition to the first set of the calculated values of $\mathrm{N}_{\mathrm{i}}\left(\mathrm{q}_{\mathrm{k}}, \mathrm{U}_{\mathrm{k}}+\Delta \mathrm{U}_{\mathrm{k}}, \Lambda, \mathrm{t}+\Delta \mathrm{t}\right)$, $\mathrm{T}_{\mathrm{i}}\left(\mathrm{q}_{\mathrm{k}}, \mathrm{U}_{\mathrm{k}}+\Delta \mathrm{U}_{\mathrm{k}}, \Lambda, \mathrm{t}+\Delta \mathrm{t}\right), \quad$ and $\mathrm{T}_{\mathrm{e}}\left(\mathrm{q}_{\mathrm{k}}, \mathrm{U}_{\mathrm{k}}+\Delta \mathrm{U}_{\mathrm{k}}, \Lambda, \mathrm{t}+\Delta \mathrm{t}\right)$, we have the second set of the calculated values of $\mathrm{N}_{\mathrm{i}}\left(\mathrm{q}_{\mathrm{k}+1}, \mathrm{U}_{\mathrm{k}+1}, \Lambda, \mathrm{t}+\Delta \mathrm{t}\right)$, $\mathrm{T}_{\mathrm{i}}\left(\mathrm{q}_{\mathrm{k}+1}, \mathrm{U}_{\mathrm{k}+1}, \Lambda, \mathrm{t}+\Delta \mathrm{t}\right)$ and $\mathrm{T}_{\mathrm{e}}\left(\mathrm{q}_{\mathrm{k}+1}, \mathrm{U}_{\mathrm{k}+1}, \Lambda, \mathrm{t}+\Delta \mathrm{t}\right)$ at the neighboring overlying computational grid dipole magnetic field line. The value of $\mathrm{q}_{k+1}$ does not coincide with the value of $\mathrm{q}_{k}$ and, thus, a search-interpolation procedure is carried out to calculate the third set of $\mathrm{N}_{\mathrm{i}}\left(\mathrm{q}_{\mathrm{k}}, \mathrm{U}_{\mathrm{k}+1}, \Lambda, \mathrm{t}+\Delta \mathrm{t}\right), \quad \mathrm{T}_{\mathrm{i}}\left(\mathrm{q}_{\mathrm{k}}, \mathrm{U}_{\mathrm{k}+1}, \Lambda, \mathrm{t}+\Delta \mathrm{t}\right) \quad$ and $\mathrm{T}_{\mathrm{e}}\left(\mathrm{q}_{\mathrm{k}}, \mathrm{U}_{\mathrm{k}+1}, \Lambda, \mathrm{t}+\Delta \mathrm{t}\right)$ (these values of $N_{i}, T_{i}$ and $T_{e}$ correspond to the neighboring overlying computational grid dipole magnetic field line as well) from the second set of the calculated $\mathrm{N}_{\mathrm{i}}, \mathrm{T}_{\mathrm{i}}$ and $\mathrm{T}_{\mathrm{e}}$. The first and the third sets of the calculated $\mathrm{N}_{\mathrm{i}}, \mathrm{T}_{\mathrm{i}}$ and $\mathrm{T}_{\mathrm{e}}$ are used to obtain the desired quantities of $\mathrm{N}_{\mathrm{i}}\left(\mathrm{q}_{\mathrm{k}}, \mathrm{U}_{\mathrm{k}}, \Lambda, \mathrm{t}+\Delta \mathrm{t}\right), \mathrm{T}_{\mathrm{i}}\left(\mathrm{q}_{\mathrm{k}}, \mathrm{U}_{\mathrm{k}}, \Lambda, \mathrm{t}+\Delta \mathrm{t}\right)$ and $\mathrm{T}_{\mathrm{e}}\left(\mathrm{q}_{\mathrm{k}}, \mathrm{U}_{\mathrm{k}}, \Lambda, \mathrm{t}+\Delta \mathrm{t}\right)$ by interpolation.

To put into practice this part of our method, it is necessary to have the sought out quantities of $\mathrm{N}_{\mathrm{i}}\left(\mathrm{q}_{\mathrm{k}}, \mathrm{U}_{\mathrm{k}}, \Lambda, \mathrm{t}+\Delta \mathrm{t}\right)$, $\mathrm{T}_{\mathrm{i}}\left(\mathrm{q}_{\mathrm{k}}, \mathrm{U}_{\mathrm{k}}, \Lambda, \mathrm{t}+\Delta \mathrm{t}\right)$ and $\mathrm{T}_{\mathrm{e}}\left(\mathrm{q}_{\mathrm{k}}, \mathrm{U}_{\mathrm{k}}, \Lambda, \mathrm{t}+\Delta \mathrm{t}\right)$ for $\mathrm{k}=\mathrm{kk}$ (the upper boundary dipole magnetic field line). This computational grid dipole magnetic field line intersects the Earth's surface at middle geomagnetic latitudes (two geomagnetic latitudes of $\pm 40^{\circ}$ are used in this study). It is well known that, unlike the auroral and equatorial ionosphere, electric fields have little effect on the mid-latitude ionosphere, and 
even relatively strong electric fields measured by the Millstone Hill radar $\left(43^{\circ} \mathrm{N}, 288^{\circ} \mathrm{E}\right)$ during a January 1997 magnetic storm had little effect on electron and ion densities (Richards et al., 2000). Therefore, we can suggest that the effects of the equatorial electric field on $N_{i}, T_{i}$ and $T_{e}$ are negligible at middle geomagnetic latitudes. As a result, the model calculations are carried out without $\boldsymbol{E} \times \boldsymbol{B}$ drift velocity for $\mathrm{k}=\mathrm{kk}$ by solving the one-dimensional, time-dependent Eqs. (A1), (A6) and (A7). It is necessary to point out that, in the case of $\mathrm{E}_{\Lambda}<0$, there are no differences in the strategy of the calculations of $\mathrm{N}_{i}, \mathrm{~T}_{\mathrm{i}}$ and $\mathrm{T}_{\mathrm{e}}$ for the grid line with $\mathrm{k}=1$ and for the grid lines with $1<\mathrm{k}<\mathrm{kk}$.

It is necessary to determine the boundary conditions to solve the one-dimensional, time-dependent Eqs. (A1), (A6) and (A7) in the first and second parts of our method. At the lower ends of each Eulerian computational grid dipole magnetic field line (which are located at the $130 \mathrm{~km}$ altitudes in the Northern and Southern Hemispheres), the diffusion and drift processes of ions and the processes of transfer of thermal energy of electrons and ions by the thermal conductivity and drift are neglected in the model calculations $\left(C_{i}=0\right.$, $\boldsymbol{V}^{E}=0, \lambda_{\mathrm{i}}=0$ and $\left.\lambda_{\mathrm{e}}=0\right)$.

The numerical simulations of $N_{i}, N_{e}, T_{i}$ and $T_{e}$ presented in Sect. 4 of this work give practically the same results, if the lower boundary grid line has more a lower apex altitude of $140 \mathrm{~km}$ and the upper boundary grid line intersects the Earth's surface at two more high middle-latitude geomagnetic latitudes: $\pm 45^{\circ}$. This may confirm the validity of the present method for simulations for geomagnetically quiet time periods. If there are regions with $\mathrm{E}_{\Lambda}<0$ and $\mathrm{E}_{\Lambda}>0$ and grid lines with $\mathrm{E}_{\Lambda}=0$ at the same time then the direction splitting technique is used. The calculations of $\mathrm{N}_{\mathrm{i}}, \mathrm{T}_{\mathrm{i}}$ and $\mathrm{T}_{\mathrm{e}}$ are carried out without $\boldsymbol{E} \times \boldsymbol{B}$ drift velocity for both boundary grid lines with $\mathrm{k}=1$ and $\mathrm{k}=\mathrm{kk}$ or (and) for grid lines with $\mathrm{E}_{\Lambda}=0$, and two different strategies for solving the continuity and energy equations described above are employed at the same time.

A2.6 Comparison between the presented new solution procedure and the CTIP and CTIM model solution procedures in the ionospheric code

The semi-Lagrangian approach has long been used in meteorology for numerical weather prediction, where the use of a large time step is essential for efficiency (Smolarkiewicz and Pudykiewicz, 1992). This approach has been introduced by Robert (1981), and the basic idea is to discretize the Lagrangian derivative of the solution in time, instead of the Eulerian derivative. The extension of the semi-Lagrangian method to the solution of Navier-Stokes equations was presented in the pioneering work of Pironneau (1982). As an efficient and accurate approach to computing the advection process, semi-Lagrangian schemes have been extensively studied and widely incorporated into many numerical models for atmospheric flows (Smolarkiewicz and Pudykiewicz, 1992). A sort of semi-Lagrangian technique was developed and employed in Sect. A2.5.2 conformably to the ionosphere and plasmasphere.

Lagrangian and Eulerian frames were used by the early version of the CTIP model (Fuller-Rowell et all., 1988). The CTIP model integrated the Global Thermospheric Model and the Sheffield University High-Latitude Ionospheric Convection Model. Unfortunately, the solution procedure used by the CTIP model for the ionospheric code is described very briefly by Fuller-Rowell et al. (1988) and, as a result, it is not possible to go into details. For geomagnetic latitudes equatorward of 65 degrees, the empirical ionospheric model of Chiu (1975) was used in the CTIP model, while our model is the theoretical model of the ionosphere and plasmasphere for geomagnetic latitudes equatorward of \pm 40 degrees. For geomagnetic latitudes northward of 65 degrees, the CTIP model uses the ionospheric code with the backward convection path integration algorithm, while the forward integration is performed in the model presented in this work. There are two fundamentally different strategies for solving the continuity and energy equations in our model for $E_{\Lambda}>0$ and $\mathrm{E}_{\Lambda}<0$ in the ionospheric and plasmaspheric code, with the use of the low or upper boundary grid line conditions (see Sect. A2.5.2), while the CTIP model ionospheric code does not depend on the sign of $E_{\Lambda}$. It should be noted that an attempt to use low boundary grid line conditions for $\mathrm{E}_{\Lambda}<0$ leads to the divergence of the numerical scheme presented in this work, and this generates the need of using upper boundary grid line conditions. It is also necessary to emphasise the newness and importance of the derived Eqs. (A15)-(A17) in the ionospheric code.

The CTIP model was enhanced by including the theoretical model of the low- and middle-latitude ionosphere and plasmasphere (Millward et al., 1996). Each plasma flux tube of the updated CTIP model circulates under the influence of the $\boldsymbol{E} \times \boldsymbol{B}$ drift such that, over a 24-hour simulation, each plasma flux tube returns exactly to its starting position (Millward et al., 1996, pages 239 and 254). It means that a Lagrangian approach is used in the CTIP model ionospheric code of Millward et al. (1996), and this determines the differences between the solution procedure presented in Sect. A2.5.2 and the solution procedure of the CTIP ionospheric code described by Millward et al. (1996). The CTIM model uses the technique of Fuller- Rowell et al. (1988) in calculating the ionospheric parameters (Fuller-Rowell et al., 1996, page 224). As a result, the differences between the solution procedure used by the CTIM model in the ionospheric code and the solution procedure presented in Sect. A2.5.2 are the same as those described above.

Acknowledgements. The research described in this publication was supported by grant 02-05-64204 from the Russian Foundation for Basic Research. The author would like to thank Dr. J. M. Picone for providing the NRLMSISE-00 model. Hourly critical frequencies fof 2, foE and maximum usable frequency parameters $\mathrm{M}(3000) \mathrm{F} 2$ data from the ionospheric sounder stations were provided by the National Geophysical Data Center, Boulder, Colorado. The author would like to thank referees for their comments on the paper, which have assisted in improving the final version. 
Topical Editor M. Lester thanks B. Emery and two other referees for their help in evaluating this paper.

\section{References}

Abdu, M. A.: Major phenomena of the equatorial ionospherethermosphere system under disturbed conditions, J. Atmos. Terr. Phys., 59, 1505-1519, 1997.

Abdu, M. A.: Outstanding problems in the equatorial ionospherethermosphere electrodynamics relevant to spread-F, Journal of Atmospheric and Solar-Terrestrial Physics, 63, 869-884, 2001.

Alfvén, H., Fälthammer, C.-G.: Cosmical Electrodynamics. Fundamental Principles., Clarendon Press, Oxford, 1963.

Anderson, D. N.: Modeling the ambient, low latitude F-region ionosphere - A review, J. Atmos. Terr. Phys., 43, 753-762, 1981.

Anderson, D. N.: A theoretical study of the ionospheric F-region equatorial anomaly I. Theory, Planet. Space Sci., 21, 409-442, 1973.

Anderson, D. N., Decker, D. T., Valladares, C. E.: Global theoretical ionospheric model (GTIM), in: Handbook of Ionospheric Models, (Ed) Schunk, R. W., Utah State Univ., Logan, Utah, 133$152,1996$.

Aponte, N., Sulzer, M. P., and Gonzalez, S. A.: Correction of the Jicamarca $T_{e} / T_{i}$ ratio problem: Verifying the effect of electron Coulomb collisions on the incoherent scatter spectrum, J. Geophys. Res., 106, 24 785-24 794, 2001.

Avakyan, S. V., Il'in, R. N., Lavrov, V. N., and Ogurtsov, G. N.: Sections of ionization and excitation of UV emissions during collisions of electrons, ions and photons with atoms and molecules of atmospheric gases. A handbook (in Russian), (Ed) Vavilov, S. I.: State Optical Institute using the financial support from the Russian Foundation for Basic Research, St.-Petersburg, 2000.

Bailey, G. J., Moffett, R. J., Swartz, W. E.: Effects of photoelectron heating and interhemisphere transport on day-time plasma temperatures at low latitudes, Planet. Space Sci., 23, 599-610, 1975.

Bailey, G. J. and Sellec, R.: A mathematical model of the Earth's plasmasphere and its applications in a study of $\mathrm{He}^{+}$at $\mathrm{L}=3$, Ann. Geophysicae, 8, 171-190, 1990.

Bailey, G. J. and Balan, N.: A low-latitude ionosphereplasmasphere model: Handbook of Ionospheric Models, (Ed) Schunk, R. W., Utah State Univ., Logan, Utah, 173-206, 1996.

Batista, I. S., Abdu, M. A., and Bittencourt, J. A.: Equatorial Fregion vertical plasma drifts: seasonal and longitudinal asymmetries in the American sector, J. Geophys. Res., 91, 12055$12064,1986$.

Berkowitz, J.: Absolute photoionization cross sections of atomic oxygen, J. Phys. B: At. Mol. Opt. Phys., 30, 583-592, 1997.

Bischof, G. and Linder, F.: Crossed beam study of $\mathrm{He}^{+}+\mathrm{O}_{2}$ charge transfer reactions in the collision energy: Atoms, Molecules and Clusters, Zeitschrift für Physik D: 1, 303-320, 1986.

Chang, T., Richards, P. G., and Torr, D. G.: Reevaluation of the $\mathrm{O}^{+}\left({ }^{2} \mathrm{P}\right)$ reaction rate coefficients derived from Atmosphere Explorer C observation, J. Geophys. Res., 98, 15 589-15 597, 1993.

Chiu, Y. T.: An improved phenomenological model of ionospheric density, J. Atmos. Terr. Phys., 37, 1563-1570, 1975.

Dudeney, J. R.: The accuracy of simple methods for determining the height of the maximum electron concentration of the F2- layer from scaled ionospheric characteristics, J. Atmos. Terr. Phys., 45, 629-640, 1983.
Dunford, E.: The relationship between the ionospheric equatorial anomaly and the E-region current system, J. Atmos. Terr. Phys., 29, 1489-1498, 1967.

Fejer, B. G., de Paula, E. R., Batista, I. S., Bonelli, E., and Woodman, R. F.: Equatorial F-region vertical plasma drifts during solar maxima, J. Geophys. Res., 94, 12 049-12 054, 1989.

Fejer, B. G.: F-region plasma drifts over Arecibo - Solar cycle, seasonal, and magnetic activity effects, J. Geophys. Res., 98, 13 645-13 652, 1993.

Fejer, B. G., de Paula, E. R., Heelis, R. A., and Hanson, W. B.: Global equatorial ionospheric vertical plasma drifts measured by the AE-E satellite, J. Geophys. Res., 100, 5769-5776, 1995.

Fesen, C. G., Crowley, G., Roble, R. G., Richmond, A. D., and Fejer, B. G.: Simulation of the pre-reversal enhancement in the low latitude vertical ion drifts, Geophys. Res. Lett., 27, 18511854, 2000.

Fuller-Rowell, T. J., Rees, D., Quegan, S., Moffett, R. J., and Bailey, G. J.: Simulations of the seasonal and universal time variations of the high-latitude thermosphere and ionosphere using a coupled, three-dimensional, model, Pure and Applied Geophysics, 127, 189-217, 1988.

Fuller-Rowell, T. J., Rees, D., Quegan, S., Moffett, R. J., Codrescu, M. V., and Millward, G. H.: A coupled thermosphere-ionosphere model (CTIM): Handbook of Ionospheric Models, (Ed) Schunk, R. W., Utah State Univ., Logan, Utah, 217-238, 1996.

Gerlich, D.: State-selected and state-to-state ion molecule reaction dynamics I: Experiment, Adv. Chem. Phys., 82, 1-176, 1991.

Hastings, J. T. and Roble, R. G.: An automatic technique for solving coupled vector systems of non-linear parabolic partial differential equations in one space dimension, Planet. Space. Sci., 25, 209-215, 1977.

Hedin, A. E., Reber, S. A., Newton, J. P., Spencer, N. W., Salah, J. E., Evans, J. V., Brinton, H. C., Kayser, D. C., Alcaydé, D., Bauer, P., and Cogger, L.: A global thermospheric model based on mass spectrometer and incoherent data MSIS: $1 . \mathrm{N}_{2}$ density and temperature, J. Geophys. Res., 82, 2139-2147, 1977a.

Hedin, A. E., Reber, S. A., Newton, J. P., Spencer, N. W., Brinton, H. C., Mayr, H. G., and Potter, W. E.: A global thermospheric model based on mass spectrometer and incoherent data MSIS: 2. Composition, J. Geophys. Res., 82, 2148-2156, 1977 b.

Hedin, A. E.: MSIS-86 thermospheric model, J. Geophys. Res., 92, 4649-4662, 1987.

Hedin, A. E., Spencer, N. W., Biondi, M. A., Burnside, R. G., Hernandez, G., and Johnson, R. M.: Revised global model of thermosphere winds using satellite and ground-based observations, J. Geophys. Res., 96, 7657-7681, 1991.

Henry, R. J. W., Burke, P. G., and Sinfailam, A.-L.: Scattering of Electrons by $\mathrm{C}, \mathrm{N}, \mathrm{O}, \mathrm{N}^{+}, \mathrm{O}^{+}$, and $\mathrm{O}^{++}$, Phys. Rev., 178, 218225, 1969.

Hierl, M. P., Dotan, I., Seeley, J. V., Van Doren, J. M., Morris, R. A., and Viggiano, A. A.: Rate constants for the reactions of $\mathrm{O}^{+}$with $\mathrm{N}_{2}$ and $\mathrm{O}_{2}$ as a function of temperature (300-1800 K), J. Chem. Phys., 106, 3540-3544, 1997.

Hochstim, A. R.: Kinetic processes in gases and plasmas, Academic Press, New York, 1969.

Hoegy, W. R.: Thermal electron heating rate: a derivation, J. Geophys. Res., 89, 977-985, 1984.

Jenkins, B., Bailey, G. J., Ennis, A. E., and Moffett, R. J.: The effect of vibrationally excited nitrogen on the low-latitude ionosphere, Ann. Geophysicae, 15, 1422-1428, 1997.

Johnsen, R., and Biondi, M. A.: Charge transfer coefficients for the $\mathrm{O}^{+}\left({ }^{2} \mathrm{D}\right)+\mathrm{N}_{2}$ and $\mathrm{O}^{+}\left({ }^{2} \mathrm{D}\right)+\mathrm{O}_{2}$ excited ion reactions at ther- 
mal energy, J. Chem. Phys., 73, 190-193, 1980a.

Johnsen, R. and Biondi, M. A.: Laboratory measurements of the $\mathrm{O}^{+}\left({ }^{2} \mathrm{D}\right)+\mathrm{N}_{2}$ and $\mathrm{O}^{+}\left({ }^{2} \mathrm{D}\right)+\mathrm{O}_{2}$ reaction rate coefficients and their ionospheric implications, Geophys. Res. Lett. , 7, 401-403, 1980b.

Kaufman, V. and Sugar, J.: Forbidden lines in $n s^{2} n p^{k}$ ground configurations and nsnp excited configurations of beryllium through molybdenum atoms and ions, J. Phys. Chem. Ref. Data, 15, 321426, 1986.

Klobuchar, J. A., Anderson, D. N., and Doherty, P. H.: Model studies of the latitudinal extent of the equatorial anomaly during equinoctial conditions, Radio Science, 26, 1025-1047, 1991.

Korenkov, Y. N., Klimenko, V. V., Forster, M., Surotkin, V. A., and Smilauer, J.: Global modelling study (GSM TIP) of the ionospheric effects of excited $\mathrm{N}_{2}$, convection and heat fluxes by comparison with EISCAT and satellite data for 31 July 1990, Ann. Geophys., 14, 1362-1374, 1996.

Krinberg, I. A. and Matafonov, G. K.: Coulomb collision-induced photoelectron trapping by the geomagnetic field and electron gas on the heating in the plasmasphere, Ann. Geophysicae, 34, 8996, 1978.

Krinberg, I. A. and Tachilin, A. V.: Ionosphere and plasmasphere (in Russian), Nauka, Moscow, 1984.

Li, X., Huang, Y.-L., Flesch, G. D., and Ng, C. Y.: A state-selected study of the ion-molecule reactions $\mathrm{O}^{+}\left({ }^{4} \mathrm{~S},{ }^{2} \mathrm{D},{ }^{2} \mathrm{P}\right)+\mathrm{N}_{2}$, J. Chem. Phys., 106, 1373-1381, 1997.

Lobzin, V. V., Pavlov, A. V., and Pavlova, N. M.: An anomalous subauroral red arc on 4 August 1972: comparison of ISIS-2 satellite data with numerical calculations, Ann. Geophysicae, 17, 1411-1425, 1999.

Marov, M. J. and Kolesnichenko, A. V.: Introduction to planetary aeronomy (in Russian), Nauka, Moscow, 1987.

McFarland, M., Albritton, D. L., Fehsenfeld, F. C., Ferguson, E. E., and Schmeltekopf, A. L.: Energy dependence and branching ratio of the $\mathrm{N}_{2}+\mathrm{O}$ reaction, J. Geophys. Res., 79, 2925-2926, 1974.

McClure, J. P.,: Diurnal variation of neutral and charged particle teperatures in the equatorial F-region, J. Geophys. Res., 74, 279291, 1969.

McClure, J. P., Nagy, A. F., Cicerone, R. J., Brace, L. H., Baron, M., Bauer, B., Carlson, H. C., Evans, J. V., and Taylor, G. N.: Comparison of $T_{e}$ and $T_{i}$ from Ogo 6 and from various incoherent scatter radars, J. Geophys. Res., 78, 197-205, 1973.

McLaughlin, B. M. and Bell, K. L.: Electronimpact excitation of the fine-structure levels $\left(1 \mathrm{~s}^{2} 2 \mathrm{~s}^{2} 2 \mathrm{p}^{34} \mathrm{~S}_{3 / 2}^{0},{ }^{2} \mathrm{D}^{0}{ }_{5 / 2,3 / 2},{ }^{2} \mathrm{P}_{3 / 2,1 / 2}\right)$ of singly ionized atomic oxygen, J. Phys. B: At. Mol. Opt. Phys., 31, 4317-4329, 1998.

Millward, G. H., Moffett, R. J., Quegan, S., and Fuller-Rowell, T. J.: A coupled thermosphere-ionosphere-plasmasphere model (CTIP) in: Handbook of Ionospheric Models, (Ed) Schunk, R. W., Utah State Univ., Logan, Utah, 239-279, 1996.

Moffett, R. J.: The Equatorial Anomaly in the Electron Distribution of the Terrestrial F-Region, Fundamentals of Cosmic Physics, 4, 313-391, 1979.

Murphy, J. A., Bailey, G. J., and Moffett, R. J.: A theoretical study of the effects of quiet-time electromagnetic drifts on the behavior of thermal plasma at mid-latitudes, J. Geophys. Res., 85, 19791986, 1980.

Namgaladze, A. A., Korenikov, Iu. N., Klimenko, V. V., Karpov, I. V., Bessarab, F. S., Surotkin, V. A., Glushchenko, T. A., and Naumova, N. M.: Global model of the thermosphere-ionosphere- protonosphere system, Pure and Applied Geophysics, 127, 219 254, 1988.

Park, C. G. and Banks, P. M.: Influence of thermal plasma flow on the mid-latitude nighttime F2-layer : effects of electric fields and neutral winds inside the plasmasphere, J. Geophys. Res., 79, 4661-4668, 1974.

Pavlov, A. V.: The role of vibrationally excited nitrogen in the ionosphere, Pure and Applied Geophysics, 127, 529-544, 1988.

Pavlov, A. V.: The role of vibrationally excited nitrogen in the formation of the mid-latitude negative ionospheric storms, Ann. Geophysicae, 12, 554-564, 1994.

Pavlov, A. V.: Subauroral red arcs as a conjugate phenomenon: comparison of OV1-10 satellite data with numerical calculations, Ann. Geophysicae, 15, 984-998, 1997.

Pavlov, A. V.: New electron energy transfer rates for vibrational excitation of $\mathrm{N}_{2}$, Ann. Geophysicae, 16, 176-182, 1998a.

Pavlov, A. V.: The role of vibrationally excited oxygen and nitrogen in the ionosphere during the undisturbed and geomagnetic storm period of 6-12 April 1990, Ann. Geophysicae, 16, 589601, 1998b.

Pavlov, A. V.: New electron energy transfer and cooling rates by excitation of $\mathrm{O}_{2}$, Ann. Geophysicae, 16, 1007-1013, 1998c.

Pavlov, A. V. and Berrington, K. A.: Cooling rate of thermal electrons by electron impact excitation of fine structure levels of atomic oxygen, Ann. Geophysicae, 17, 919-924, 1999.

Pavlov, A. V. and Buonsanto, M. J.: Comparison of model electron densities and temperatures with Millstone Hill observations during undisturbed periods and the geomagnetic storms of March 16-23 and April 6-12, 1990, Ann. Geophysicae, 15, 327-344, 1997.

Pavlov, A. V., Buonsanto, M. J., Schlesier, A. C., and Richards, P. G.: Comparison of models and data at Millstone Hill during the 5-11 June, 1991, storm, J. Atmosph. Terr. Phys., 61, 263-279, 1999.

Pavlov, A. V. and Namgaladze, A. A.: Vibrationally excited molecular nitrogen in the upper atmosphere (Review), Geomagnetism and Aeronomy, 28, 607-619, 1988.

Pavlov, A. V., Abe, T., and Oyama, K.-I.: Comparison of the measured and modelled electron densities and temperatures in the ionosphere and plasmasphere during 20-30 January 1993, Ann. Geophysicae, 18, 1257-1272, 2000.

Pavlov, A. V., Abe, T., and Oyama, K.-I.: Comparison of the measured and modeled electron densities and temperatures in the ionosphere and plasmasphere during the period of 25-29 June 1990, J. Atmos. Solar-Terr. Phys., 63, 605-616, 2001.

Pavlov, A. V. and Foster, J. C.: Model/data comparison of F-region ionospheric perturbation over Millstone Hill during the severe geomagnetic storm of 15-16 July 2000, J. Geophys. Res., 106, 29051-29070, 2001.

Peverall, R., Rosen, S., Peterson, J. R., Larsson, M., Al-Khalili, A., Vikor, L., Semaniak, J., Bobbenkamp, R., Le Padellec, A., Maurellis, A. N., and van der Zande, W. J.: Dissociative recombination and excitation of $\mathrm{O}_{2}{ }^{+}$: Cross sections, product yields and implications for studies of ionospheric airglows, J. Chem. Phys., 114, 6679-6689, 2001.

Pesnell, W. D.: Momentum transfer collision frequency of $\mathrm{O}+-\mathrm{O}$, Geoph. Res. Lett., 20 ,1343-1346, 1993.

Picone, J. M., Hedin, A.E., Drob, D.P., Meier, R.R., Lean, J., Nicholas, A.C., and Thonnard, S.E.: Enhanced empirical models of the thermosphere, Physics and Chemistry of the Earth, Part C: Solar-Terrestrial and Planetary Science, 25(5-6), 537-542, 2000.

Picone, J. M., Hedin, A. E., Drob D. P., and Aikin, A. C.: 
NRLMSISE-00 empirical model of the atmosphere: statistical comparisons and scientific issues, J. Geophys. Res., 107 (A12), 1468, doi:10.1029/2002JA009430, 2002.

Pingree, J. E. and Fejer, B. G.: On the height variation of the equatorial F-region vertical plasma drifts, J. Geophys. Res., 92, 47634766, 1987.

Pironneau, O.: On the transport-diffusion algorithm and its applications to the NavierStokes equations, Numer. Math. 38, 309-332, 1982.

Prasad, S. S. and Furman, D. R.: Electron cooling by molecular oxygen, J. Geophys. Res., 78, 6701-6707, 1973.

Radzig, A. A. and Smirnov, B. V.: The reference book in atomic and molecular physics (in Russian), Atomizdat, Moscow, 1980.

Rasmussen, C. E., Guiter, S. M., and Thomas, S. G.: A twodimensional model of the plasmasphere - Refilling time constants, Planetary and Space Science, 41, 35-43, 1993.

Ratcliffe, J. A.: The formation of the ionospheric layers F1 and F2, J. Atmosph. Terr. Phys., 8, 260-269, 1956.

Richards, P. G.: An improved algorithm for determining neutral winds from the height of the F2 peak electron density, J. Geophys. Res., 96, 17 839-17 846, 1991.

Richards, P. G., Fennelly, J. A., and Torr, D. G.: EUVAC: A solar EUV flux model for aeronomical calculations, J. Geophys. Res., 99, 8981-8992, 1994, Correction in: J. Geophys. Res., 99, $13283,1994$.

Richards, P. G.; Buonsanto, M. J.,Reinisch, B. W., Holt, J., Fennelly, J. A., Scali, J. L., Comfort, R. H., Germany, G. A., Spann, J., Brittnacher, M., and Fok, M.-C.: On the relative importance of convection and temperature to the behavior of the ionosphere in North America during January 6-12, 1997, J. Geophys. Res., 105, 12 763-12 776, 2000.

Rishbeth, H.: The equatorial F-layer: progress and puzzles, Annales Geophysicae, 18, 730-739, 2000.

Richmond, A. D. and Lu, G.: Upper-atmospheric effects of magnetic storms: a brief tutorial, J. Atmos. Terr. Phys., 62, 11151127, 2000.

Robert, A.: A stable numerical integration scheme for the primitive meteorological equations, Atmosphere-Ocean, 19, 35-46, 1981.

Samson, J. A. R., He, Z. X., Yin, L., and Haddad, G. N.: Precision measurements of the absolute photoionization cross sections of He, J. Phys. B : At. Mol. Opt. Phys., 27, 887-898, 1994.

Schaphorst, R., Krause, M. O., Kaldwell, C. D., Saha, H. P., Pahler, M., and Jimenez-Mier, J.: Photoionization of atomic oxygen at the multiplet term level from 20 to $212 \mathrm{eV}$, Phys. Rev. A, 52, 4656-4664, 1995.

Scherliess, L. and Fejer, B. G.: Radar and satellite global equatorial
F-region vertical drift model, J. Geophys. Res., 104, 6829-6842, 1999.

Schunk, R. W. and Nagy, A. F.: Electron temperatures in the Fregion of the ionosphere: Theory and observations, Rev. Geophys. Space Phys., 16, 355-399, 1978.

Schmeltekopf, A. L., Ferguson, E. E., and Fehsenfeld, F. C.: Afterglow studies of the reactions $\mathrm{He}^{+}, \mathrm{He}\left(2^{3} \mathrm{~S}\right)$ and $\mathrm{O}^{+}$with vibrationally excited $\mathrm{N}_{2}$, J. Chem. Phys, 48, 2966-2973, 1968.

Schieldge, J. P., Venkateswran, S. V., and Richmond, A. D.: The ionospheric dynamo and equatorial magnetic variations, J. Atmosph. Terr., Phys., 35, 1045-1061, 1973.

Shimazaki, T.: World-wide variations in the height of the maximum electron density of the ionospheric F2-layer, J. Radio Res. Labs. Japan, 2(7), 85-97, 1955.

Smith, W. H., Bromander, J., Curtis, L. J., Berry, H. G., and Buchta, R.: Lifetime measurements and absolute oscillator strengths for some vacuum-ultraviolet transitions in O I and O II, Astrophysical Journal, 165, 217-221, 1971.

Smolarkiewicz, P. K. and Pudykiewicz, J. A.: A class of semiLagrangian approximations for fluids, J. Atmos. Sci. 49, 2082 2089, 1992.

Su, Y. Z., Bailey, G. J., Oyama, K. I., and Balan, N.: A modelling study of the longitudinal variations in the north-south asymmetries of the ionospheric equatorial anomaly, J. Atmos. Terr. Phys., 59, 1299-1310, 1997.

Sulzer, M. P. and Gonzalez, S.: The effect of electron Coulomb collisionson the incoherent scatter spectrum in the F-region at Jicamarca, J. Geophys. Res., 104, 22 535-22 551, 1999.

St.-Maurice, J.-P. and Torr D. G.: Nonthermal rate coefficients in the ionosphere:The reaction of $\mathrm{O}$ with $\mathrm{N}$, and NO, J. Geophys. Res., 83, 969-977, 1978.

Tayal, S. S. and Richardson, L. M.: Oscillator strengths and inelastic scattering of electrons from O II, J. Phys. B: At. Mol. Opt. Phys. 33, 443-453, 2000.

Titheridge, J. E.: Model results for the ionospheric E-region: solar and seasonal changes, Ann. Geophysicae, 15, 63-78, 1997.

Tobiska, W. K. and Eparvier, F. G.: EUV97: Improvements to EUV irradiance modeling in the soft X-rays and FUV, Solar Physics, 177, 147-159, 1998.

Torr, M. R. and Torr, D. G.: The role of metastable species in the thermosphere, Rev. Geophys. Space Phys., 20, 91-144, 1982.

Walker, G. O.: Longitudinal structure of the F-region equatorial anomaly - A review, Journal of Atmospheric and Terrestrial Physics, 43, 763-774, 1981.

Woodman, R. F.: Vertical drift velocities and east-west electric fields at the magnetic equator, J. Geophys. Res., 75, 6249-6259, 1970 . 